\title{
Report of the Committee on a Commercially Developed Space Facility
}

Aeronautics and Space Engineering Board

Commission on Engineering and Technical Systems

National Research Council 
NOTICE: The project that is the subject of this report was approved by the Governing Board of the National Research Council, whose members are drawn from the councils of the National Academy of Sciences, the National Academy of Engineering, and the Institute of Medicine. The members of the committee responsible for the report were chosen for their special competences and with regard for appropriate balance.

This report has been reviewed by a group other than the authors according to procedures approved by a Report Review Committee consisting of members of the National Academy of Sciences, the National Academy of Engineering, and the Institute of Medicine.

The National Academy of Sciences is a private, nonprofit, self-perpetuating society of distinguished scholars engaged in scientific and engineering research, dedicated to the furtherance of science and technology and to their use for the general welfare. Upon the authority of the charter granted to it by the Congress in 1863, the Academy has a mandate that requires it to advise the federal government on scientific and technical matters. Dr. Frank Press is president of the National Academy of Sciences.

The National Academy of Engineering was established in 1964, under the charter of the National Academy of Sciences, as a parallel organization of outstanding engineers. It is autonomous in its administration and in the selection of its members, sharing with the National Academy of Sciences the responsibility for advising the federal government. The National Academy of Engineering also sponsors engineering programs aimed at meeting national needs, encourages education and research, and recognizes the superior achievements of engineers. Dr. Robert $M$. White is president of the National Academy of Engineering.

The Institute of Medicine was established in $\mathbf{1 9 7 0}$ by the National Academy of Sciences to secure the services of eminent members of appropriate professions in the examination of policy matters pertaining to the health of the public. The Institute acts under the responsibility given to the National Academy of Sciences by its congressional charter to be an adviser to the federal government and, upon its own initiative, to identify issues of medical care, research, and education. Dr. Samuel $O$. Thier is president of the Institute of Medicine.

The National Research Council was organized by the National Academy of Sciences in 1916 to associate the broad community of science and technology with the Academy's purposes of furthering knowledge and advising the federal government. Functioning in accordance with general policies determined by the Academy, the Council has become the principal operating agency of both the National Academy of Sciences and the National Academy of Engineering in providing services to the government, the public, and the scientific and engineering communities. The Council is administered jointly by both Academies and the Institute of Medicine. Dr. Frank Press and Dr. Robert M. White are chairman and vice chairman, respectively, of the National Research Council.

The Committee on a Commercially Developed Space Facility was convened at the request of the administrator of the National Aeronautics and Space Administration (NASA). The study was supported by Contract No. NASW -4003 between NASA and the National Academy of Sciences.

Available from:

Committee on a Commercially Developed Space Facility

National Research Council

2101 Constitution Avenue, N.W.

Washington, DC 20418

Printed in the United States of America 


\section{Committee on a Commercially Developed Space Facility}

JOSEPH F. SHEA (Chairman), Senior Vice President, Engineering, Raytheon Company, $R / 851220$
Lexington, Massachusetts H. GUYFORD STEVER (Vice Chairman), National Academy of Engineering, Washington, D C W. BOWMAN CUTTER III, Partner, Coopers \& Lybrand, Washington, D.C. WOLFGANG H. DEMISCH, Director of Research, UBS Securities, New York, New York DANIEL J. FINK, President, D. J. Fink Associates, Inc., Potomac, Maryland ALEXANDER H. FLAX, National Academy of Engineering, Washington, D.C. NRle

HARRY C. GATOS, Professor of Electronic Materials and Molecular Engineering, Massachusetts Institute of Technology

$$
\text { - MJ700 }
$$

MARTIN E. GLICKSMAN, Professor, Department of Materials Engineering, Rensselaer Polytechnic Institute

LOUIS J. LANZEROTTI, Research, Physics Division, AT\&T Bell Laboratories, Murray Hill, New Jersey

JOHN M. LOGSDON III, Director, Space Policy Institute, George Washington University

DUANE T. McRUER, President, Systems Technologies, Inc., Hawthorne, California

SIMON OSTRACH, Professor of Engineering, Department of Mechanical and Aerospace Engineering, Case Western Reserve University

THOMAS B. SHERIDAN, Professor of Engineering and Applied Psychology, Man-Machine Systems Laboratory, Massachusetts Institute of Technology

ARTHUR C. VAILAS, Director, Biodynamics Laboratory, University of Wisconsin, Madison

Staff

ROBERT H. KORKEGI, Director, Aeronautics and Space Engineering Board

JOANN C. CLAYTON, Senior Program Officer

DAVID S. JOHNSON, Senior Program Officer

RICHARD M. OBERMANN, Senior Program Officer

ELIZABETH LEE, Project Secretary

ANNA L. FARRAR, Administrative Assistant

JENNIFER T. ESTEP, Administrative Secretary 


\section{Aeronautics and Space Engineering Board}

ALberTUS D. Welliver (Chairman), Vice President, The Boeing Company, Seattle, Washington

EUGENE E. COVERT (Vice Chairman), Head, Department of Aeronautics and Astronautics, Massachusetts Institute of Technology

JAMES M. BEGGS, Bethesda, Maryland

RICHARD G. BRADLEY, Director, Aerospace Technology, General Dynamics, Ft. Worth, Texas

BERNARD BUDIANSKY, Gordon McKay Professor of Structural Mechanics, Abbot and James Lawrence Professor of Engineering, Harvard University

ROBERT H. CANNON, JR., Charles Lee Powell Professor and Chairman, Department of Aeronautics and Astronautics, Stanford University

RICHARD W. HESSELBACHER, Executive Vice President-Programs, Fairchild Space Company, Germantown, Maryland

BYRON K. LICHTENBERG, President, Payload Systems, Inc., Cambridge, Massachusetts

ROBERT G. LOEWY, Institute Professor, Mechanical and Aerospace Sciences, Rensselaer Polytechnic Institute

STANLEY MARTIN, JR., Technical Director, Bell-Boeing Joint Program Office, Arlington, Virginia

JOHN H. McELROY, Dean of Engineering, University of Texas-Arlington,

DUANE T. McRUER, President, Systems Technology, Inc., Hawthorne, California

GARNER W. MILLER, Senior Vice President, Maintenance and Engineering, USAir, Pittsburg, Pennsylvania

GEORGE W. MORGENTHALER, Associate Dean for Research, College of Engineering and Applied Science, Professor and Chair, Department of Aerospace Engineering Sciences, University of Colorado

HARVEY O. NAY, Director of Engineering, Piper Aircraft Corp., Vero Beach, Florida

FRANK E. PICKERING, Vice President \& General Manager, Aircraft Engines Engineering Division, General Electric Co., Lynn, Massachusetts

R. BYRON PIPES, Dean of Engineering, College of Engineering, University of Delaware

ANATOL ROSHKO, Theodore Von Karman Professor of Aeronautics, Acting Director, Graduate Aeronautics Lab, California Institute of Technology

RICHARD S. SHEVELL, Professor, Department of Aeronautics and Astronautics, Stanford University

THOMAS P. STAFFORD, Defense Technologies, Inc., Oklahoma City, Oklahoma

Liaison Member

FRANKLIN K. MOORE, Joseph C. Ford Professor of Mechanical Engineering, Cornell University (Sabbatical at NASA Headquarters through September 1989)

Staff

ROBERT H. KORKEGI, Director

JOANN C. CLAYTON, Senior Program Officer

RICHARD M. OBERMANN, Senior Program Officer

ANNA L. FARRAR, Administrative Assistant

JENNIFER T. ESTEP, Administrative Secretary

ELIZABETH LEE, Senior Secretary 


\section{Acknowledgments}

The members of the Committee on a Commercially Developed Space Facility wish to thank the many individuals from government, academia, and industry who took the time to either brief us in person or respond to our inquiries. Several offices of the National Aeronautics and Space Adminstration deserve special thanks for sharing with us projections into the 1992-1997 time frame and, in some cases, for developing and analyzing new long-range projections at our request and in response to our tight deadlines. There is sometimes a natural reluctance to venture forth with such estimates, and we very much appreciate the good faith efforts that were exerted to help us fulfill our task. We are especially indebted to the many scientists from private industry who travelled to Washington, D.C., to describe their company's involvement in research in the space environment. 


\section{Contents}

EXECUTIVE SUMMARY

1. INTRODUCTION 5

2. RESEARCH IN THE MICROGRAVITY ENVIRONMENT 9

The Nature of Microgravity Research

$\begin{array}{ll}\text { Key Parameters in Microgravity Research } & 10\end{array}$

Gravitational Acceleration Environment 10

Energy Intensiveness of Processes 11

$\begin{array}{ll}\text { Duration of Processes } & 12\end{array}$

Degree of Experimenter Understanding of Phenomena

Under Study

3. DEMAND FOR MICROGRAVITY RESEARCH AND APPLICATIONS ACTIVITIES

$\begin{array}{ll}\text { NASA Programs } & 15\end{array}$

$\begin{array}{lr}\text { Space Science and Applications Activities } & 15\end{array}$

Experiments in Materials Science and Transport

Phenomena

$\begin{array}{ll}\text { Experiments in the Life Sciences } & 17\end{array}$

$\begin{array}{lr}\text { Commercialization Activities } & 18\end{array}$

$\begin{array}{ll}\text { Advanced Space Technology Development } & 19\end{array}$

$\begin{array}{ll}\text { Space Station Development } & 20\end{array}$

$\begin{array}{ll}\text { Observations on NASA Microgravity Programs } & 20\end{array}$

Other Governmental and Private Requirements for

Microgravity Research

$\begin{array}{ll}\text { Manufacturing in Space } & 22\end{array}$

vii 
Summary Requirements for Research in the Microgravity

Environment

4. FACILITIES TO SUPPORT MICROGRAVITY RESEARCH AND APPLICATIONS

Ground-Based Facilities $\quad 25$

Space Shuttle-Based Capabilities $\quad 26$

$\begin{array}{ll}\text { Get-Away-Special Canister } & 26\end{array}$

$\begin{array}{ll}\text { Space Shuttle Middeck } & 26\end{array}$

Material Science Laboratory and

$\begin{array}{ll}\text { U.S. Microgravity Payload } & 27\end{array}$

$\begin{array}{ll}\text { Spacelab Module } & 27\end{array}$

$\begin{array}{ll}\text { Impact of Extended Duration Orbiter } & 28\end{array}$

Proposed U.S. Facilities $\quad 28$

$\begin{array}{lr}\text { AMICA } & 28\end{array}$

$\begin{array}{ll}\text { External Tank-Based Facilities } & 28\end{array}$

$\begin{array}{lr}\text { Industrial Space Facility } & 29\end{array}$

$\begin{array}{ll}\text { Leasecraft } & 30\end{array}$

SPACEHAB

Space Station Freedom $\quad 31$

Non-U.S. Facilities

$\begin{array}{ll}\text { EURECA } & 32\end{array}$

FSW $\quad 33$

Japanese Free-Flyer $\quad 33$

$\begin{array}{ll}\text { Photon } & 33\end{array}$

$\begin{array}{ll}\text { Space Station Mir } & 34\end{array}$

Summary of Information on Space-Based Facilities 34 
Impact of Space Transportation Schedule on Microgravity

Research

5. DIRECT MANNED INTERACTION, AUTOMATION, ROBOTICS, AND TELESCIENCE

$\begin{array}{ll}\text { Manned Interaction } & 41\end{array}$

Automation, Robotics, and Telescience $\quad 42$

$\begin{array}{ll}\text { Conclusions } & 44\end{array}$

6. ASSESSMENT OF THE NEED FOR A CDSF 47

$\begin{array}{ll}\text { Requirements Versus Capabilities } & 48\end{array}$

$\begin{array}{ll}\text { Acceleration, or } \mathrm{g} \text { Level } & 48\end{array}$

$\begin{array}{ll}\text { Duration } & 49\end{array}$

$\begin{array}{ll}\text { Power } & 49\end{array}$

Adequacy of Anticipated Flight Opportunities $\quad 50$

A\&R and Telescience Considerations $\quad 51$

Resource Considerations

Economic and Commercial Considerations $\quad 52$

Need for a CDSF in the Pre-Space Station Era 53

$\begin{array}{ll}\text { ACRONYMS } & 57\end{array}$

$\begin{array}{ll}\text { ABBREVIATIONS/SYMBOLS } & 59\end{array}$

$\begin{array}{lc}\text { APPENDIXES } & 61\end{array}$

A. Letter from James Fletcher and Statement of Work 63

B. List of Participants $\quad 69$

C. NASA Office of Space Science and Applications Projected

$\begin{array}{ll}\text { Requirements for Materials Microgravity Experiments } & 75\end{array}$

D. NASA Office of Space Science and Applications Projected
Requirements for Life Sciences Microgravity Experiments 
E. NASA Office of Commercial Programs Projected Requirements for Microgravity Experiments 


\section{Executive Summary}

In late 1988, at the request of the administrator of the National Aeronautics and Space Administration (NASA), the National Research Council formed the Committee on a Commercially Developed Space Facility to assess the scientific and commercial benefit to the nation of having a Commercially Developed Space Facility (CDSF) in place prior to space Station operations. The committee was to examine planned and anticipated microgravity research and manufacturing requirements of the federal government and commercial users as well as the extent to which existing, planned, and proposed capabilities and infrastructure could support these requirements. (See Appendix A for the full charge to the committee.) The committee was not charged with assessing the implications of various approaches to commercial development of space facilities or with estimating the costs of a CDSF. Thus, the committee's findings concentrate on the desirability of having an additional space facility in service in the interim preceding space Station Freedom.

The committee also examined the potential use of a CDSF to test and demonstrate Space Station and other advanced space technology, but found few applications in this area. Thus, the focus of its deliberations was on using a CDSF for microgravity experiments.

What is the status of microgravity science in 1989? Microgravity science and applications represent a broad, interdisciplinary area, less than twenty years old, encompassing fluid dynamics, materials science and processing, combustion, biotechnology, and life sciences research. Virtually all microgravity experiments in the United States, both governmental and private, are supported by NASA's office of Space Science and Applications (OSSA) or its Office of Commercial Programs (OCP). These offices exist for different purposes, one for the advancement of science and the other to promote the commercial uses of space. In the field of microgravity research, the committee believes enhanced interaction between these offices, for example in reviewing proposed experiments, would increase the effectiveness of the national effort. 
The committee considers that microgravity science is at an immature stage due to lack of understanding of the fundamental processes involved in this area of space research. As more experimentation takes place, a data base of results will be acquired, and it will become possible to strategically plan the future microgravity research program.

What would be the benefit to the nation of providing an orbiting manufacturing facility as early as possible? The committee found no evidence to suggest microgravity research would lead to significant space-based manufacturing in the next five to ten years. Rather, the deeper understanding of fundamental phenomena obtained from orbit, in the short term, will primarily be used to improve terrestrial processes.

Do existing Shuttle-based facilities meet anticipated microgravity needs? Important parameters in microgravity research are the magnitude and direction of gravitational acceleration, the amount of power available to an experiment (especially important for experiments requiring furnaces), and flight duration (important, for example, for growing large crystals). Lack of flight opportunities and funding for flight experiments have been major constraints on the national microgravity program. In the last few years, however, NASA has responded to recommendations of both internal and external advisory groups with increased emphasis on future flight opportunities and with enhanced budgets.

The committee studied the capabilities of existing Shuttle-based facilities for microgravity experiments. Thes generally offer acceleration environments of approximately $10^{-3} \mathrm{~g}$ and microgravity duration of approximately one week, although longer durations will be made possible by the Extended Duration Orbiter (EDO). With an EDO, 16-day Shuttle missions will be possible, and 28-day missions are also under consideration. While the amount of peak power available would remain unchanged, the total energy available would increase in proportion to the increased duration of the Shuttle mission.

The committee found that over 85 percent of proposed experiments could be accommodated with a 16-day mission, and that a 28-day mission would accommodate virtually all of the remainder. Experiments or processes needing on-orbit duration greater than presently available include such things as biotechnology research with living cells and crystal growth.

An examination of the projected requirements of OSSA and OCP experiments revealed that fewer than four percent need peak power levels greater than $2.0 \mathrm{~kW}$, less than will be available through Shuttle-based facilities in the 1992-1997 time frame. Higher power levels enable more experiments to be conducted simultaneously, however. Thus far, with careful mission planning, experimenters have been able to work effectively around restricted electrical energy and total peak power.

Based on mathematical modelling, some important experiments are believed to require accelerations with magnitudes lower that $10^{-6} \mathrm{~g}$, but little experimental evidence is yet available about the need for such very low accelerations. The presence of humans, spacecraft 
docking, and thruster firings cause perturbations that have disruptive effects on microgravity research. It appears that some compound and alloy-type electronic and optoelectronic crystal growth experiments may require very low microgravity levels that can only be provided by a free-flyer. The committee believes the data base in this area is too limited to provide adequate information to make a final judgment.

The committee found that the available and tentatively manifested experiments, power levels, anticipated flight durations, and the microgravity environment of the NASA Shuttle-based facilities would not impose serious constraints on the experiments planned by OSSA and OCP in the period from 1990 to 1996, recognizing that planning for the later years is far from firm. Existing and planned facilities will accommodate the vast majority of anticipated experiments, assuming the space transportation system is able to carry out a substantial fraction of its planned missions.

In addition, if any of the commercial facilities on the horizon materialize, the committee believes there will be room for growth in the national microgravity program. The committee explored many proposed or planned U.S. and non-U.S. facilities for microgravity experiments. Many of these capabilities, as described in Chapter 4, are innovative, and they have varying individual advantages.

What is the status of space automation technology and what is its relevance to the capabilities for a CDSF? The present generation of microgravity experiments is largely designed to be tended by humans, and approximately 40 percent of experiments to date have required unscheduled human intervention. Advances in automation, robotics, and telescience have been demonstrated in laboratories and industrial applications, but typically it takes 24 to 48 months to adapt we11-understood microgravity experiments so that they can be conducted in an automated fashion. Data from presently planned microgravity experiments will, in many cases, be required in order to properly design robust experiments incorporating automation and robotics (A\&R) and telescience to take advantage of free-flyers. Full automation and telescience techniques are essential if experiments are to be performed in a vehicle such as a CDSF where man will not be present when many experiments are performed. The time and costs of developing such experiment capabilities must be taken into account in reaching a decision to utilize a free-flyer in NASA's programs.

What are the implications of Space Transportation schedules for the microgravity program? The current Space Shuttle manifest through 1994 contains no reserve for contingencies; the committee believes that the flight rate projected for 1991-1994 is higher than will be achieved and that there may be a loss of opportunities for microgravity payloads during this period. However, the possibility also exists that not all manifested payloads will materialize. For example, some Department of Defense (DOD) bookings may not be required, and therefore more opportunities may eventually be available than now appear. 
The committee discounts the notion of developing a CDSF as insurance against lower flight rates or against a delay in the deployment of the Space Station. The usefulness of a CDSF remaining untended in orbit for long periods between Shuttle visits is likely to be limited given the level of maturity of microgravity experimentation, automation, and robotics. In addition, the minimum cost to NASA of a CDSF as insurance has been stated to be $\$ 700$ million over four to five years, which rivals the total national support for microgravity programs (approximately $\$ 150$ million in FY 1989).

Is a CDSF required prior to Space Station operations? No. However, in the era of the Space Station, a U.S. long-duration, human-tended free-flying spacecraft for microgravity research may well have merit. The committee believes free-flyers eventually will be needed for microgravity research, development, and applications. But their use will be predicated on developing the knowledge base, hardware systems, and appropriate $A \& R$ and telescience needed to make them practical. Results of on-going flight experiment programs will be used to define meaningful classes of future experiments. The needs of these experiments will then dictate the detailed design of the free-flying platform. As a minimum, such a facility for microgravity activities should be readily accessible from the Space Station and compatible with it, yet have the advantages of a "clean" microgravity environment, and should be able to take advantage of expected advances in A\&R and telescience.

If there should be a delay in the initial operations of the Space Station of one to two years, the committee's judgment would not change. However, if it should become apparent that there will be a much longer delay, the committee recommends reconsideration of the need for additional flight opportunities for microgravity activities. This reconsideration should be based on progress in understanding the basic scientific processes that are involved, the status of automation, robotics, and telescience, and upon whether requirements for manufacturing can be identified. In such a case, consideration should be given to some of the more modest facilities described in Chapter 4 in trying to match requirements with capabilities.

Although the potential benefits to the nation of microgravity experimentation lie in the future, the committee believes it is important to continue to explore this new frontier of human knowledge and to begin to build the foundation for eventual commercial exploitation of the space environment. 


\section{Introduction}

The potential of the microgravity environment of space for productive research into the behavior of materials, thermal and fluid processes, and living organisms has been recognized for two decades. Microgravity research in the United States began in the late $1960 \mathrm{~s}$ during the Apollo program. The Soviet Union initiated a microgravity research program during the 1970s, and Europe, Japan, and China have followed suit in this decade. There is little disagreement that research in a microgravity environment can produce scientific results of considerable interest in a variety of disciplines. More controversial is the suggestion that some of these results can be applied to the development of products or processes with significant economic payoffs, but there are enough indications that such could be the case to have attracted considerable attention in all countries active in microgravity research.

For example, a committee of the National Research Council (NRC) as long ago as 1978 concluded that "there is opportunity for meaningful science and technology (related to materials processing) developed from experiments in space," although it did not discover "any examples of economically justifiable processes for producing materials in space." A decade later, another committee of the NRC characterized the microgravity environment as "unique" and "valuable," and recommended that it should "be considered primarily as a tool for research and secondarily as a manufacturing site," since "significant demands for manufacturing opportunities are unlikely in the near term." This committee also noted that access to the microgravity environment for research purposes is "presently available to U.S. investigators only through resources provided by NASA."

Until recently NASA had not been effective in providing adequate access for researchers to the microgravity environment. A 1987 internal NASA review of the agency's microgravity materials science program 
concluded that the "lack of flight opportunities is impeding scientific and commercial progress," noting that "without flight opportunities, this research field can neither acquire the scientific foundation to attract and involve a community of first-class researchers, nor develop the results which are necessary to demonstrate realistically whether private investment in potential commercial opportunities poses an acceptable risk." ${ }^{3}$ This critical assessment assumed that the planned Space Station Freedom would provide the long-duration, adequately powered facilities required for a substantial program of microgravity research once it becomes available in the late 1990s. It also commented that NASA's "currently defined flight opportunities for the period prior to construction of the U.S. Space Station are not adequate...to create a foundation for a vigorous, broad-based program. " 4

Over the past 18 months, NASA has responded to the recommendations of its Microgravity Materials Science Assessment Task Force and to other suggestions for improving U.S. activities in microgravity research by significant budgetary enhancements and increased flight opportunities aboard the Space Transportation System. In addition, the February 1988 Commercial Space Initiative developed under the auspices of the White House Economic Policy Council and endorsed by President Reagan announced that the U.S. government would take the lead in enhancing opportunities for microgravity activities by becoming the "anchor tenant" of a Commercially Developed Space Facility (CDSF).

As defined in a draft NASA Request for Proposals (RFP) dated March 24, 1988, such a facility would provide in low Earth orbit a sizeable pressurizable volume containing standard Space

Station-compatible racks for mounting various types of equipment, and would make available specified average and peak power levels to such equipment. It would be capable of operating in two modes. When attached to the Shuttle orbiter, the CDSF would accommodate at least two persons working in a shirt-sleeve environment for a specified period; when in a free-flying mode, separate from the Shuttle, it would be capable of operating autonomously and maintaining a high-quality microgravity environment.

This CDSF concept has been represented by its advocates as being both a significant enhancement of opportunities for microgravity research and technology development activities on-orbit, and a new way for NASA to gain access to such opportunities, since the CDSF would be financed, owned, and operated by the private sector rather than by NASA, a government agency. 5 The "anchor tenant" concept, however, would involve a significant commitment of public funds at some future time for leasing up to 70 percent of the facility.

Given the magnitude of the potential government commitment, on April 28, 1988, the U.S. Senate Committee on Commerce, Science, and Transportation requested that the NASA administrator ask the NRC to conduct an independent study addressing the value of a CDSF to the nation. On June 2, 1988, the House of Representatives passed H.R. 4561, which included language coinciding with the Senate request, and futher 
stipulated that the National Academy of Public Administration conduct a parallel study of the cost implications of the CDSF proposal.

In response, on September 19, 1988, NASA Administrator Dr. James Fletcher formally requested that the NRC conduct an independent study of the CDSF that addressed the following issues: (1) the scientific and commercial benefit to the nation of developing a Commercially Developed Space Facility prior to Space Station operations; (2) definitions of the criteria for optimum use; and (3) the technical characteristics of a CDSF that would enable its optimum use. Further, the NRC was asked to assess planned and anticipated microgravity research and manufacturing requirements of the federal government and commercial users prior to Space Station operations and how and to what extent existing, planned, and proposed capabilities and infrastructure could support these requirements. Dr. Fletcher's letter and the accompanying statement of Work are included as Appendix A.

To respond to this request, the Aeronautics and Space Engineering Board of the NRC's Commission on Engineering and Technical Systems convened the 14-member Committee on a Commercially Developed Space Facility. Members of the committee had backgrounds in science, engineering, management, finance, and policy. The full committee met four times during the period from November 1988 to February 1989 and heard presentations from a wide variety of individuals and organizations interested in the country's microgravity research effort and the facilities required for its implementation. (See Appendix B for a list of study participants.) A subcommittee on microgravity requirements held additional meetings.

The Statement of Work for the study did not request a perspective on the implications of "commercially developed," and commercial development is not a subject of the following report. The committee recognized that the earlier NASA draft RFP may or may not represent the optimal configuration for a "space facility" for microgravity research. Thus, to help make its judgments, it sought information about the capabilities of as many space facilities as possible ranging from the most modest to those of space stations.

The committee devoted most of its time to assessing the potential role of a CDSF in the U.S. microgravity research program, although it also considered use of the facility for such purposes as validating the performance of various technologies being developed for use in space or gaining experience relevant to Space Station assembly or operation. Because of the dynamic nature of NASA's microgravity program (including the selection and design of experiments) and the long-range manifest of the Space Shuttle, the committee based its analyses on projected payloads and manifest capabilities as envisioned in early 1989. It was also necessary, however, to examine several contingencies having to do with transportation to space and the timing of the Space Station's deployment.

The committee's conclusions are contained in the subsequent chapters of this report. The committee recognizes that space has significant 
potential to advance knowledge about materials, biology, and other physical and scientific phenomena, and its conclusions and recommendations are meant to help further the utilization of space for human benefit.

\section{NOTES}

1. S1ichter, 1978, p. 5 .

2. Todd, 1988, p. 1 .

3. Dunbar, 1987, p. 7.

4. Ibid.

5. A commercial enterprise, as opposed to a government activity, is generally defined as being funded by money from private sources with private capital at risk, in which the product or service is paid for on delivery, and which receives little or no government supervision. If the above conditions exist and only one government agency is the customer, the effect is simply that the government is using a slightly different procurement approach, that is, delaying payment. 


\title{
II \\ Research in the Microgravity Environment
}

\author{
THE NATURE OF MICROGRAVITY RESEARCH
}

Microgravity sciences and applications comprise a broad range of research and development activities that are less than 20 years old. As basic and applied scientific research conducted in space, this field is gaining recognition as a legitimate, cohesive, scientific endeavor. Microgravity applications are similarly new, and collectively constitute an immature technology without demonstrable commercial successes as yet, but with potential practical importance. The nearer term practical impact of microgravity research likely will be on the terrestrial processing of materials, enhancement of some biotechnology, and the improvement of industrial processes.

An important aspect of microgravity research to be considered is its inherent breadth and interdisciplinary nature. The field of microgravity science encompasses a number of subfields including:

- fluid, thermal, and transport sciences;

- condensed matter and gravitational physics;

- materials science and materials processing;

- combustion science;

- biotechnology and separation science; and

- life sciences.

The scientific constituency for microgravity research is dispersed over a number of contributing disciplines, although a unifying, almost ubiquitous feature of microgravity research is the study of gravitationally modified physicochemical transport phenomena. Included among the phenomena of interest are: (1) reduction of gravitational sedimentation, which is the spatial separation of heavy and light objects immersed in a fluid medium; (2) elimination of hydrostatic pressure, which is the internal pressure of a fluid resulting from its weight; and (3) reduction of buoyancy-driven fluid flows, which normally arise from local density differences due to variations in temperature or chemical 
composition within a fluid body. These fundamental fluid effects interact with ordinary chemical, physical, and biological processes to produce both quantitatively and qualitatively altered states displaying novel physicochemical behavior. For example, surface tension forces, normally so weak as to be generally unimportant under terrestrial conditions, can become dominant under microgravity conditions, suggesting the possibility of containerless confinement of fluids under their own molecular forces for a variety of basic experiments and practical applications.

A spectrum of space- and ground-based experiments will be required to advance microgravity research. This spectrum will make use of facilities ranging from drop towers to suborbital and orbiting spacecraft.

The complexity of research in the transport, materials, and 1 ife sciences disciplines usually requires, in the terrestrial laboratory, human interaction with experiments in order to observe nuances and unexpected phenomena and to adjust experimental parameters in real time. Many space-based materials experiments will require similar human interaction, including communication with principal investigators on the ground. To date, few resources and limited focused efforts have been invested in developing microgravity research hardware that would be capable of semiautonomous or teleoperational modes, although a broad range of robotic and telescience technology is available. clearly, further effort is required in this area. In addition, microgravity sciences are highly reliant on the return to Earth of processed materials and biologicals.

\section{KEY PARAMETERS IN MICROGRAVITY RESEARCH}

A number of parameters characterize types of microgravity research and applications activity: the gravitational acceleration environment, the energy intensiveness of the process, the duration of the process, and the degree of experimenter understanding of the phenomena under study. These requirements dictate which type of experimental facility is preferable for particular research projects.

As noted above, however, exhaustive experimentation on Earth must precede experimentation in space. Research conducted in space is too expensive to allow trial and error experiments.

\section{Gravitational Acceleration Environment}

The microgravity environment in Earth orbit is characterized by several components. The first is the set of quasi-steady accelerations on a vehicle due to atmospheric drag and gravity gradient effects. The second is the set of random, broadband accelerations (referred to as "g-jitter") that time-average to zero, but that might detrimentally influence certain processes with relatively short characteristic times. Sources of g-jitter include crew motion, thruster firings, and mechanical 
vibrations. In general, the net effect of the above-mentioned accelerations on an experiment can be either minimized or exacerbated by the spacecraft's orientation, frequency of thruster firings, placement of the experiment relative to the spacecraft's center of gravity, degree of experiment isplation, overall flexibility of the spacecraft's structure, and so forth. ${ }^{2}$

The limited experience of U.S. microgravity investigators in orbital processing and the lack of well-documented experimental observations backed by accurate timelined microgravity accelerometer data make it difficult to assess how the acceleration power spectrum (in effect, the "g" level) really affects the outcome of an experiment. The greater Soviet experience in microgravity science has shown that some classes of experiments can be successfully executed below $10^{-3} \mathrm{~g}$ (at frequencies $<1$ $\mathrm{Hz}$ ), but the true influence of the full spectrum remains uncertain, as do such critical issues as the effect of the orientation of the net acceleration vector with respect to the thermal and solutal gradients developed during processing. Recent results by the Soviets seem to indicate that there is a strong correlation between increased crew activity and degraded crystal quality obtained from orbital processing.

It is thus apparent that the trade-offs needed to achieve a cleaner g-spectrum must be carefully evaluated. For example, what is the trade-off between having crew intervention during an experiment and accepting more g-jitter? Which experiments degrade sufficiently because of human presence as to be inappropriate on a manned platform such as the Shuttle or the Space Station? When would a free-flyer mode, with its greater reliance on teleoperation, prove to be a better compromise than a fully manned vehicle? Clearly, a thorough assessment of the gravitational acceleration power spectrum must be available for any microgravity platform in order to decide these issues.

Although such information is not presently available at the level of detail required, NASA is supporting computational fluid dynamics research that addresses the theoretical aspects of these issues ${ }^{3}$ and, in paralle1, is developing a Space Acceleration Measurement System (SAMS) capable of microgravity measurements over the relevant frequency range.

\section{Energy Intensiveness of Processes}

The energy requirements of microgravity experiments vary greatly, and it is not possible to specify a unique value range. Peak power required for some experiments involving use of furnace facilities can range up to several kilowatts. Other experiments require lower power levels but involve processes that require energy input over a long duration. Researchers generally agree that in the available as well as in most planned space facilities, power limitations will impose restrictions on some experiments. 


\section{Duration of Processes}

As with energy, the required time durations of processes of interest to microgravity researchers vary widely. Some experimental processes reach completion within a fraction of a second; others, notably those involving vapor-phase and solution crystal growth, ideally could make use of experimental run times on the order of several days or weeks. However, the committee did not find substantial interest in long-duration microgravity research at present. For example, the responses to a recent NASA Announcement of Opportunity for microgravity experiments showed that only 13 percent of the proposals required a mission duration in excess of 16 days. (The committee recognizes that the proposers may have been influenced by their knowledge of the duration capability planned for the Shuttle.)

\section{Degree of Experimenter Understanding of Phenomena Under Study}

The microgravity phenomena of interest to researchers differ greatly in terms of the degree to which they are understood. Typically, experiments and applications activities involving processes for which the underlying phenomena are reasonably well understood are likely to require little human interaction on a real-time basis and could be automated. The converse is likely to hold when novel phenomena are under study. In general, however, microgravity research on materials, fluids, and processes is an embryonic science. Ground research will not only help develop more meaningful experiments that are likely to succeed, but will also insure the identification and assessment of reduced gravity effects. Large amounts of experimental and analytic work will be required before comprehensive research strategies can be mapped and before the potential advantages of a human-tended free-flyer can be optimized.

These parameters for microgravity research (the gravity environment, energy requirements, duration, and degree of experimenter understanding of phenomena under study) determine an experimenter's choice of the type of access to space that is appropriate for his or her research.

\section{NOTES}

1. More detailed discussions of microgravity phenomena are contained in Slichter, pp. 7-20, and in Ostrach, pp. 313-345.

2. Naumann, June 8, 1988.

3. For example, recent computations for Bridgman crystal growth from the melt show that alignment of the quasi-steady state gravity vector with the crystal growth direction is desirable. Components of the gravity vector orthogonal to the crystal growth axis are an order of magnitude more effective than the axially aligned component in inducing fluid flow and causing dopant inhomogeneities in the resulting crystal. Similar studies 
are needed for other high-priority microgravity experiments such as protein crystal growth, float zone growth, solution crystal growth, and vapor-phase crystal growth. 


\section{Demand for Microgravity Research and Applications Activity}

In the United States, NASA has been the major sponsor of microgravity research and applications activities. The following sections discuss NASA's role in such research and outline existing and planned actions of other governmental and private organizations.

\section{NASA PROGRAMS}

Several offices of NASA have programs addressing research in the microgravity environment. The Office of Space Science and Applications (OSSA) programs encompass basic research on transport phenomena, materials, and industrial processes as well as research in the life sciences. The Office of Commercial Programs (OCP) attempts to bring together academic research and industrial interest in commercially relevant advances in materials and processes that might be made in the space environment. To do this it has created a number of Centers for the Commercial Development of Space focused on relevant disciplines.

In a broader context than just microgravity research, the office of Aeronautics and Space Technology (OAST) performs basic research on structures and other technology development and, in the context of in-space research, tests the efficacy of new technological developments in situ. The office of Space Station also plans to utilize in-space proof-of-concept technology demonstrations and demonstrations of research equipment in advance of the Space Station's deployment.

\section{Space Science and Applications Activities}

The OSSA microgravity activities address research in the areas of materials (including metals and alloys, electronic and photonic 
materials, ceramics and glass), fluids and transport phenomena, combustion, fundamental physics and chemistry, and biotechnology and life sciences. The main program focus has been toward materials science, not only because the scientific questions surrounding this field are profound, but because of its potential for practical applications. Consideration is also being given to broadening the scope of research on transport phenomena in order to expand its applications to diverse industrial processes.

The flight research program is centered about three different capabilities provided by the Space Shuttle system, viz., the Spacelab, the orbiter middeck, and the cargo bay; ultimately, the capabilities of the Space Station will be used. Current OSSA planning reflects the reality of flight availability.

In terms of demand, microgravity flight opportunities are formally manifested on the Shuttle through FY 1994. Primary payloads (e.g., Spacelabs) have been essentially fully booked for the manifested microgravity missions by OSSA as far out as the USML-1 Spacelab flight (scheduled for the STS-54 flight in early 1992). The OSSA allocation of the USML- 1 experiment space (50 percent of the total, with the remainder allocated to OCP) has not yet been filled, but OSSA believes that it will be. Microgravity experiments are not yet specifically manifested for flights after USML-1.

The current OSSA demand for microgravity research is outlined in Appendixes $C$ and D. As can be seen from those appendixes, the planned/proposed experiments fall into two broad categories: those related to materials science and transport phenomena and those related to the life sciences.

\section{Experiments in Materials Science and Transport Phenomena}

Studies of materials science and transport phenomena in space are closely coupled. Each represents a typical laboratory science that requires human interaction with the experiments to make observations and identify novel or unexpected effects. There have been limited flight opportunities to gain a better understanding of the complex phenomena involved in microgravity processes or to develop experimental

facilities.

Most of the microgravity experiments performed to date have carried into space materials processing techniques that were developed and optimized for a terrestrial environment in order to identify phenomena and improvements that might result from the suppression of gravitational effects. Such a trend is likely to hold for the period prior to space Station operations. The committee believes that only when scientists can live and work in space for extended periods, with sufficient resources and capabilities to investigate new ideas, will new processing techniques be developed that take full advantage of the unique microgravity environment, that is, techniques that by their inherent nature cannot be developed on Earth. 
The committee reviewed the OSSA Microgravity Science and Applications Divisions (MSAD) program, which has responsibility for the activity in materials science and transport phenomena. The committee believes that MSAD has developed a strategic plan for the development of microgravity research in materials science and transport phenomena along an evolutionary path that allows necessary manned intervention and provides for the creation of facilities and enabling technologies leading to the productive use of the Space Station, when it becomes available. That plan has not indicated a requirement for CDSF-like facilities.

The 1989 budget for MSAD was $\$ 75.6 \mathrm{million}$, up from $\$ 62.7 \mathrm{million}$ in 1988 , and a 23 percent increase (to $\$ 92.7$ million) is requested for 1990 .

\section{Experiments in the Life Sciences}

The main thrusts of OSSA life sciences research are directed toward (1) understanding human physical reactions and adaptation to both shortand long-duration flights and the development of ways to offset any deleterious effects that occur in flight as well as after return to earth, and (2) the conduct of basic research to improve understanding of life processes and the origins of life. The life sciences flight program strategy for the $1990 \mathrm{~s}$ is built around the existing and planned capabilities of the Shuttle, Spacelab, and Space Station.

The life sciences microgravity program includes research efforts in the areas of cellular and molecular biology, botany, genetics, and organismic biology. Exposure to microgravity induces changes in fluid-electrolyte balance; endocrine function; neurophysiological function; immune system, cardiovascular, and renal function; bone mineralization; and muscle mass. It is uncertain whether microgravity alone is responsible for these alterations, since a combination of factors that cannot be simulated in their totality on Earth may be involved. However, it is essential to understand the impact of microgravity on life and life-support systems before undertaking extended human space flights.

Much of the NASA OSSA life sciences microgravity research program focuses on identifying important mechanisms associated with microgravity-induced changes in biological functions and on developing the countermeasures needed to restore a "normal" equilibrium. The investigative work concerns the effects of microgravity on (1) bone mineral metabolism, (2) structural and material properties of soft and mineralized tissues, (3) immune function and cell differentiation, (4) embryogenesis, (5) membrane transport, (6) muscle contractile properties, (7) protein synthesis and degradation in various tissues, (8) gene expression, (9) signal transduction, (10) extracellular matrix organization, (11) tissue energetics, (12) motor unit function,

(13) neural activation, (14) root growth, (15) tissue regeneration, and

(16) endocrine functions. 
Because of the lack of a long-duration, space-based research capability, life science research has focused on short-term,

Shuttle-based studies that require human-tended operations. However, researchers acknowledge the need to investigate longer exposures to microgravity for various subfields in the life sciences. Besides those experiments requiring human subjects, most other investigations depend on human intervention for their execution. At present, NASA is proceeding with studies and development to provide a capability to conduct life science investigations on unmanned, free-flying, recoverable bioplatforms. The ability to perform studies of longer term phenomena and space radiation effects is the prime driver for the activity rather than the need for high-quality microgravity. Life sciences' flight requirements appear in Appendix $D$.

The 1989 budget for life sciences research was $\$ 78$ million, of which $\$ 36$ million is for microgravity flight programs. An increase in the life sciences budget to $\$ 124.2$ million is requested for 1990 , of which $\$ 70.4$ million would be for microgravity flight programs.

\section{Commercialization Activities}

In 1984 Congress declared "that the general welfare of the United States requires that the National Aeronautics and Space Administration seek and encourage, to the maximum extent possible, the fullest commercial use of space." 1 As a response to this directive and Presidential pronouncements of that same year, NASA established the Office of Commercial Programs (OCP).

The OCP sponsors flight experiments and hardware systems primarily through Joint Endeavor Agreements (JEAs), Space System Development Agreements (SSDAs), and the activities of the Centers for the Commercial Development of Space (CCDSs). A large number of experiments have been proposed, particularly by the CCDSs. They are rated primarily on the basis of commercial potential and appear not to have been reviewed yet for technical merit. Enhanced interaction and cooperation between OCP and OSSA could lead to greater scientific understanding in the OCP programs and to other advantages associated with "feedback" between the two offices.

In essence, the commercialization process starts with an idea for a potential research or commercial activity, proceeds through ground-based and flight research phases, development, and finally to pilot projects, initial production, test marketing, and full-scale production. The OCP has estimated that a period of about seven years from inception of a concept will normally be required to reach the pilot production phase for any promising microgravity process. Thus, until at least the mid-1990s, NASA's commercialization program for microgravity essentially will be in a research and development stage. The current flight strategy, therefore, is similar to that evolved by MSAD, except that it relies primarily on secondary payload manifesting. 
OCP has facilitated research in materials and processes and in biomedical and agricultural areas. Much of the potential commercial interest in the life sciences, as documented by OCP, requires access to microgravity for a short duration ( $<16$ days).

OCP microgravity experiments are expected to continue to be carried mainly as secondary payloads. Appendix E contains OCP's estimates of experiments that will need to be flown through FY 1996. It is the committee's view that, at present, the commercially oriented microgravity payload manifests of OCP appear to be less firm than those of OSSA. At the same time, OCP planning incorporates the ability to respond quickly to the unanticipated availability of secondary payload space.

The 1989 OCP budget for the commercial use of space was $\$ 28.2$ million, and $\$ 38.3$ million has been requested for 1990 .

\section{Advanced Space Technology Development}

Most existing space technologies have been developed on the ground and then tested in a flight program. However, future space systems are likely to be large and expensive. Thus, undertaking feasibility, or proof-of-concept, demonstrations in space would seem to offer a cost-effective way to ensure technology readiness for future missions. of necessity, in-space flight testing is becoming part of advanced technology programs. The Office of Aeronautics and Space Technology (OAST) has identified the following as the most likely technology areas to require such testing:

- space structures (assembly, dynamics, and contro1);

- fluid management;

- space environment effects;

- life support;

- information systems;

- space environment characterization;

- automation and robotics; and

- in-space operations.

The current OAST strategy is based on the nature of the experiments, the available flight opportunities, and the planned budget. Present OAST plans call for the majority of the experiments to use the Shuttle bay, the Space Station's attachment points, or expendable launch vehicle (ELV)-based, free-flying spacecraft. Only a relatively small percentage are planned for the Shuttle middeck or the Space Station's U.S. Laboratory Module. Most, but not all, of the experiments are of durations that can be achieved on Shuttle-based facilities, and many require human interventions. Finding budgetary resources to define and develop such experiments poses a separate problem. Only one of the projects that could be accomplished in an untended mode is currently funded, and that only for the concept definition phase. 


\section{Space Station Development}

The Office of Space Station (OSS) has not identified any requirements for space-based microgravity research or technology development beyond those activities already planned for and manifested on the Shuttle. OSS believes that neutral buoyancy simulators, other simulators and prototype equipment, and Shuttle experiments have to date proven adequate to develop the necessary levels of confidence in technology and procedures. Terrestrial testing clearly is less expensive. The committee believes some pre-Space Station R\&D will need to be performed in space, such as some long-duration materials research, but, in its deliberations the committee could find no space Station-related technology or process development that could only be undertaken successfully on a human-tended free-flyer.

\section{Observations on NASA Microgravity Programs}

As the study committee examined the NASA microgravity programs described on the preceding pages, it noted some significant manifestations of the embryonic state of microgravity research, which follow.

1. Because of the immaturity of our understanding of basic processes in space, there is only a limited supply of the kind of reliable, powerful, flight-tested, general purpose or easily adaptable equipment needed for effective research programs. Because of this, it is not unusual for individual researchers to devote a decade to designing the hardware necessary to permit scientific investigation. Both time and sufficient resources will be needed to address this inadequacy.

2. The selection of flight experiments sometimes appears to be occurring on an ad hoc basis. OSSA has candidate flight experiments reviewed for scientific merit (see the report of the Schrieffer committee regarding this procedure ${ }^{2}$ ). The mission of OCP, however, is to encourage private participation, especially outside of the scientific research community, with the hope of eventually enabling successful commercial ventures. OCP programs thus are not as a matter of course reviewed for scientific and technical merit or even for redundancy with other research. The committee is concerned that the experiments selected for a national microgravity research program, a program conducted in a unique and expensive environment, should be carefully coordinated within NASA. NASA has conscientiously stood up to its mandate to promote the commercialization of space; the OCP Centers for the Commercial Development of Space must therefore pursue all reasonable paths in this direction. Nonetheless, the committee believes enhanced cooperation between OSSA and OCP could benefit both programs, could help ensure a greater return for the national investment, and could help 
avoid nonproductive, redundant, or poorly conceived experiments that might reflect badly on the whole microgravity program.

\section{OTHER GOVERNMENTAL AND PRIVATE REQUIREMENTS FOR MICROGRAVITY RESEARCH}

Representatives from the National Institute of Standards and Technology (NIST) of the U.S. Department of Commerce met with the committee and expressed an interest in microgravity research, but their requirements are small. The committee also contacted relevant organizations within the Department of Defense--U.S. Air Force, Office of Naval Research, and Defense Advanced Research Projects Agency (DARPA)--only one of which identified in its planning a small anticipated demand for microgravity experiments. Thus the microgravity research and applications plans of governmental agencies other than NASA do not appear to be significant at this time.

In addition to governmental and university involvement (by means of governmental funding) in research on materials and processes in a microgravity environment, not-for-profit and for-profit private entities have also expressed limited interest in such possibilities. In general, the not-for-profit entities have pursued their research in much the same manner as university groups, with support coming primarily from NASA program offices. The for-profit industrial interest has always been small, as measured by the amount of private resources invested in the program.

A highly visible industrial investment in materials (pharmaceuticals) separation utilizing electrophoresis was essentially abandoned during a period of no flight opportunities when newly invented ground-based techniques made the space-based process too expensive for the particular product involved. At present, only one U.S. company has been identified as having an enduring commitment to research in a microgravity environment that is directed toward possible commercial products. Most industrial involvement is centered on collaborative/consultative projects with university-based NASA/OCP CCDSs. Those companies that have invested either at a nominal "in-kind" level (i.e., provision of staff, equipment, and facilities rather than funds) or that have made funds available clearly view their participation in terms of a long-term commitment directed toward developing a basic understanding of materials and processes.

The relatively low level of industrial commitment to activity in the microgravity environment, especially in terms of work directed toward materials processing, is consistent with the conclusions of a number of NRC reports on the subject and even with observations of potential facility providers that "there are no manufacturing requirements." 3 This low level of industrial commitment to microgravity research and development accurately reflects the perceived value of space experimentation compared with ground-based work directed toward similar industrial objectives. 


\section{MANUFACTURING IN SPACE}

The potential benefits of the microgravity environment for manufacturing are both direct and indirect.

Direct benefits may be derived by producing materials or products in space and bringing them back to Earth for consumption. The value added in space processing, however, must outweigh the cost of transportation and of the use of space-based facilities. At the present time, the transportation costs alone are in the range of $\$ 5,000$ to $\$ 10,000$ per pound. It has been argued that certain pharmaceuticals, electronic materials (e.g., the semiconductor gallium arsenide), and some catalysts can be produced in space with sufficiently superior quality or in sufficiently greater quantity to render their production economically feasible. Very few people argue that this will happen in the near future, however.

Indirect benefits are derived by studying a process for manufacturing a certain product in space under reduced gravity conditions where it is possible to control and study various parameters such as temperature, processing rates, and chemical composition gradients. Such separation of process parameters typically is unattainable on Earth. The findings from the space-based activity are then applied advantageously to alter and optimize manufacturing processes on Earth, for example, the production of chemicals, metals, and food items. Realization of these benefits does not require full-scale manufacturing in space.

Setting up a manufacturing process or the study of such a process is a complex undertaking on Earth and even more difficult in space. The behavior of materials systems involving fluids (liquids and/or gases) can be profoundly different in space than on Earth and there is not yet a good data base describing this behavior. Fundamental experiments in space to provide this data are a necessary prerequisite to space manufacturing. In addition, step-by-step evaluation of a space-based manufacturing process must precede pilot plant investigation or production. On Earth the introduction of a new product from its concept to production typically requires several years. Such an undertaking in space would most likely take longer, at least until researchers move up the learning curve with experience.

Since a data base for manufacturing materials in space is nonexistent and the number of (relatively primitive) experiments to date has been small, the committee believes that there will be no need for a facility to produce or manufacture materials in space within the next seven to ten years. This statement is not intended to detract from the potential long-term benefits of space manufacturing. Rather, it is intended to accent the immediate need for basic and applied research and development of materials processing under reduced gravity--an indispensable preamble to this aspect of the commercial exploitation of the space environment. 


\section{SUMMARY REQUIREMENTS FOR RESEARCH \\ IN THE MICROGRAVITY ENVIRONMENT}

The committee explored needs for microgravity research with the following: the scientific and technical microgravity research communities associated with the NASA Office of Space Science and Applications; the NASA Office of Commercial Programs and the industrial and academic communities that are working with the Centers for the Commercial Development of Space; the defense research community; the Department of Commerce and the National Institute of Standards and Technology; and leading experts from government and corporations involved in research on materials and processes in the space environment. In addition, the committee investigated the needs for technology development and verification to facilitate transition into the Space Station era.

The majority of the demand for microgravity research in the United States comes from NASA through the programs of either OSSA or OCP. The demand for microgravity research by federal agencies other than NASA was found to be minimal.

Based on some hard data and many best estimates, the following specific requirements were identified by the committee.

- Duration: An examination of the anticipated needs of 83 proposers of microgravity experiments to NASA's OSSA Microgravity Science and Applications Division (MSAD) revealed that only 13 percent of experiments require periods in space longer than 16 days (the time expected to be available with the use of an extended duration orbiter, although a 28-day extended duration on orbit is also being investigated). This low demand for long-duration flight also holds true for OCP activities. (See Appendixes C, D, and E for the projected requirements.) The proposed experiments for which long-duration exposure is sought fall into the following categories:

(1) Biotechnology research with living cells, including work with enzymes and protein nucleation. This type of long-duration (beyond a week) scientific investigation has yet to be conducted, and it is not clear what results can be anticipated.

(2) Production of materials such as pharmaceuticals.

(3) Crystal growth, for example, semiconductors and protein crystals. While this process can be performed on flights of a week or 16 days, a few researchers are seeking 90-180 day process durations for production of larger crystals.

- Power levels: An examination of the projected requirements of OSSA and OCP classes of experiments listed in Appendixes C, D, and E revealed that less than four percent need peak power levels greater than $2.0 \mathrm{~kW}$, which will be available through the Shuttle with USMP, Spacelab, and so on during the 1992-1997 time frame. Obviously, however, higher power levels enable more experiments to be conducted simultaneously. 
- Microgravity acceleration levels: Because of the paucity of microgravity experiments that have been flown with adequate measurements of the acceleration of gravity, there is little experimental data to use in specifying the requirements for future experiments. Instead, the results of limited experiments, simple analytical models, and (in the case of the most demanding and highest priority microgravity experiments) a computational fluid dynamics model, have been used to come up with plausible estimates of acceleration that are acceptable for different classes of experiments. The estimates will need to be verified by the results of many well-instrumented flight experiments. The nature of the acceleration requirements and their basis are set forth very well by Naumann. ${ }^{4}$ Appendixes $C, D$, and $E$ include estimates of acceleration levels for the various NASA microgravity experiments. A large number of experiments specify maximum accelerations in the range of from $10^{-3}$ to $10^{-5} \mathrm{~g}$. However, a number of important experiments may require less than $10^{-6} \mathrm{~g}$. An example of the latter is obtaining a homogeneous distribution ( $<1$ percent variation) of a dopant or alloying agent within the final solid produced in bulk (diameter of about $1 \mathrm{~cm}$ ) crystal growth experiments.

NOTES

1. Public Law 98-361, 1984.

2. Schrieffer, 1987.

3. Joseph Allen, Space Industries, Inc., Presentation to Committee, December 15, 1988 .

4. Naumann, June 8, 1988. 


\section{Facilities to Support Microgravity Research and Applications}

There is a wide range of existing, planned, and proposed facilities to conduct microgravity research and applications activities. One class includes ground-based facilities, such as drop towers, aircraft flying parabolic trajectories, and sounding rockets. Another class includes facilities that are intrinsically tied to the Space Shuttle, ranging from "Get-Away-Special" canisters to Spacelab long modules. There are also orbital facilities, which include recoverable capsules launched on expendable launch vehicles, free-flying spacecraft, and space stations. Some of these existing, planned, and proposed facilities are non-U.S. in origin, but potentially are available to U.S. investigators. In addition, some are governmentally developed and operated whereas others are planned to be privately developed and/or operated. Major facilities that could support significant microgravity research and applications activity are discussed briefly in the following section.

\section{GROUND-BASED FACILITIES}

Ground-based facilities provide a microgravity environment with limited capabilities for research for short periods of time. Drop tubes, drop towers, aircraft flying a parabolic trajectory (e.g., KC-135, Learjet Model 25) provide microgravity conditions for periods of from 2 to 25 seconds. The gravitational accelerations range from about $10^{-2} \mathrm{~g}$ for the $\mathrm{KC}-135$ to $10^{-6} \mathrm{~g}$ for drop tubes.

Sounding rockets, of which there are at least 15 different types, provide microgravity durations of up to 10 minutes, although with the limitation that the orientation of the acceleration vector changes during flight. The acceleration environment is on the order of $10^{-4} \mathrm{~g}$. 
Advantages: These facilities are relatively inexpensive compared to space-based facilities and are readily available. For the most part, the experimenter has access to the experiment until it is run, and retrieval is quick.

\section{SPACE SHUTTLE-BASED CAPABILITIES}

The following section describes a wide variety of facilities for microgravity experimentation that are closely tied to the Shuttle. The list treats current or planned major capabilities and is not exhaustive. For example, the West German SPAS (Shuttle Pallet Satellite) and the U.S. astronomical satellite, SPARTAN, both of which have been used to co-orbit with the Shuttle during flight, are not discussed. The potential effects of an Extended Duration Orbiter are discussed only briefly.

\section{Get-Away-Special Canister}

The concept of the Get-Away-Special canister, or GAS Can, was first introduced by NASA as a means of making available to a wide variety of users a relatively quick, inexpensive means of providing access to the space environment. The GAS Can has minimal interaction with the Shuttle: it is completely self-contained, and each experimenter is responsible for providing his or her own power, thermal control, data handling, and so forth, with only the on-off controls operated by an astronaut. The volume provided is $0.15 \mathrm{~m}^{3}$, with each GAS Can able to carry up to $90.7 \mathrm{~kg}$ of payload. The GAS Cans can ride in many locations throughout the cargo bay, and a number of structures, bridges, and pallets have been designed to accommodate them. The experimenter must deliver the payload seven months before launch and can have access to them up to 60-90 days before launch.

Advantages: Costs to users of GAS Cans are low, and flight opportunities are frequent.

Status: As of early 1989, 39 GAS Cans had been flown.

\section{Space Shuttle Middeck}

"Middeck" refers to the middeck lockers that were originally provided to contain crew equipment (food, clothing, and personal effects), some number of which can be made available for experiments. Each locker can hold $0.06 \mathrm{~m}^{3}$ of equipment weighing up to $27 \mathrm{~kg}$. About $115 \mathrm{~W}$ of power is available to each locker. The accelerations of gravity are in the $10^{-3} \mathrm{~g}$ range.

Advantages: While the experiment volume is limited, the middeck experiments have become popular because of the flexibility permitted by the 
ability of experimenters to have late preflight and early postflight access and the ease of crew interaction.

Status: Usually about ten lockers are available for research on each Shuttle mission.

\section{Material Sclence Laboratory and U.S. Microgravity Payload}

The Material Science Laboratory (MSL) is a structure that is mounted across the payload bay and provides power, data channels, thermal control, and an experiment mounting area sized to accommodate material science experiments. A payload mass of up to $925 \mathrm{~kg}$ can be accommodated on $4.8 \mathrm{~m}^{2}$ of mounting area. Remote operation of experiments by the Shuttle crew or ground investigators is intended. The U.S. Microgravity Payload (USMP) is approximately equivalent to two MSLs.

Advantages: The MSL and USMP can enhance flight opportunities.

Status: MSL was first flown on STS-24 in January 1986. One previously manifested MSL flight now has been replaced by USMP-01. Four USMP flights are manifested for the period from 1991 to 1993. Additional MSL flights have been requested but are not yet manifested.

\section{Spacelab Module}

Spacelab, developed by the European Space Agency (ESA), is a pressurized laboratory module that can accommodate two experimenters (mission or payload specialists) working simultaneously. Spacelab STS missions have been flown or are planned for the Federal Republic of Germany (D-1, D-2, and D-3), Japan (J-1), and DOD, as well as for U.S. life science and materials research. Both the German and Japanese missions have a large concentration of microgravity research experiments.

The Spacelab elements are carried in the Shuttle payload bay. Spacelab has both short- and long-module configurations as well as unpressurized pallets that can be used for astronomy and materials experiments. The short module has never been flown, and the following data refer to the long module. Spacelab provides $7.7 \mathrm{~kW}$ peak power for 15 minutes every 3 hours and $3.4 \mathrm{~kW}$ maximum continuous power. Each flight can accommodate up to $4,550 \mathrm{~kg}$ of payload, with a volume of $8.07 \mathrm{~m}^{3}$ available to the user. Experimenters have access to their experiments up to 28 weeks before launch.

Advantages: Spacelab currently provides the maximum available Shuttle-based laboratory accommodations in terms of volume, power, cooling, crew time, data management, and other resources.

Status: Three joint U.S.-European missions have been flown, and the modules are scheduled to fly several dedicated U.S. missions, as well as joint missions with the Europeans and Japanese. Eleven additional non-DOD Spacelab long-module missions are manifested through FY 1994. 


\section{Impact of Extended Duration Orbiter}

Current Shuttle flights are limited to a duration of ten days or less. For some time NASA has been studying the modifications required to provide an Extended Duration Orbiter (EDO) capability that could extend the maximum mission duration from ten to 16 or even up to 28 days (if concerns over potential pilot performance degradation on reentry are satisfactorily resolved). The required changes involve relatively minor modifications to the life-support systems and the provision of a new mission extension kit (cryogenic pallet). Shuttle oV-102 (Columbia) would be modified to be able to provide a 16-day mission capability, while the new ov-105 would be modified to provide a 16-day mission capability, which might then be extended to 28 days.

Advantages: Extending the flight duration of the Space Shuttle provides the ability to perform more experiments and to have longer experiment run times, for example for crystal growth.

Status: The 1990 budget proposal, which was under review at this writing, called for the EDO cryogenic kit to be privately financed and developed. Since the EDO has direct interface with vital Shuttle systems, there is some controversy about such an approach.

\section{PROPOSED U.S. FACILITIES}

The following subsections briefly describe a number of proposed U.S. facilities (listed in alphabetical order) that could be used to support microgravity research and applications activities. Specific information was supplied largely by the companies concerned. NASA has committed no microgravity payloads to specific commercial carriers.

\section{AMICA (See the discussion of EURECA for details.)}

Under a Teaming Agreement, General Electric's Astro Space Division and MBB-ERNO propose to start acquisition activities for a spacecraft identical to the European Retrievable Carrier (EURECA) for the U.S. and international markets, with the possibility of launching AMICA as early as 1992.

\section{External Tank-Based Facilities}

A number of entrepreneurs have proposed on-orbit uses for the $8.5 \mathrm{~m}$ diameter, $46 \mathrm{~m}$ long external tanks of the Space Shuttle. At present the tanks that supply fuel to the Shuttle's main engine are jettisoned when they are no longer needed. By the time they are jettisoned, they have reached 98 percent of full orbital velocity, and a relatively small effort is needed to carry them into orbit. Proposals have been put forth by 
Global Outposts, Inc., Space Phoenix Program (initiated by the University Corporation for Atmospheric Research), and others that would use the external tanks as platforms for microgravity research, among other activities.

Advantages: Costs can be expected to be low since an aerospace frame designed for other purposes will be used with no extra launch costs. No manifesting is required on the Shuttle.

Status: As part of President Reagan's commercialization initiative, as well as under congressional urging, NASA will make tanks available to the private sector and recently conducted a competition to select a small number of projects to pursue. Neither of the above two companies or others that the committee approached have a flight-readiness timetable. Space Phoenix had earlier negotiated a Memorandum of Understanding with NASA to use five tanks for suborbital research.

\section{Industrial Space Facility}

The Industrial Space Facility (ISF) is a privately developed, pressurized, orbiting laboratory proposed by the Space Industries Partnership (SIP)* that can be utilized as a free-flyer or as a human-tended facility when attached to the Shuttle. Its internal dimensions are $11 \mathrm{~m}$ long and $3 \mathrm{~m}$ in diameter (providing to the user space for seven Space Station double racks and six modular containers for user experiments). The ISF depends on the Shuttle for transportation to orbit, resupply, and servicing, and it is intended to use off-the-shelf technologies. SIP has proposed that the facility could be used for technology validation and to work out potential Space station solutions in such areas as docking system design, operation and utilization of Space Station racks, as well as for microgravity research or production.

The ISF would remain on orbit rather than return to Earth with the Shuttle and thus would provide long-duration exposure to the microgravity environment. It is designed to stay in space for three years without a revisit if necessary. Experiments conducted in the free-flying mode would require specifically designed automation and/or teleoperation capabilities. As a free-flyer, ISF is predicted to have an optimal microgravity level of $10^{-5}$ or $10^{-6} \mathrm{~g}$. When it is attached to the Shuttle at an angle extending out of the payload bay, some deterioration in the quality of the microgravity environment can be expected because the ISF will not be at the center of gravity of the configuration and also will be subject to transient $g$ accelerations due to the presence of humans.

*Space Industries Partnership was set up by Space Industries, Inc., Westinghouse Electric Corp., Lockheed Missile and Space Corp. (the solar array contractor), and Boeing Commercial Space Company (the docking system and rack contractor). 
However, human interaction with experiments is possible in this mode. Power available to payloads in the free-flying mode is expected to average $7 \mathrm{~kW}$, with $10 \mathrm{~kW}$ of peak power. SIP has indicated that the ISF can be available for flight within 36 to 42 months from a commitment. Experimenters are expected to have access to their experiments up to 28 weeks before launch. One-half of the Shuttle payload bay will be required for resupply visits to the ISF.

Advantages: When the ISF is in the attached mode, SIP believes that the ISF could extend the capabilities of the Shuttle up to 21 days without an EDO. In this mode, it provides a shirt-sleeve environment. As a free-flyer, ISF has the advantage of remaining on orbit and not requiring relaunch. ISF racks will be compatible with those of the Space Station.

Status: ISF engineering design has been completed and the Preliminary Design Review with NASA has taken place. In addition, the Payload Implementation Plan, detailing operations and interfaces with the Shuttle, has been signed. SIP has a 1985 Space System Development Agreement with NASA stipulating that SIP may reimburse NASA for two and one-half Shuttle flights at 12 percent of their cash flow starting two years after the launches. The ISF is currently manifested on three Shuttle flights for orbital insertion and revisits beginning in January 1993 . No payloads are known to be committed to the ISF. Financing arrangements currently await the decision of the U.S. government on an anchor tenant contract.

\section{Leasecraft}

Leasecraft is an unpressurized, unmanned, multimission modular spacecraft (MMS) proposed by Fairchild Space Company for payloads up to $6,800 \mathrm{~kg}$. The MMS was used for the Solar Maximum mission and for the Explorer series. The Extreme Ultraviolet Explorer is scheduled to be launched on a Delta ELV, after which it will scan the sky for approximately 13 months, then rendezvous with the Shuttle. At that time the instrument module, which is designed to be readily removable, will be exchanged for the X-Ray Timing Experiment, and so on. A pressurized module can be carried on Leasecraft if desired. Continuous power ranging from 1 to 7.3 $\mathrm{kW}$ can be made available to the payload, depending on the configuration.

Advantages: In conjunction with the Shuttle or co-orbiting with a Space Station, Leasecraft could provide long-duration exposure in a free-flyer based on an existing spacecraft design. Depending on the payload configuration, Leasecraft can be launched on the Delta ELV and avoid complete dependence on the Shuttle.

Status: In 1987, Fairchild and NASA revalidated a Joint Endeavor Agreement for the commercial development of Leasecraft under which NASA would provide a free launch and the first servicing flight along with flight test planning and test resources. 


\section{SPACEHAB}

Established in 1983, the SPACEHAB Corporation will provide a commercially developed pressurized module designed to augment the available Space Shuttle middeck volume. It is patterned after the pressure vessel designed for Spacelab and is intended to fit in the forward end of the payload bay with a short tunnel providing accessibility for researchers that is nearly identical to that of the middeck lockers. It is $3 \mathrm{~m}$ long, $4.1 \mathrm{~m}$ in diameter, and provides $31 \mathrm{~m}^{3}$ of pressurized volume. In an all-middeck locker configuration, the SPACEHAB would contain 69 usable lockers with a total volume of $4.6 \mathrm{~m}^{3}$. It can also be configured with standard Space Station racks replacing all or some of the lockers. The SPACEHAB Corporation anticipates that half of its payloads will be non-U.S. and that NASA will lease the other half.

Advantages: SPACEHAB is designed to reduce the amount of time required from identification of a payload to flight to 12 months and to provide a rapid turnaround so that results are available quickly to the investigator (with turnaround estimated by SPACEHAB Corporation to be four times as rapid as Spacelab). Astronauts will have ready access to experiments. Because its computer systems do not rely on those of the Shuttle, operations are quicker and cheaper than for Spacelab. In addition, SPACEHAB may be easier to manifest than payloads that require the entire payload bay.

Status: A 1988 Space Systems Development Agreement between The SPACEHAB Corporation and NASA provides a commitment for six shared Shuttle flights. NASA is to be reimbursed for standard Shuttle services within 30 days subsequent to each launch. The SPACEHAB Corporation has contracted with McDonnel1 Douglas to fabricate three units, two of which will be flight articles. It is manifested five times from late 1991 through 1994 , and four additional flights have been requested. SPACEHAB officials indicated that by the summer of 1989 they will have firm payload commitments and deposits from Europe and Japan. They have identified sources and are completing financing arrangements for all funding needed to complete development and production of the module.

\section{Space Station Freedom}

The Space Station Freedom will be a multiuser, on-orbit facility with three pressurized laboratory modules and numerous attachment points on its truss structure for unpressurized payloads. It is scheduled to be available for human-tended operations in late 1995, with permanent manning in late 1996, and an intended lifetime of 30 years. The Space Station is projected to provide a quasi-steady $(<0.001 \mathrm{~Hz})$ microgravity environment of no worse than $2 \times 10^{-6} \mathrm{~g}$ inside the pressurized laboratory modules, and $10^{-6} \mathrm{~g}$ within a substantial fraction of that volume. Total pressurized volume for user equipment is estimated to be approximately $60 \mathrm{~m}^{3}(120$ 
standard 19-inch racks). This level of microgravity environment is required to be available for six continuous periods per year of at least 30 days each. Transient disturbances are anticipated from the following: Shuttle Orbiter docking (about $10^{-3} \mathrm{~g}$, four to five times per year); Space Station reboost (about $10^{-4} \mathrm{~g}$ for two to three hours, four to five times per year); various moving mechanisms, especially the mobile servicing system (about $10^{-5} \mathrm{~g}$ at $0.17 \mathrm{~Hz}$, when in use); crew exercise (although the effects are not yet known and understood, they are expected to be manageable with suitable isolation); and other crew activity inside the modules (about $10^{-5}$ to $10^{-4} \mathrm{~g}$, if not isolated--the degree of isolation possible is still under study).

Advantages: The unique characteristics of the Space station for microgravity research and applications work are the availability of high user power levels (up to $45 \mathrm{~kW}$ total), large user experiment volumes, continuing human interaction with experiments, and long experiment run times.

Status: The Space Station has completed several requirements reviews and is in the preliminary design phase. Assembly of the Space Station on orbit is scheduled to begin in 1995, with a human-tended capability expected by late 1995 .

\section{NON-U.S. FACILITIES}

\section{EURECA}

EURECA (European Retrievable Carrier) will be an unmanned, freeflying, retrievable orbiting facility. Its development is sponsored by the European Space Agency, and it is being built by MBB-ERNO. It is not human-tended. (AMICA is an identical commercial facility proposed by the European firms and General Electric's Astro Space Division.) Initiated as a Spacelab follow-on activity, hardware development for EURECA began in 1985, and EURECA is manifested for a Shuttle launch in 1991 and retrieval six months after launch. The initial mission has a complement of 15 instruments and facilities dedicated to a variety of science and applications experiments. Additional missions are scheduled for 1993 and 1995. EUREÇA has a recoverable payload capability of $1,000 \mathrm{~kg}$, with at least $8.5 \mathrm{~m}^{3}$ of payload volume available to users. Average power available to payloads is $1.0 \mathrm{~kW}$ with a $1.5 \mathrm{~kW}$ peak. Microgravity levels are expected to be from $10^{-5}$ to $10^{-7} \mathrm{~g}$ in the low-frequency $(\leq 0.1 \mathrm{~Hz})$ range.

A turnaround time of 1.5 years is required between retrieval and the next launch, but studies are underway to reduce that time to one year. The EURECA platform's expected life is five missions over ten years.

Advantages: EURECA is designed to provide flexibility and ease in integrating experiments into the system and thus reducing costs to users. AMICA's cost is estimated at $\$ 110,000$ per kilogram. 
Status: While the initial EURECA flight in 1991 is fully manifested, largely with European payloads, EURECA representatives are actively seeking customers for subsequent flights.

\section{FSW}

FSW is a retrievable Chinese capsule orbited by the Long March 2 expendable launch vehicle. Missions of 6-15 days are possible with $100 \mathrm{~W}$ of power and maximum payloads of $300 \mathrm{~kg}$. However, deceleration of about $13 \mathrm{~g}$ is encountered on recovery of the capsule.

Advantages: FSW is competitively priced, and it is possible to integrate and fly some types of experiments within a relatively short period ( $<1$ year) once an agreement with the Chinese has been reached.

Status: The first non-Chinese experiment payload was carried on an FSW-1 capsule launched on August 5, 1987, and retrieved on August 10 under an agreement between the Great Wall Industry Corporation and Matra Espace. The payload included an ESA microgravity accelerometer experiment and a biological experiment dealing with algae growth. In 1988 the German company Intospace launched a microgravity test facility with 104 protein crystal samples on a Long March 2, and a number of follow-on flights are planned.

\section{Japanese Free-F1yer}

The Japanese Space Flyer Unit (SFU) will be a reusable, free-flying platform suitable for microgravity materials experiments. As currently planned, the SFU would be an $8,000 \mathrm{~kg}$ (gross weight) platform first launched by the Japanese H-II rocket in early 1993 and retrieved by the Space Shuttle about 6 months later. The experiments to be carried out on the first flight would include space observation, advanced technology experiments, flight tests of advanced industrial technologies, and verification of the exposed facility of the Japanese Experiment Module of the Space Station. It is likely that the SFU will initially be filled to capacity with Japanese materials and life sciences experiments.

Advantages: As a free-flyer, the SFU should provide a high-quality microgravity environment. Reusability should lower costs for flying experiments.

Status: The SFU is in the development phase. SFU retrieval is manifested for the STS 70 mission in mid-1993.

\section{Photon}

Photon is a Soviet recoverable capsule launched on an SL-4 expendable launch vehicle to a 220 to $400 \mathrm{~km}$ orbit, typically at an inclination of 
62.8 degrees. Mission duration is 14-30 days. The maximum payload mass is $500 \mathrm{~kg}$, and the available volume is $4.7 \mathrm{~m}^{3}$. Four hundred watts of power can be supplied to the payload, rising to $700 \mathrm{~W}$ for 1.5 hours a day. The acceleration levels inside the craft are $10^{-5} \mathrm{~g}$ and lower during the flight, but deceleration levels during reentry can reach eight to ten g's. The facilities that have flown aboard Photon include the Zona 1 and Splav-2 electric furnaces and the Kashtan electrophoresis unit.

Advantages: As of early 1989, flight opportunities on the Photon capsule were being offered commercially by Glavcosmos at $\$ 15,000$ per kilogram. This price is negotiable if either the data received from the experiment or the new hardware developed for it are shared with the Soviets.

Status: The Soviets first orbited the Photon capsule in 1983, and it has flown three times since. The French have a firm commercial contract for use of the Photon, and negotiations have begun with other potential customers.

\section{Space Station Mir}

The Soviets claim a microgravity environment of $10^{-3}$ to $10^{-5} \mathrm{~g}$ for the Mir space station. Mir's current total power is approximately $10 \mathrm{~kW}$, down from $11.6 \mathrm{~kW}$ due to solar panel degradation. The solar panels of a new module scheduled to be added to Mir in late 1989 are expected to double the available power. Another module also is scheduled for late 1989. Mir operational requirements use approximately $1.0 \mathrm{~kW}$. There currently is little space available within Mir for new experiments, and major new research facilities will need to go either on the exterior or in additional modules. A current bottleneck in the Mir system appears to be: the return of items from Mir to Earth, in that only 120 to $150 \mathrm{~kg}$ can be returned via Soyuz two or three times a year, at least until the Soviet Shuttle enters service. Reentry g levels are on the order of six to seven g's.

Advantages: Mir allows long-duration microgravity exposure (on the order of years), with the capability for extensive manned interaction.

Status: Mir was put into orbit in 1986, and it has been continuously occupied since 1987.

\section{SUMMARY OF INFORMATION ON SPACE-BASED FACILITIES}

The list of facilities discussed in this chapter is not meant to be an exhaustive one. For example, OSSA is studying the development of a recoverable capsule, Lifesat, for life sciences research. Similarly, a non-U.S. company, Dornier, is developing a recoverable capsule called Space Courier, which it intends to offer commercially. Additional facilities are likely to be proposed over the next few years. 
Table 1 summarizes available information on the characteristics and capabilities of some of the previously described space-based facilities.

\section{IMPACT OF SPACE TRANSPORTATION SCHEDULE ON MICROGRAVITY RESEARCH}

Almost all of the U.S. capabilities and some of the non-U.S. ones, such as EURECA, depend on the Space Shuttle for launch into orbit and/or servicing. Thus, the frequency of the microgravity research missions carried on the facilities depends both on how quickly the facility can be made ready for another flight and on shuttle flight rates.

The current Shuttle manifest (January 1989 through September 1994) includes microgravity payloads (excluding middeck experiments) given in terms of Shuttle-equivalent flights, that is, equivalent to the balance of the payload bay, as shown in Table 2. The NASA payloads shown reflect requirements for microgravity research identified by the NASA Office of Space Science and Applications and the Office of Commercial Programs, although the manifest does not satisfy all proposed requirements. NASA payloads account for 2.87 and 2.70 Shuttle-equivalent flights in 1993 and 1994, respectively, while non-U.S. microgravity payloads account for 0.70 in each of those years. SPACEHAB and ISF manifested space accounts for two and one and one-half Shuttle-equivalent flights in FY 1993 and FY 1994, respectively. However, the microgravity experiments they would carry are as yet undefined.

The number of launches anticipated by NASA in the most recent manifest (January 1989) builds up to 13 to 14 per year in the FY 1993 to 1994 period after the replacement fourth orbiter, oV-105, becomes operational. The ability to reach and sustain such flight rates can be described as optimistic or "success oriented," especially since NASA does not set aside a flight contingency reserve. While a recent National Research Council study estimates a sustainable rate of 11 to 13 flights per year for a four-orbiter fleet, it cautions that "these estimates do not account for contingencies" that, aside from the obvious ones of loss or major damage to an orbiter, include "diverted landings; weather delays; late manifest and/or flight plan changes; unforeseen payload delays; facility or support system downtime; lack of timely availability of spares/logistic support."

Should Space Shuttle launch rates of 13 to 14 per year not materialize, some microgravity research goals may not be achieved in the desired time frames since there is no readily available alternative for Shuttle-transported microgravity payloads. Some Shuttle flights that are presently booked, however, may be freed up, and that might help to compensate for lower flight rates. If there is a serious shortfall in Shuttle launch rates, many research goals will not be met. If NASA management and the national leadership believe it important to promote research in the microgravity sciences, they must make an effort to ensure that flight opportunities for microgravity research do not suffer disproportionately during remanifesting. In addition, NASA and the 


\begin{tabular}{|c|c|c|c|c|}
\hline Facilities & Developer & $\begin{array}{l}\mu-\boldsymbol{g} \\
\text { Duration }\end{array}$ & $\begin{array}{l}\text { Eatimated } \\
\text { Gravity (8) } \\
\text { Level }\end{array}$ & $\begin{array}{l}\text { Crew } \\
\text { Interaction }\end{array}$ \\
\hline$\frac{\text { Shuttles: Existing }}{\text { Getaway Specials }}$ & NASA & 4-7 days* & $10^{-3}$ & $\begin{array}{l}\text { Payload bay; } \\
\text { Crew has on/of } \\
\text { switches only }\end{array}$ \\
\hline MSL & NASA & 4-7 days* & $10^{-3}$ & $\begin{array}{l}\text { Payload bay; } \\
\text { Remote } \\
\text { operation }\end{array}$ \\
\hline Middeck & NASA & 4-7 days* & $10^{-3}$ & Crew-tended \\
\hline $\begin{array}{l}\text { Spacelab } \\
\text { (Long Module) }\end{array}$ & ESA/NASA & 4-7 days* & $10^{-3}$ & Crew-tended \\
\hline$\frac{\text { Shuttle: Proposed }}{\text { Spacehab }}$ & $\begin{array}{l}\text { Spacehab Co. } \\
\text { McDonnell- } \\
\text { Douglas } \\
\text { Aeritalia }\end{array}$ & 4-7 days* & $10^{-3}$ & Crew-tended \\
\hline$\frac{\text { ISF (Facility }}{\text { Module) }}$ & $\begin{array}{l}\text { Space } \\
\text { Industries } \\
\text { Partnership }\end{array}$ & years & $10^{-5}-10^{-6}$ & $\begin{array}{l}\text { Crew-tended in } \\
\text { attached mode; } \\
\text { Free-flyer } \\
\text { capability }\end{array}$ \\
\hline Eureca/Amica & ESA & 6 months & $10^{-5}-10^{-7}$ & $\begin{array}{l}\text { Free-flyer; } \\
\text { Shuttle deploy } \\
\text { \& return }\end{array}$ \\
\hline $\begin{array}{l}\text { Japanese Free- } \\
\text { Flyer }\end{array}$ & Japan & 6 months & $\mathbf{N} / \mathbf{A}$ & $\begin{array}{l}\text { Free-flyer; } \\
\text { Shuttle return }\end{array}$ \\
\hline Leasecraft & Fairchild & years & $\mathbf{N} / \mathbf{A}$ & $\begin{array}{l}\text { Free-flyer; } \\
\text { Shuttle return }\end{array}$ \\
\hline Photon & USSR & 14-30 days & $\leq 10^{-5}$ & $\begin{array}{l}\text { Untended } \\
\text { Free-flyer }\end{array}$ \\
\hline FSW & China & 6-15 days & $\mathbf{N} / \mathbf{A}$ & $\begin{array}{l}\text { Untended } \\
\text { Free-flyer }\end{array}$ \\
\hline Space Station Mir & USSR & years & $10^{-3}-10^{-5}$ & Crew-tended \\
\hline $\begin{array}{l}\text { Space Station } \\
\text { Freedom }\end{array}$ & $\begin{array}{l}\text { NASA, ESA, } \\
\text { Japan, } \\
\text { Canada }\end{array}$ & years & $10^{-5}-10^{-6}$ & Crew-tended \\
\hline
\end{tabular}

*Can be extended with EDO capabilities.

Sources: NASA, Teledyne Brown Engineering, ESA, Private Companies 


\begin{tabular}{|c|c|c|c|c|}
\hline $\begin{array}{l}\text { Flight } \\
\text { Frequency }\end{array}$ & $\begin{array}{l}\text { Year } \\
\text { Available } \\
\text { (Projected) }\end{array}$ & $\begin{array}{l}\text { Power to } \\
\text { Payload }\end{array}$ & $\begin{array}{l}\text { Payload } \\
\text { Volume }\end{array}$ & $\begin{array}{l}\text { Maximum } \\
\text { Payload Mass }\end{array}$ \\
\hline $\begin{array}{l}\text { Up to } \\
\text { 50/year } \\
\text { (Shuttle) }\end{array}$ & Operational & $\begin{array}{l}\text { Supplied by } \\
\text { Experimenter }\end{array}$ & $0.15 \mathrm{~m}^{3}$ & $90 \mathbf{~ k g}$ \\
\hline $\begin{array}{l}5 / \text { year } \\
\text { (Shuttle) }\end{array}$ & Operational & $\begin{array}{l}1.41 \mathrm{~kW} \text { (Ave) } \\
2.59 \mathrm{~kW} \text { (Peak) }\end{array}$ & $\begin{array}{l}4.85 \mathrm{~m}^{2} \\
\text { mounting area }\end{array}$ & $925 \mathrm{~kg}$ \\
\hline $\begin{array}{l}\text { Up to } \\
14 / \text { year } \\
\text { (Shuttle) }\end{array}$ & Operational & $115 \mathrm{~W} /$ locker & $\begin{array}{l}.06 \mathrm{~m}^{3} / \text { locker } \\
\text { ( 10 lockers/ } \\
\text { mission) }\end{array}$ & $\begin{array}{l}27 \mathrm{~kg} / \text { locker } \\
\text { ( 10 lockers/ } \\
\text { mission) }\end{array}$ \\
\hline $\begin{array}{l}\text { 1-4/year } \\
\text { (Shuttle) }\end{array}$ & Operational & $\begin{array}{l}3.4 \mathrm{~kW} \text { (Ave) } \\
7.7 \mathrm{~kW} \text { (Peak) }\end{array}$ & $8.07 \mathrm{~m}^{3}$ & $4,550 \mathrm{~kg}$ \\
\hline $\begin{array}{l}1-3 / \text { year } \\
\text { (Shuttle) }\end{array}$ & 1991 & $\begin{array}{l}3.2 \mathrm{~kW} \text { (Ave) } \\
5.7 \mathrm{~kW} \text { (Peak) }\end{array}$ & $\begin{array}{l}4.6 \mathrm{~m}^{3} \\
\text { (69 lockers) }\end{array}$ & $1,360 \mathrm{~kg}$ \\
\hline $\begin{array}{l}\sim 3 / \text { year } \\
\text { revisits } \\
\text { (Shuttle) }\end{array}$ & 1993 & $\begin{array}{l}7 \mathrm{~kW} \text { (Ave) } \\
10 \mathrm{~kW} \text { (Peak) } \\
\text { (Free Flyer) }\end{array}$ & $9.50 \mathrm{~m}^{3}$ & $\begin{array}{l}2,950-6,220 \mathrm{~kg} \\
\text { by orbiter }\end{array}$ \\
\hline $\begin{array}{l}\text { 1/year } \\
\text { (Shuttle) }\end{array}$ & 1991 & $\begin{array}{l}1 \mathrm{~kW} \text { (Ave) } \\
1.5 \mathrm{~kW} \text { (Peak) }\end{array}$ & $8.5 \mathrm{~m}^{3}$ & $1,000 \mathrm{~kg}$ \\
\hline N/A & 1993 & N/A & $\mathbf{N} / \mathbf{A}$ & $\mathbf{N} / \mathbf{A}$ \\
\hline N/A & In abeyance & 1-7 kW (Ave) & $\mathbf{N} / \mathbf{A}$ & $6,800 \mathrm{~kg}$ \\
\hline N/A & Operational & $\begin{array}{l}100 \mathrm{~W} \text { (Ave) } \\
700 \mathrm{~W} \text { (Peak) }\end{array}$ & $4.7 \mathrm{~m}^{3}$ & $500 \mathrm{~kg}$ \\
\hline N/A & Operational & $100 \mathrm{~W}$ & N/A & $300 \mathrm{~kg}$ \\
\hline $\begin{array}{l}\text { Continuous } \\
\text { Operation }\end{array}$ & Operational & $\begin{array}{l}\text { 10 kw total } \\
\text { power; should } \\
\text { increase }\end{array}$ & $\begin{array}{l}90 \mathrm{~m}^{3} \text { total } \\
\text { volume }\end{array}$ & $\mathbf{N} / \mathbf{A}$ \\
\hline $\begin{array}{l}\text { Continuous } \\
\text { Operation }\end{array}$ & 1996 & $\begin{array}{l}45 \mathrm{kw} \text { total } \\
\text { user power (Ave) }\end{array}$ & $\begin{array}{l}60 \mathrm{~m}^{3} \text { total } \\
\text { usable Lab } \\
\text { volume } \\
\text { (120 std racks) }\end{array}$ & $>68,200 \mathrm{~kg}$ \\
\hline
\end{tabular}


TABLE 2 Manifesting of Microgravity Payloads

\begin{tabular}{|c|c|c|c|c|c|}
\hline & $\begin{array}{l}\text { Summary in } \\
\text { (Shuttle }\end{array}$ & $\begin{array}{l}\text { Shuttle-E } \\
\text { Cargo Bay }\end{array}$ & $\begin{array}{l}\text { quivalent } \\
\text { Payloads }\end{array}$ & $\begin{array}{l}\text { Flights } \\
\text { Only) }\end{array}$ & \\
\hline Fiscal Year & 1990 & 1991 & 1992 & 1993 & 1994 \\
\hline NASA & 1.00 & 1.65 & 2.60 & 2.87 & 2.70 \\
\hline $\begin{array}{l}\text { Non-U.S. } \\
\text { Spacelab-J } \\
\text { (Japanese) }\end{array}$ & & 0.45 & & & \\
\hline $\begin{array}{l}\text { Spacelab-D2 and D3 } \\
\text { (German) }\end{array}$ & & & $0.70^{\underline{a}}$ & & $0.70^{\mathrm{a}}$ \\
\hline $\begin{array}{c}\text { EURECA } \\
\text { (ESA) }\end{array}$ & & 0.25 & 0.25 & 0.50 & \\
\hline $\begin{array}{l}\text { SFU } \\
\text { (J apanese) }\end{array}$ & & & & 0.20 & \\
\hline $\begin{array}{l}\text { Commercial } \\
\text { SPACEHAB } \\
\text { ISF }\end{array}$ & & & 0.50 & $\begin{array}{l}0.25 \\
1.75\end{array}$ & $\begin{array}{l}0.50 \\
1.00\end{array}$ \\
\hline Total & 1.00 & 2.35 & 4.05 & 5.57 & 4.90 \\
\hline
\end{tabular}

$\underline{a}_{\text {Being Negotiated }}$

(Source: NASA) 
national leadership should continue to develop mixed fleet options for access to space so that microgravity activities in orbit are not completely Shuttle-dependent. To effectively use expendable launchers and free- flyers, however, greater emphasis will be needed on automation, robotics, and telescience, as discussed in the following chapter.

\section{NOTES}

1. National Research Council, Committee on NASA Scientific and Technological Program Reviews. 1986. Post-Challenger Assessment of Space Shuttle Flight Rates and Utilization pp. 7-8. 


\title{
$\mathbf{V}$ \\ Direct Manned Interaction, Automation, Robotics, and Telescience
}

\author{
MANNED INTERACTION
}

The presence of humans allows for interaction with experiments and repair of malfunctioning equipment. At the same time, human presence degrades the quality of the microgravity environment; for that reason, it often is desirable to observe experiments and perform many tasks without direct human involvement. Where experiments on a CDSF or other free-flyer are concerned, it becomes not only desirable but mandatory to rely on automation, robotics, and telescience. The following section explores the unique value of having humans in space at this stage of our understanding of the behavior of materials and processes in space and assesses the state of the art in $A \& R$ and telescience.

In a normal terrestrial setting, the fluid, material, and life sciences are researched by experimenters who are trained observers, astute to the appearance of unusual occurrences or unpredicted behavior. The situation in microgravity research, ideally, should be no different: the trained scientist should remain in close contact with his or her experiment. However, the rigor and cost of spaceflight is severely limiting to a human presence, and the practical conduct of science in space must compensate for this limitation.

The short history of microgravity research has shown that most experiments benefit greatly from human presence, but, as mentioned earlier, the chief drawback is the accompanying and usually unavoidable degradation of the microgravity environment. The solution to the problem of how to involve researchers in microgravity research without accepting the interference of their associated perturbations or accelerations is to establish effective, near real-time telecommunication and teleoperation links between the terrestrial and orbital laboratories. Teleoperation combined with limited direct manned interaction may indeed be the best approach for many applications. This approach was used as early as the Skylab missions, in which astronauts could describe microgravity phenomena as they occurred to scientists on the ground, and on recent Spacelab 
flights, in which mission specialists carried out critical on-orbit repairs on malfunctioning automated microgravity equipment, thereby rescuing several experiments from total failure. In the future, entire space experiments could be teleobserved and/or teleoperated from the ground.

NASA's plans for microgravity R\&D in the 1990s include use of the U.S. Microgravity Laboratory (USML), the U.S. Microgravity Payload (USMP), as well as secondary payloads such as middeck lockers, "Get-Away-Specials," attached payloads, and so on. These payloads and locations vary considerably in their ability to support up-linking and down-linking to Earth-based scientists, but each experimental mode is an opportunity for NASA and the microgravity community to further develop telescience capabilities. When the Space Station era starts in the late 1990s, there will be an opportunity for truly long-term, nearly continuous microgravity exposures, combined with the desired manned presence, and augmented with more advanced telescience.

\section{AUTOMATION, ROBOTICS, AND TELESCIENCE}

Whether performed by a human, a machine, or some combination of the two, most microgravity experiments still require close monitoring and control, over a period ranging from seconds to weeks, of many variables, all of which would obviously differ in number and kind for different experiments. Some form of automation has been used from the outset in such experiments, such as in generating carefully planned inputs to the experiments and measuring and recording responses. Ideally the principal investigator would like to be in space to make visual observations, especially of phenomena that are not easily captured by instruments and automation, and to reconfigure the experiment during the mission or to make repairs in case of failure. Delegating these functions to space Shuttle mission specialists has generally worked well, and such "human-tending" has indeed saved several experiments. The salient question is to what extent in the 1992-1997 time frame the mission specialist can be aided or replaced by automation, robotics, or teleoperation, to make feasible the use of periodically human-tended or unmanned free-flyers as experimental facilities.

Automation and robotics (A\&R) is far from a stagnant field, and many recent advances have been demonstrated in the laboratory and in industrial applications. An example is computer visual and tactile recognition and performance of simple assembly and disassembly tasks at speeds and accuracies an order of magnitude greater than those attainable through human performance. Another example is computer-based intelligent decision-making (in which there is a well-established knowledge base). NASA microgravity research automation requirements are different from those of production-line automation, in which conditions are predictable, easily controllable, and repetitive. Microgravity research sensing and control needs are typically one-of-a-kind, and full automation would have 
to be tailored to the individual experiment. Even though computer hardware configurations might be shared among many researchers, the software, sensing, and control automation hardware may have to be unique and tailored to each individual experiment.

There are so many unpredictable aspects of most microgravity experiments today that providing fully autonomous operation (i.e., no human observation or intervention during the flight mission) is often too much to ask of automation and robotics. During at least the early stages of experimental work, the appropriate responses for all of the contingencies cannot be anticipated and programmed. This does not mean that the only alternative is experiment tending by a person who is physically present, with all of the associated costs and overhead constraints. An alternative that holds much promise for microgravity research is telescience or teleoperation, wherein the principal investigator observes the experiment from the ground (or a mission specialist does so from another orbiting vehicle). Using video and other modes for sensing, communications, and display, the investigator reprograms the on-board computer and/or moves a joystick or multiaxis hand device to control various actuators on the experiment. Such operator control devices can be simple built-in knobs or switches or multiaxis handles that can be positioned to control in-space manipulators to perform minor modifications to the experiment or to repair the apparatus when it fails.

NASA has had an active program in automation and robotics for many years. Public Law 98-371, which took effect in 1984, gave it a further boost, committing 10 percent of the Space Station budget to A\&R in one form or another. Perhaps even more significant is the development over three decades of teleoperated submarines for use in the deep ocean by the oil industry and the Navy and development of similar devices for nuclear "hot laboratories." There is much accumulated experience in performing remote viewing and manipulation (telescience) tasks in the laboratory and in the two application areas mentioned above. Human operators, given modest training and current state-of-the-art video devices using remotely controlled pan, tilt, and zoom functions, and current state-of-the-art five or six degree-of-freedom telemanipulators, can easily do requisite observation and manipulation to perform simple assemblies, adjustments, and repairs. There can be difficulties with depth perception, but stereopsis and multicamera techniques are being developed. Continual improvements in fineness of dexterity are being made as well, including touch and proximity sensors and displays, and operator adjustment of the impedance (mechanical stiffness and viscosity) to make the manipulation either compliant and gentle or stiff and precise, as appropriate to the task.

Special problems have been posed by the existence of communication time delays in teleoperation control loops, whether caused by the finite speed of light or by the multiple signal processing delays in computers of the Tracking and Data Relay Satellite System (TDRSS) or ground stations. In either case, the result is two to six second round-trip delays that 
force the human operator to repetitively make small movements and wait for confirming feedback, thereby making tasks take two to ten times longer than they would with no delay, or five to 25 times longer than they would if done by hands. One way around this problem is to use "supervisory control" or "telerobotics" systems, whereby the human operator sends packets of instructions to a remote computer/robot (telerobot) to perform a task segment. The telerobot uses its own tactile or optical sensors as references ("move in direction $x$ until touch, then back off, open jaws and move up and grasp ..."), that is, the control loop is closed locally, with no time delay, and thus the whole operation can be accelerated and made more reliable.

Such telerobots, which can also fall back on the more primitive direct master-slave teleoperation, are being developed experimentally by the Jet Propulsion Laboratory and the Marshall Space Flight Center. The two-arm, one-leg Flight Telerobotic Servicer, which is being designed for use on the Space Station Freedom, is being developed at the Goddard Space Flight Center. NASA is also developing miniature displays to be worn on the operator's head that would send control signals to point the video camera in the same direction as the operator's eyes, thus giving him or her a sense of being there ("telepresence").

Most likely to be available for use in space in the near term, say prior to 1995, are teleoperated video cameras that pan, tilt, and zoom, and single manipulator arms that are controlled in direct master-slave fashion. Such techniques will allow relatively slow control movements by the human operator, which are nevertheless more satisfactory than having no ability to remotely human-tend the experiment, and in most cases probably are tolerable. In fact, these time delays can be ameliorated through use of computer-based systems that take the operator's control inputs, model the geometry of the task and kinematics of the manipulator, and overlay on the delayed video an undelayed stick figure model of where the hand or end point of the manipulator is predicted to be, thus speeding up the operator's ability to make confident moves.

Another form of computer automation that has seen rapid progress recently is one that provides the ability to process a variety of signals, make comparisons to updated process models as well as an a priori data base, and provide early warning of abnormalities or failures. Such computations could be done in the space vehicle or on the ground. Many other expert systems and computer-based decision aids are becoming available, with progress driven in part by the DOD strategic computing program.

\section{CONCLUSIONS}

Technology for teleoperation and computer-assisted decision-making has not yet been used to a great extent in the designs of microgravity experiments. The microgravity researchers on the committee stressed the current importance of human oversight of experiments, whether direct or by 
means of telescience techniques. The committee believes that human-tending of experiments through telescience is likely to prove a productive and cost-effective approach over time.

While many existing experiments, for example those currently manifested on the Spacelab, would be difficult to convert to make use of telescience at this stage, the committee believes that experiments planned for the 1992-1997 period should be designed to make effective use of telescience, where appropriate. It should be noted that the degree to which telescience techniques and apparatus will have to be tailored to individual experiments and not used in a multipurpose fashion is still somewhat of an unknown.

The incorporation of telescience into the design of microgravity experiments likely will occur in an evolutionary manner. Presently, roughly 24 to 48 months are needed to adapt well-understood experiments so that they can be conducted in an automated fashion. However, because there is a poor understanding of many of the scientific processes involved in microgravity research, increased knowledge will be needed before teleoperated microgravity experiments become the norm and the majority of experiments can be carried out on a free-flyer. It should also be noted that the microgravity research culture will have to adjust to a new way of doing things if telescience is to become widely adopted by that community. In summary, current A\&R/telescience technology can provide any information to a ground-based human observer that a video camera can see; it also can give the observer the ability to activate switches and valves on the space vehicle, reprogram its computers, and perform simple manipulations on the experiment using multiaxis remote manipulators. Eventually, computer-graphic displays with pull-down menus and active cursors may enable the remote human operator to elicit advice from the computer, get unsolicited warnings or other information in an understandable form, and make a variety of reconfigurations in an experiment. Given time and adequate resources, most microgravity experiments that can be completely rehearsed can be automated. Clearly, full automation and telescience techniques are essential if experiments are to be performed in a vehicle such as a CDSF where humans will not be present when many experiments are performed. 


\section{VI}

\section{Assessment of the Need for a CDSF}

In addressing the issues posed in its charge (Appendix A), the committee found itself faced with a multitude of related questions. To evaluate properly the need for a CDSF or for any additional flight capabilities beyond existing and planned facilities, it was necessary to examine the current national program in microgravity sciences and to investigate the scientific and commercial potentials of microgravity research. In recent years there has been an abundance of literature to the effect that flight opportunities were insufficient and that $U . S$. microgravity scientists were at a disadvantage internationally. 1 Certainly this was true during the flight hiatus after the Challenger accident. In response to these critiques, NASA clearly has taken positive actions to increase both microgravity budgets and flight opportunities.

The committee was confronted with questions of readiness, that is, whether the state of the art in the emerging area of microgravity sciences was such that a human-tended free-flyer represented the most effective approach to future research; whether the state of automation, robotics, and telescience would enable scientists to make rapid progress; and whether there existed adequate reliable, flight-tested, general purpose or easily adaptable equipment.

The committee also faced questions concerning the optimum timing for additional government-sponsored facilities; whether projected payloads were likely to materialize and, if so, whether they would fill manifested flights; and questions regarding the resources that would be needed to effectively utilize a human-tended free-flyer should it come into being. These questions are discussed in the sections that follow. 


\section{REQUIREMENTS VERSUS CAPABILITIES}

The study committee examined the planned and anticipated microgravity research and manufacturing requirements of the federal government and commercial users prior to the initiation of space station operations. It found that almost all of the proposed activities are supported by NASA under microgravity research programs intended to develop knowledge in this new field and to foster potential commercial applications developed by universities and industries affiliated with the NASA Centers for the Commercial Development of Space, and/or using Joint Endeavor Agreements or Space Systems Development Agreements with industry.

In addition, NASA is expected to provide the major U.S. in-space microgravity research capabilities by means of its Shuttle-based facilities in the 1992-1997 time frame. Both the NASA microgravity program and manifesting for the Shuttle are dynamic and evolving. Therefore, the analyses in this report are based on information available in early 1989.

There is general agreement that until recently NASA had not been effective in providing adequate access for researchers to the microgravity environment. Over the past 18 months, however, NASA has responded to the recommendations of its Microgravity Materials Science Assessment Task Force and others ${ }^{2}$ for enhancing U.S. activities in microgravity research by significant budgetary increases and by planning more flight opportunities aboard Shuttle-based facilities.

Indeed, roughly 18 Shuttle equivalent missions for materials and life sciences microgravity research are tentatively manifested by NASA for the period prior to FY 1995. Experiment space is essentially booked for flights leading up to USML-1 (manifested on flight STS-54 in early 1992), although the payloads for USML-1 are not yet firm. Specific microgravity experiments are not yet designated for flights after STS-54. Thus it appears there may be considerable flexibility to accommodate new experiments that might be developed over the next few years. It also should be noted that there will be opportunities for additional secondary payloads to be manifested on earlier flights, due to the Shuttle weight margin reserves that are released at a certain point before each flight.

In examining the available and proposed facilities (see Chapter 4), the committee probed whether limitations of existing capabilities (the most important being $g$ level, duration, and power) seriously affect the quality of pre-Space Station experiments; it found few serious constraints in these areas. Indeed, the committee believes that over the next few years, capability limitations notwithstanding, the nation should have a challenging program under current plans of what appear to be meritorious experiments that promise to yield useful new scientific data.

\section{Acceleration, or $g$ Level}

Although in a number of cases the need for a high-quality microgravity environment remains to be demonstrated, the quality or "cleanliness" of 
the microgravity environment is of concern to many scientists. On a free-flyer, much depends on the flight mode. If a free-flying platform is only periodically tended by humans, its environment will probably display a lower gravitational level and contain fewer disturbances than either the Shuttle or the Space Station with their attendant human activity and periodic thruster firings. Also, the low-frequency, or quasi-static, components of the acceleration vector, which play the major role in affecting many types of microgravity experiments, are themselves sensitive to the platform's orbital parameters, flight path, and vehicular orientation. Since the specific CDSF design has not been determined, there is an insufficient basis to make detailed quantitative comparisons of its expected microgravity environment with that of other orbiting vehicles. Some preliminary data suggest, however, that the probable center of gravity of a Shuttle-CDSF configuration (used in human-tended operations) is likely to lead to a less ideal microgravity environment for experiments than would be realized on the Shuttle or CDSF alone.

In trying to determine whether existing facilities will meet desirable experimental requirements, it appears there may be some compound and alloy-type electronic and optoelectronic crystal growth experiments that require very low microgravity levels that may only be approached by a free-flyer, as discussed earlier in the requirements section.

\section{Duration}

As the microgravity program matures and longer on-orbit processing times become necessary for extremely slow processes like vapor-phase and solution crystal growth, a long-duration free-flyer with enhanced energy and power doubtlessly will be desirable. Over the next decade or so, however, NASA's microgravity program is structured along an evolutionary path that includes enhanced flight opportunities on Spacelab and other Shuttle-based carriers followed by use of the Space Station; equivalent detailed plans for other federal agencies do not yet exist.

Shuttle flights will be configured around mission rules that will provide a beneficial microgravity environment. Secondary payload opportunities, for example on the Shuttle middeck, may have less favorable mission rules, but judicious selection of the experiments should lead to scientific progress. Use of an Extended Duration Orbiter to lengthen planned missions should provide significant data on long-duration processes prior to the space Station. At the same time, the advent of a CDSF in the next five years also could possibly accelerate progress along the evolutionary path by providing longer orbital processing times for those experiments that are automated or designed to use teleoperation.

\section{Power}

The projected number of classes of experimenters requiring high peak power, that is, greater than $2.0 \mathrm{~kW}$, is small with the exception of those 
concerned with experiment facilities being designed for the Space Station. However, there may be conflicts among high-power users in some operations on Shuttle-based facilities. The highest power consumers are the furnace and levitators planned for flight on Spacelab in support of containerless processing experiments. Problems arising from users requiring high power in conflict with one another can be addressed to a significant degree by efficient manifesting and timelining using the EDO.

The total peak power available to Shuttle-based experiments is approximately $7.7 \mathrm{~kW}$ for 15 minutes every 3 hours; average power is $3.4 \mathrm{~kW}$ (on Spacelab). While the peak power duration can be extended by use of an EDO, the amount of power available at a given moment remains limited by the current-carrying capacity of the Shuttle's wiring.

\section{ADEQUACY OF ANTICIPATED FLIGHT OPPORTUNITIES}

The committee sought and based its deliberations on input concerning the maximum microgravity research activity that might reasonably be undertaken in the interim period preceding the Space Station. As was noted earlier, there is necessarily some softness in the estimates for commercial demand and for scientific investigation given that the time frame exceeds that for which completely reliable projections are possible. However, it is the committee's view that these estimates are higher than will be actually achieved. Therefore, the analysis of flight capabilities needed to meet these estimated requirements is conservative.

In any event, additional insurance against shortfalls in capabilities to address unanticipated increases in demand is likely to be available if one or more of the proposed commercial facilities discussed in Chapter 4 comes to fruition. During meetings with the providers of the proposed facilities, it became evident that they will rely on NASA to supply a large portion of their payloads.

As earlier indicated, NASA has manifested an increased number of microgravity-related Shuttle missions through the mid-1990s. The committee believes that the overall annual Shuttle flight rates assumed by NASA are not likely to be achieved. Thus, there is likely to be some loss or slippage of microgravity research opportunities during this period unless some presently manifested payloads, for example from the Department of Defense, do not materialize.

The committee believes that, barring a drastic reduction in flight rates from the planned 13 or 14 missions per year shown in the current manifest for 1993-1994, the microgravity research community should have adequate flight opportunities to carry on a meaningful research activity. In the event of Shuttle flight rate reductions, NASA should make an effort to ensure that microgravity flight opportunities do not suffer

disproportionately during the required remanifesting. Over the long term, it would be highly beneficial for NASA to build a contingency reserve (e.g., on the order of 20 percent) into its manifesting process to compensate for potential flight rate shortfalls. 
In some respects, the dilemma of the nation's microgravity scientists is comparable to that of its other space scientists who faced a long hiatus in flight opportunities that resulted in a backlog of missions needing to be flown. However, flight opportunities are being made available. Moreover, the nature of current microgravity research in materials, fluids, and life sciences is such that the results of certain basic science missions are needed before a follow-on research and development strategy can be clearly mapped out; in addition, human interaction with experiments is highly desirable if not necessary.

\section{A\&R AND TELESCIENCE CONSIDERATIONS}

The gaps between what is needed for a human-tended free-flyer and what currently exists are not so much in the availability of the technology as in how it is applied (with the exception of repair of complex machinery). Terrestrial automation and robotics is generally sufficient for remote monitoring, reconfiguration, and simple modification and repair of microgravity experiments provided that:

- $A \& R$ and telescience specialists and microgravity researchers communicate and work together to a greater degree than in the past,

- microgravity experiments are designed to accommodate $A \& R$ and telescience, and

- prelaunch checkout also includes systematic trials with A\&R and telescience to observe normal phenomena, detect failures, and make modifications and repairs.

Again, it should be noted that there currently are not adequate resources allocated to implement $A \& R$ and telescience in the array of planned and projected NASA microgravity experiments.

\section{RESOURCE CONSIDERATIONS}

Development of the capability to conduct microgravity research and applications activity with a CDSF will require commitment of resources by the U.S. government for the lease (or purchase) of the facility itself and also for the development of all that will go into the facility: furnaces, telescience equipment, other support equipment, and, of course, experiments (since NASA funds the vast majority of U.S. microgravity research). This latter commitment is especially important to keep in mind when considering the resource implications of a CDSF.

It was beyond the scope of the committee's charge to calculate the total cost of a CDSF to the U.S. government. However, some indication of the magnitude of the resources involved can be gained by noting that a total CDSF lease cost to the government of $\$ 700$ million represents about five times the total annual NASA microgravity budget (currently at 
approximately $\$ 150$ million per year). Moreover, the above-mentioned CDSF cost estimate may well prove a lower bound on the total cost. In addition, as noted above, the budget for microgravity experimentation would have to be considerably enhanced to provide equipment for experiments along with automation for a free-flyer.

\section{ECONOMIC AND COMMERCIAL CONSIDERATIONS}

Based on historical experience, the broadened comprehension generated by innovative research ultimately will have commercial consequences. There are few examples of a widened span of process control that have not brought a corresponding payoff, from the time that hotter fires fed by air blasts made smelting iron possible. The extra dimensions (e.g., microgravity, vacuum) opened by space are almost unprecedented as variables in industrial processing. Their exploitation will be slow and laborious, both as a result of the novelty of the environment and the high cost that tends to be inherent in space-based activities. Nevertheless, given the competitive nature of the global economy, it is in the national interest that the existing long-term investment in space by the United States be exploited aggressively to allow the U.S. economy to benefit from these new capabilities as they become available.

Given the high costs, the lead times, and the uncertainties involved in setting up new facilities and developing new markets, it is clear the first returns from this research will grow out of a better understanding of physical phenomena that will allow further optimization of existing Earth-based processes. A much greater level of knowledge (along with reduced cost of access to space) will be required to permit the emergence of a more completely space-based industry. A sound foundation of practical and theoretical understanding must be put in place if industry is to achieve the ability to invest with some confidence in this area.

The dollar cost of space activity is another restriction. At a very conservative estimate of $\$ 110$ million, the price of the payload bay per Shuttle flight represents some five percent of the National Science Foundation's annual budget. For a commercial enterprise, this translates to a multimillion dollar cost per experiment, with restricted access, stringent weight and volume limitations, and at best only limited power. Unsurprisingly, there have been no takers, except on terms that transfer the cost of space access to NASA.

Recognizing these constraints, there nevertheless is a broad range of facilities to allow simulation or exploration of the microgravity environment of space. These range from relatively simple capabilities, including ground-based drop tubes, to very complex ones such as the Shuttle-borne Spacelab. Their costs vary from a few thousand dollars per test up to millions, and they differ in accessibility, ease of use, and utility. The need for new facilities must be measured against these existing assets to determine what extra capabilities are needed and at what cost. The existing facilities are described in detail in Chapter 4. 
Although it was not the focus of this study, the question of opportunity costs arises repeatedly. Is a government guarantee of at least $\$ 700$ million as an anchor tenant in a CDSF the most beneficial expenditure of that amount for microgravity research (considering an annual program budget of approximately $\$ 150$ million for MSAD, life sciences, and commercial programs) or, for that matter, for the national space program? At issue is whether a CDSF fills a national need of sufficient import to warrant the investment.

In summary, once initial scientific understanding of the underlying microgravity influences is achieved, the promise of in-space research and applications activity for scientific and commercial benefit is great. The value of the program may eventually exceed its cost in terms of potential scientific breakthroughs or in terms of the U.S. competitive posture vis-a-vis Europe, Japan, and the Soviet Union. Although the potential benefits to the nation lie in the future, it is important to explore this new frontier of human knowledge and to build the foundation for eventual private exploitation of the space environment.

\section{NEED FOR A CDSF IN THE PRE-SPACE STATION ERA}

NASA, in its CDSF Request for Proposals in the spring of 1988 , described a spacecraft similar to the Industrial Space Facility. Studies since that time have considered a spacecraft roughly 20 percent the size of the earlier concept, as well as other tradeoffs. ${ }^{3}$ Thus, the committee approached its evaluations without preconceptions of what a CDSF might be and examined a number of potential facility types. Clearly, its dimensions could be scaled to the anticipated need and its timing made flexible on the same basis. Only a few functional requirements would appear to be essential. If a CDSF were to be built, its experiment accommodations should be compatible with those of the Space Station, it should be optimized for telescience operations, and it logically should be accessible from the Shuttle and/or space Station for payload tending by humans. The committee did not address costs or the implications of commercial development because those are the subjects of a simultaneous study under the auspices of the National Academy of Public Administration.

Considering the requirements presented in Chapter 3 , the capabilities described in Chapter 4, and the issues discussed above, however, the committee does not foresee a need for a U.S. human-tended free-flyer in the period prior to the Space station to meet microgravity research or manufacturing requirements. Anticipated microgravity experimental activities requiring a human presence can be adequately conducted using current Shuttle-based facilities during the 1992-1997 time period, assuming reasonably reliable access to space. At the same time, the committee is concerned that microgravity research and planning for transition of this research to the Space station receive adequate visibility in future NASA planning. This would be especially true should 
all of the expected Shuttle flight opportunities not materialize. A delay in the deployment of Space Station Freedom of one to two years because of policy, budgetary, schedule, or transportation problems would not affect the committee's conclusion. A more extensive delay that would jeopardize expected advances in microgravity sciences would warrant a reconsideration of the need for a CDSF or other free-flyer. The committee notes, however, that a human-tended free-flyer is not an adequate long-term substitute for particular microgravity research capabilities (e.g., continuous manned interaction, high available user power) planned for the Space Station.

Another potential use for a CDSF to which the committee has given consideration is as a platform for technology development and demonstration needed for the Space Station. It also has been argued that a CDSF would prove a useful operations testbed for Space Station systems. However, the committee remains unconvinced by these arguments. Given that the CDSF is not likely to fly until at least 1993 and the assembly of the Space Station on orbit is scheduled to begin in 1995, the CDSF would not have more than a marginal impact on Space Station technology development and demonstration.

The committee also considered the benefit of having a CDSF as a form of "insurance policy" against Shuttle flight rate reductions, the loss of existing microgravity research facilities (e.g., Spacelab), or delay in initial utilization of the Space Station. As indicated earlier, the ability of a CDSF to stay in orbit untended for long periods to compensate for reduced Shuttle flight rates will not be of significant value until the state of microgravity experimentation is considerably more advanced, including the effective use of $A \& R$ and telescience. Furthermore, the committee is skeptical of an insurance policy for which the annual cost of the "premium" (i.e., the CDSF facility lease/purchase price and associated experiment/equipment development costs) exceeds the annual cost of the "insured" (i.e., the NASA microgravity program, currently budgeted at about $\$ 150$ million per year).

The committee does not wish to leave the impression that the concept of a long-duration free-flyer for microgravity research is without merit. The question to be asked is when such a free-flyer might be of benefit to the nation, and the level of maturity of the U.S. microgravity program is a key to answering this question. Microgravity sciences are in an embryonic stage, and it is difficult to anticipate their future needs and to develop a long-term research strategy. For example, the uncertainties surrounding the influence of gravitational acceleration on fundamental heat and mass transport near reaction zones and internal interfaces make it difficult to plan processing strategies and obtain optimum results. Our limited basic understanding of and experience with fundamental fluid physics and materials behavior in reduced gravity severely restricts practical applications at this time. This pervasive situation, recognized by OCP, probably means that the development of viable commercial processes in space will take nearly a decade, although the committee acknowledges the possibility of early, serendipitous research successes that could advance the period by several years. 
The value of having some kind of free-flyer concurrent with mature operations of the Space Station seems apparent. Such a facility should be readily accessible from the Station and be compatible with it, yet have the advantages of a "cleaner" microgravity environment, and should be able to take advantage of expected advances in A\&R and telescience. Indeed, plans already exist for a Space Station Man-Tended Free-Flyer to be developed by the European Space Agency.

The committee's analysis indicates that having greatly enhanced access to space up to five years earlier than the Space station is anticipated actually would add little toward speeding space commercialization based on exploitation of the microgravity environment. Free-flyers eventually will be needed in the performance of microgravity $R \& D$ and applications work, but their use will be predicated on developing the knowledge base, hardware systems, and appropriate $A \& R$ and telescience needed to make them practical.

\section{NOTES}

1. Todd, Dunbar, Slichter, and The Task Force on the Scientific Uses of a Space Station (TFSUSS).

2. Dunbar, 1987, p.7. For critical assessments of the available capabilities for microgravity research, see also slichter and Todd.

3. Langley Research Center, 1989. 


\section{ACRONYMS}

A\& R

AMICA

CCDS

CDSF

DARPA

DOD

EDO

ELV

ESA

EURECA

GAS Can

ISF

JEA

MBB

MMS

MSAD

MSL

NASA
Automation and Robotics

Autonomous Microgravity Industrial Carrier

Center for the Commercial Development of Space

Commercially Developed Space Facility

Defense Advanced Research Projects Agency

Department of Defense

Extended Duration Orbiter

Expendable Launch Vehicle

European Space Agency

European Retrievable Carrier

Get-Away-Special Canister

Industrial Space Facility

Joint Endeavor Agreement

Messerschmitt-Boelkow-Blohm

Multimission Modular Spacecraft

Microgravity Science and Applications Division (NASA)

Material Science Laboratory

National Aeronautics and Space Administration 


$\begin{array}{ll}\text { NIST } & \text { National Institute of Standards and Technology } \\ \text { NRC } & \text { National Research Council } \\ \text { OAST } & \text { Office of Aeronautics and Space Technology (NASA) } \\ \text { OCP } & \text { Office of Commercial Programs (NASA) } \\ \text { OSS } & \text { Office of Space Station (NASA) } \\ \text { OSSA } & \text { Office of Space Science and Applications (NASA) } \\ \text { R\&D } & \text { Research and Development } \\ \text { RFP } & \text { Request for Proposals } \\ \text { SAMS } & \text { Space Acceleration Measurement System } \\ \text { SFU } & \text { Space Flyer Unit } \\ \text { SIP } & \text { Space Industries Partnership } \\ \text { SPAS } & \text { Shuttle Pallet Satellite } \\ \text { SSDA } & \text { Space Systems Development Agreement } \\ \text { TDRSS } & \text { Tracking and Data Relay Satellite System } \\ \text { USML } & \text { United States Microgravity Laboratory } \\ \text { USMP } & \text { United States Microgravity Payload } \\ \end{array}$




\section{ABBREVIATIONS/SYMBOLS}

$\begin{array}{ll}\text { ave } & \text { average } \\ \mathrm{cm} & \text { centimeter } \\ \mathrm{g} & \text { gravitational acceleration } \\ \mathrm{Hz} & \text { Hertz } \\ \mathrm{kg} & \text { kilogram } \\ \mathrm{kW} & \text { kilowatt } \\ \mathrm{m} & \text { meter } \\ \mathrm{std} & \text { standard } \\ \mathrm{W} & \text { watt } \\ \sim & \text { approximately equal } \\ < & \text { less than } \\ > & \text { greater than } \\ 10^{-2} & 1 / 100\end{array}$




\section{Appendixes}

PRECEDING PAGE BLANK NOT FILMED 


\section{APPENDIX A}

\section{LETTER FROM JAMES FLETCHER AND STATEMENT OF WORK}

PRECEDING PAGE BLANK NOT FILMED 


\section{NMSA}

National Aeronaulics and Space Administration

Washinglon, D.C.

20546

Otice of the Adminisliator

Dr. Frank Press

Chairman

National Research Council

Washington, DC 20418

Dear Frank:

As you know, the executive and legislative branches have had a keen interest in an independent assessment of the viability ana characteristics of a Commerciaily Developed Space Facility.

For the past several weeks, we have been working toward developing a study plan to address this issue. The study plan reflects the informational requirements of both the executive and legislative branches in their consideration of tinis important initiative. The study plan includes a proposed statement of Work for the study requested to be performed by the National Research Council, as well as a proposed statement of Work for a parallel study to be performed by the National Academy of Public Administration concerning cost.

I, therefore, take this opportunity to make a formal request of the National Research Council to undertake, as expeditiously as possible, the proposed study outlined in the enclosure and to provide a final report by April 10, 1989.

I appreciate the willingness of the Council to carry out this important analysis.

Enclosure

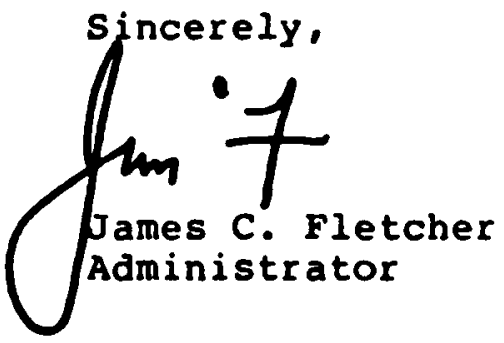

CC:

NRC/Dr . Robert M. White 
ORIGINAL PAGE IS

OF POOR QUALITY

NATIONAL AERONAUTICS AND SPACE ADMINISTRATION

STATEMENT OF WORK

NRC STUDY

The NATIONAL RESEARCH COUNCIL (NRC) shall conduct an independent study of the Commercially Developed Space Facility (CDSF) that addresses the following issues:

(1) The scientific and commercial benefit to the nation of developing a commercially developed space facility prior to Space Station operations.

(2) Definition of the criteria for optimum use.

(3) The technical characteristics of a CDSF that would enable its optimum use.

The study shall include the following assessments:

- The planned and anticipated microgravity research and manufacturing requirements of the federal government and commercial users prior to space station operations. Power, duration, micro $G$ level shall be evaluated. Some indication of the quantity or percentage of the total that requires long duration in the FY 92 to 97 time period shall be assessed to identify unique requirements for a free flyer. Issues such as automation, re-entry $\mathrm{G}$ level, etc. shall be considered.

- How and to what extent existing, planned, and proposed capabilities and infrastructure could support these requirements. This shall include an assessment of the capabilities, and potential benefits of a CDSF, Spacelab, Spacehab, Extended Duration Orbiter, free-flying spacecraft, Expendable Launch Vehicles, and any feasible combination of these capabilities and infrastructure.

- The state of space automation technology and its relevance to the capabilities for a CDSF.

- A comparison of the microgravity research requirements projections based on the maintenance of the Space Station Program's currently planned schedule. . 


\section{NATIONAL AERONAUTICS AND SPACE ADMINISTRATION \\ STATEMENT OF WORK \\ NRC STUDY (CONTINUED)}

- The relationship of a CDSF to other proposed facilities of a similar nature.

- The effect a commitment to the CDSF would have on the current space transportation system launch schedule.

- The benefit to the nation of providing an orbiting microgravity research and manufacturing capability as early as possible.

The study shall be completed and conclusions and recommendations provided to the Administrator of NASA on or before April 10, 1989. Documentation of the study details, conclusions, recommendations and findings are required in a final report. 


\section{NATIONAL AERONAUTICS AND SPACE ADMINISTRATION}

\section{STATEMENT OF WORK}

NAPA STUDY

The NATIONAL ACADEMY OF PUBLIC ADMINISTRATION (NAPA) shall conduct an independent study of the Commercially Developed Space Facility (CDSF) that:

- Provides an estimate of the development, operations, and other costs to the government associated with the CDSF, and the estimated lease cost per year for five years which must be paid by the government to meet investment criteria for a viable business.

- Assesses the likelihood that a CDSF would become commercially self-sustaining and an estimate of when that could occur.

- Considers, per the lease option, the practicability of reducing on a yearly basis the level of government lease operations during the years of operation of a CDSF, instead of providing for a flat level of lease obligations.

- Considers, per the lease option, the practicability of making the minimum levels of government lease options in the years of operation of a CDSF contingent on the attainment by the CDSF operator, of certain minimum levels of firm contract commitments with entities other than the United States Government.

- Assesses how a decision by the government to lease facilities on a CDSF might effect the viability of other existing or proposed commercial microgravity facilities.

Periodic progress and status briefings are required.

The study shall be completed and conclusions and recommendations provided to the Administrator of NASA on or before April 10, 1989. Documentation of the study details, conclusions, recommendations and findings are required in a final report.

ENCLOSURE \#2 


\section{APPENDIX B}

LIST OF PARTICIPANTS 


\section{LIST OF PARTICIPANTS}

\section{NASA HEADQUARTERS}

Joseph K. Alexander, Assistant Associate Administrator (Science \& Applications), Office of Space Science and Applications (OSSA)

Judith Ambrus, Acting Assistant Director, Space Station Technology, Office of Aeronautics and Space Technology (OAST)

John-David Bartoe, Chief Scientist, Office of Space Station (OSS)

Gene Beam, Office of Space Flight (OSF) on temporary duty from Marshall Space Flight Center

Roger K. Crouch, Chief Scientist Microgravity Science and Applications Division, OSSA

Jerry J. Fitts, Director, Transportation Services, OSF

William P. Gilbreath, Life Sciences Division, Flight Programs Branch, OSSA

Leonard Harris, Chief Engineer, OAST

Lawrence F. Herbolsheimer, Deputy Assistant Administrator, Office of Commercial Programs (OCP)

Ralph M. Hoodless, Jr., Director, Commercially Developed Space Facility, OSF

Keith Hudkins, OSF

Frank D. Lemkey, Acting Director, Microgravity Science and Applications Division, OSSA

Thomas L. Moser, Deputy Associate Administrator (Development), OSS

Dale D. Myers, Deputy Administrator, NASA

Richard H. Ott, Director, Commercial Development Division, OCP

Robert C. Rhome, Acting Assistant Associate Administrator (Space Station), OSSA

James T. Rose, Assistant Administrator for Commercial Programs, OCP

Anna Villamil, Venture Liaison, Commercial Development Division, OCP

\section{NASA CENTERS FOR THE COMMERCIAL DEVELOPMENT OF SPACE}

Raymond Askew, Director, Space Power Institute, Auburn University

Larry DeLucas, Assistant Director, Center for Macromolecular Crystallography at the University of Alabama, Birmingham

Alex Ignatiev, Director, Space Vacuum Epitaxy Center, University of Houston

Frank Jelinek, Associate Director, Advanced Materials Center, Battelle-Columbus

Charles Lundquist, Director of Consortium for Materials Development in Space, University of Alabama, Huntsville

Fred Speer, Director, Center for Advanced Space Propulsion, University of Tennessee Space Institute

\section{JOHNSON SPACE CENTER}

Bonnie J. Dunbar, Mission Specialist, Flight Crew Operations

\section{LANGLEY RESEARCH CENTER}

Leonard DeRyder, Deputy Manager, Systems Engineering \& Integration

W. Ray Hook, Director for Space

Joseph Talbot, Head of Systems Engineering \& Integration 


\section{MARSHALL SPACE FLIGHT CENTER}

Robert J. Naumann, Chief, Microgravity Science and Applications Division

\section{DEPARTMENT OF COMMERCE}

Richard Endres, Director, Office of Space Commercialization

Cary Gravatt, Deputy Director, National Measurement Laboratory of National Institute of Standards and Technology (NIST)

Shellyn McCaffrey, Associate Deputy Secretary of Commerce

Paul W. Todd, Biophysicist, Center for Chemical Engineering, NIST

\section{U.S. SENATE}

Martin P. Kress, Senior Staff, Subcommittee on Science, Technology and Space, Committee on Commerce, Science and Transportation

CONGRESSIONAL BUDGET OFFICE

David H. Moore, Principal Analyst, Natural Resources and Commerce Division

NATIONAL ACADEMY OF PUBLIC ADMINISTRATION

William Lilly, CDSF Study Chairman

Carol Neves, Staff

Frank Rosenberg, Staff

AMOCO CHEMICAL COMPANY

Jack R. Knox, Senior Research Associate

BABCOCK AND WILCOX

Robert Salm, Senior Principal Engineer, Space and Power Propulsion

Ed Gaffney, Vice President for Government Operations

DOW CHEMICAL COMPANY

John W. Stevens, Jr., Manager of Discovery Research

EUROPEAN SPACE RESEARCH AND TECHNOLOGY CENTRE

Dieter Andresen, EURECA

EXTERNAL TANKS CORPORATION

John Dutton, Dean of Engineering, Pennsylvania State University, and President, UCAR Foundation

Randolph Ware, External Tanks Corporation 


\section{FAIRCHILD INDUSTRIES}

Morton Cohen, Fairchild Space Co.

Steven Flajser, Head of Government Relations, Fairchild Industries

Bernie Raab, Director of Advanced Programs, Fairchild Space Co.

Martin Titland, President, Fairchild Space Co.

GENERAL ELECTRIC COMPANY (AMICA)

Gilbert Silverman, Manager, Program Development

David J. Wright, Manager, Marketing, Civil Space Programs

MAXWELL LABORATORIES

Andrew Wilson, Vice President

SPACEHAB, INC.

James M. Beggs, Chairman of the Board

Richard Jacobson, Chief Executive Officer

Chester Lee, Executive Vice President

SPACE INDUSTRIES, INC.

Joseph P. Allen, Executive Vice President

James D. Calaway, Vice President, Marketing and Founder

Maxime A. Faget, President and Chief Executive Officer and Founder

Allen J. Louviere, Senior Vice President, Engineering and Operations

TELEDYNE BROWN ENGINEERING

Nicholas L. Johnson, Advisory Scientist

3M CORPORATION

Christopher Podsiadly, Director, Science Research Laboratory 


\title{
APPENDIX C
}

NATIONAL AERONAUTICS AND SPACE ADMINISTRATION OFFICE OF SPACE SCIENCE AND APPLICATIONS

\author{
PROJECTED REQUIREMENTS FOR \\ MATERIALS MICROGRAVITY EXPERIMENTS
}




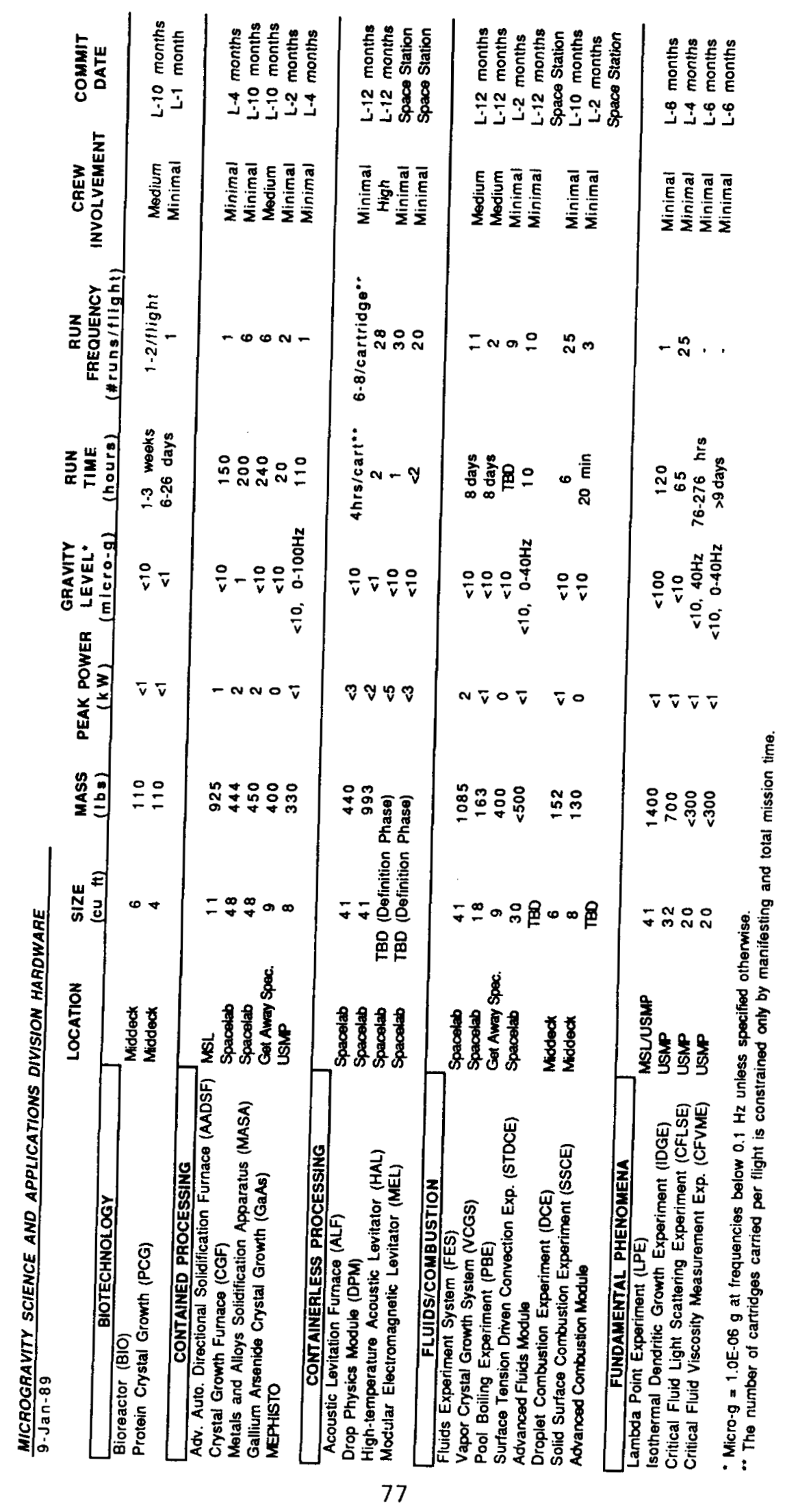




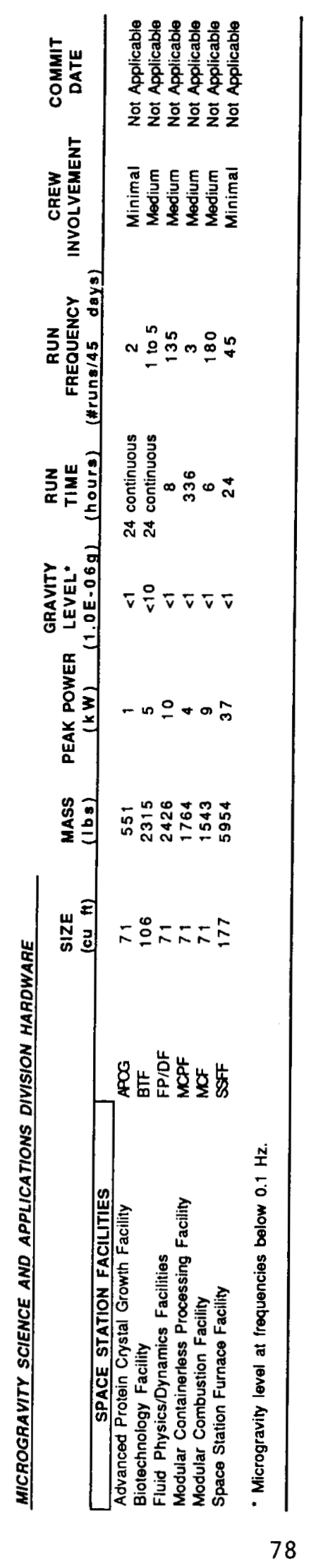




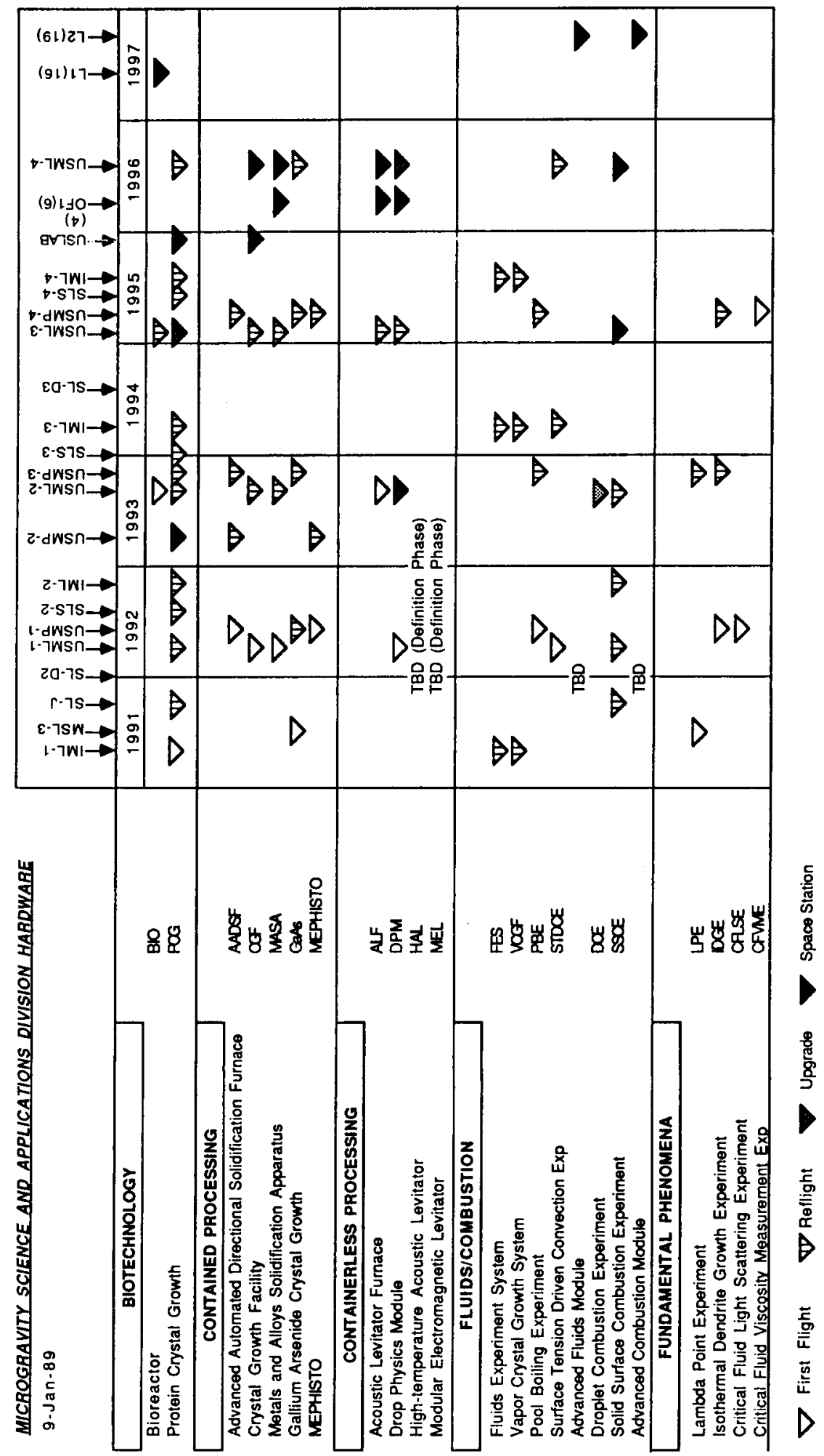




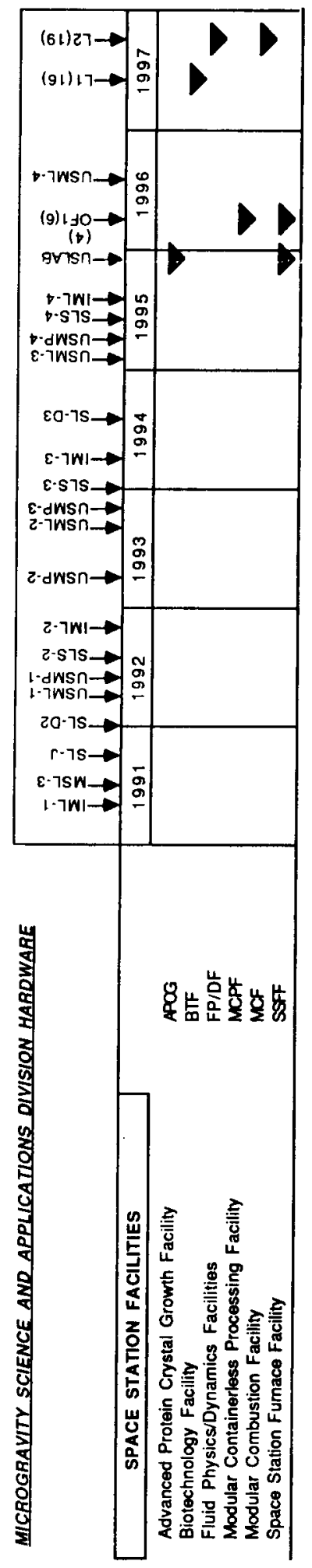




\section{APPENDIX D}

\section{NATIONAL AERONAUTICS AND SPACE ADMINISTRATION OFFICE OF SPACE SCIENCE AND APPLICATIONS}

\section{PROJECTED REQUIREMENTS FOR LIFE SCIENCES MICROGRAVITY EXPERIMENTS}

(Draft mission planning chart and statement of generalized requirements for experiments) 


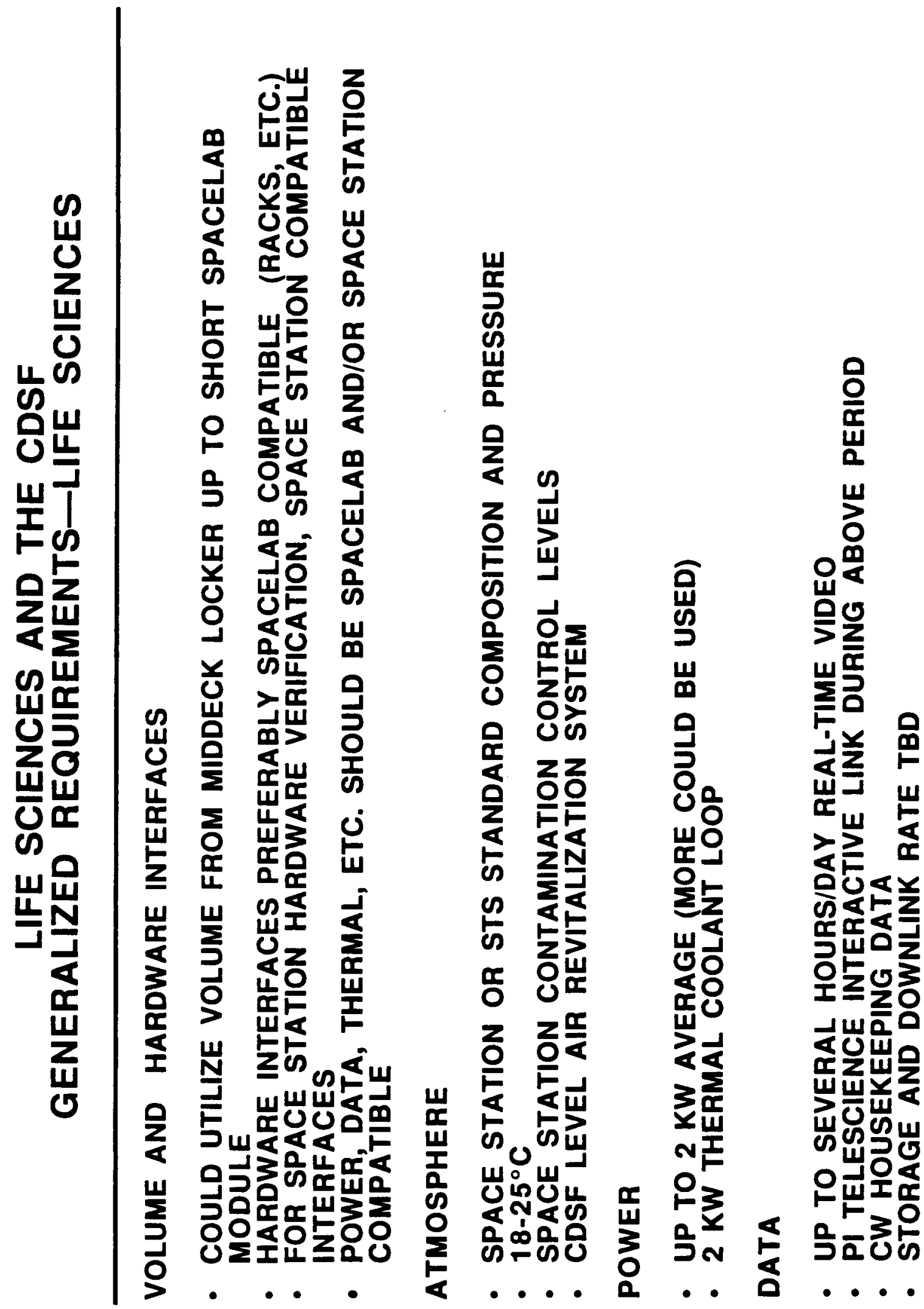




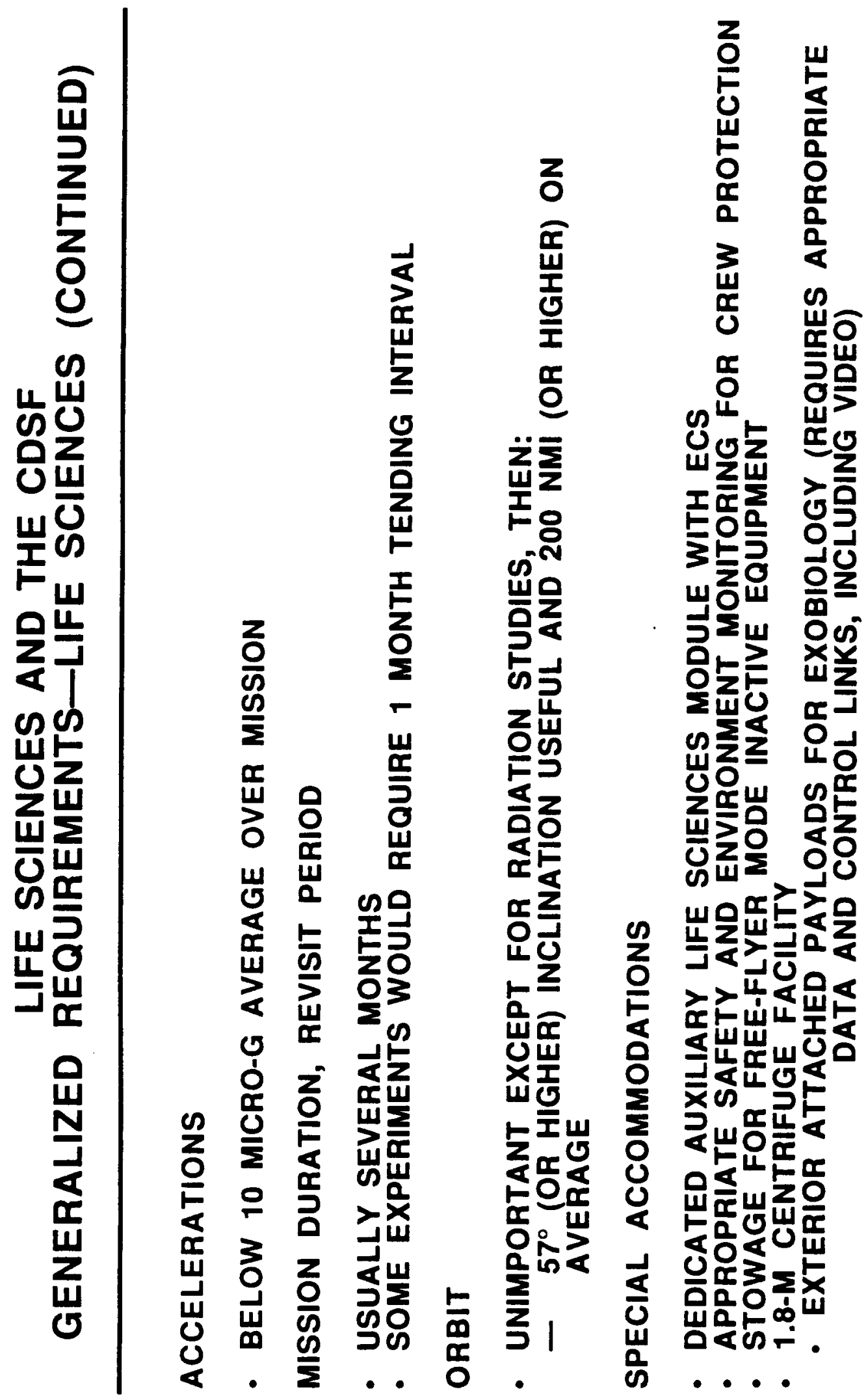


ORIGINAL PAGE IS

OF POOR QUALITY

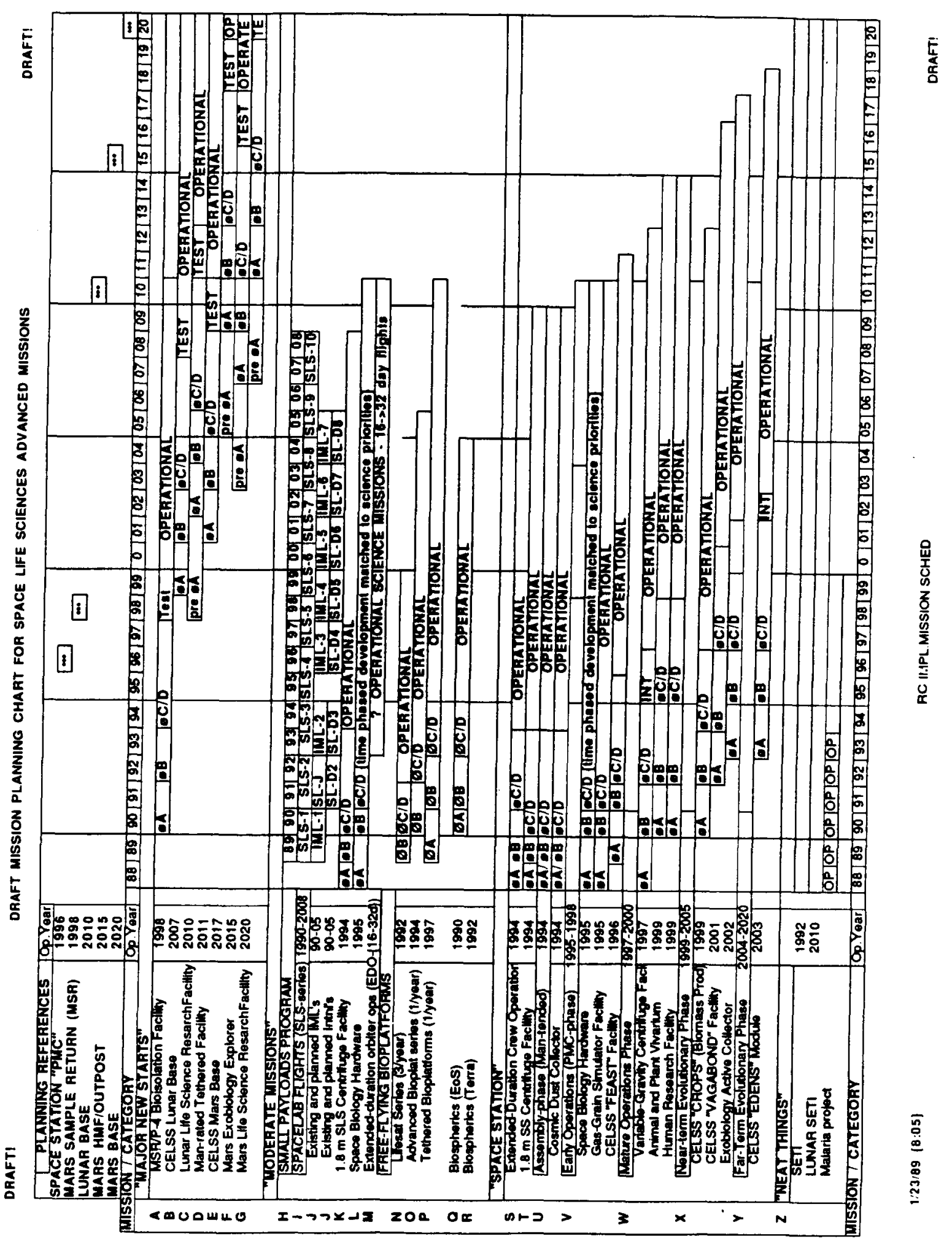




\section{APPENDIX E}

NATIONAL AERONAUTICS AND SPACE ADMINISTRATION OFFICE OF COMMERCIAL PROGRAMS

PROJECTED REQUIREMENTS FOR MICROGRAVITY EXPERIMENTS 


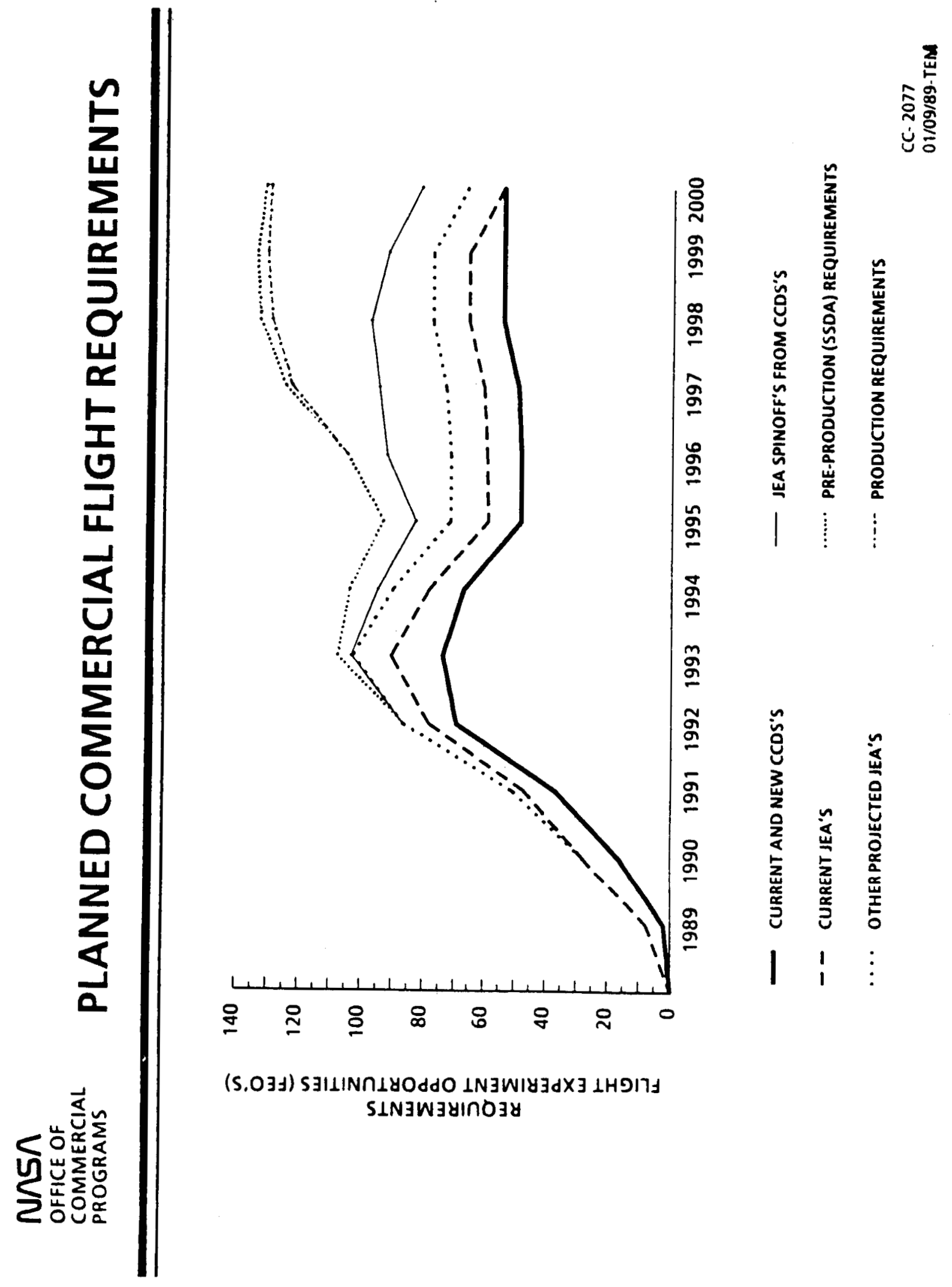




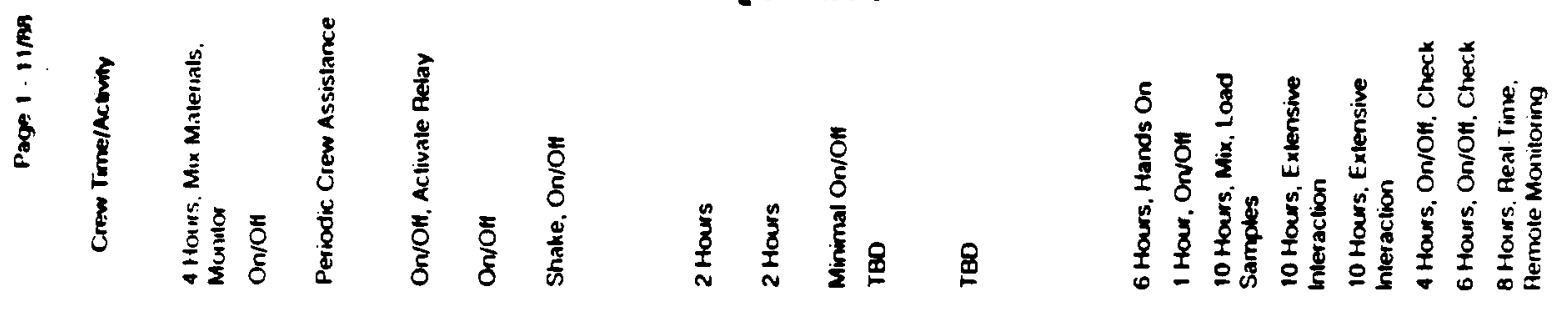

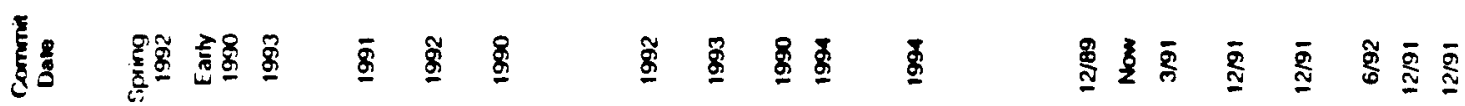

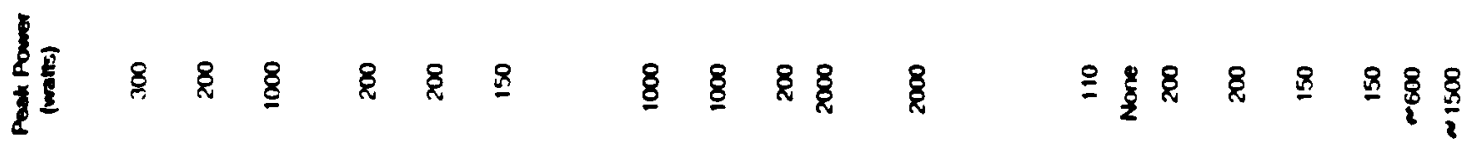

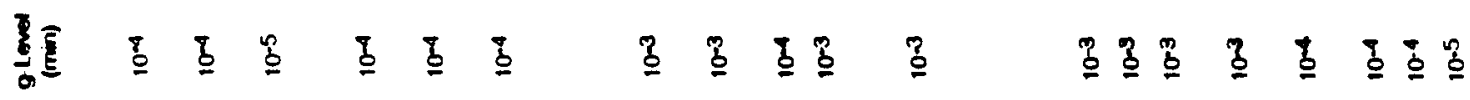

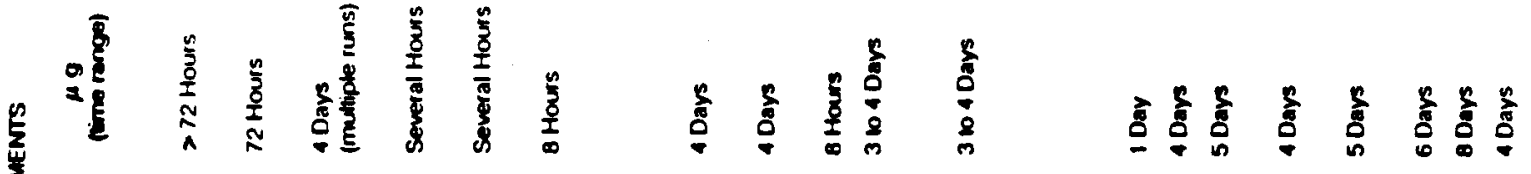

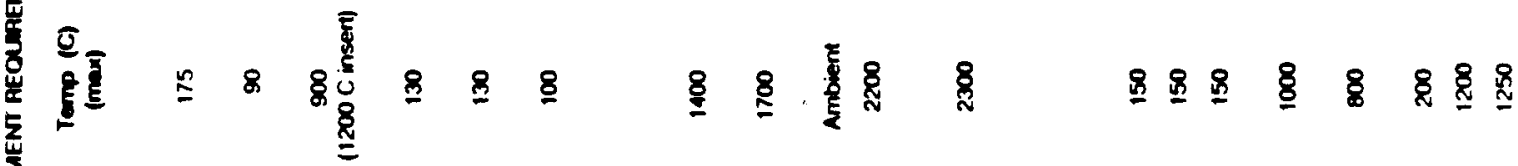

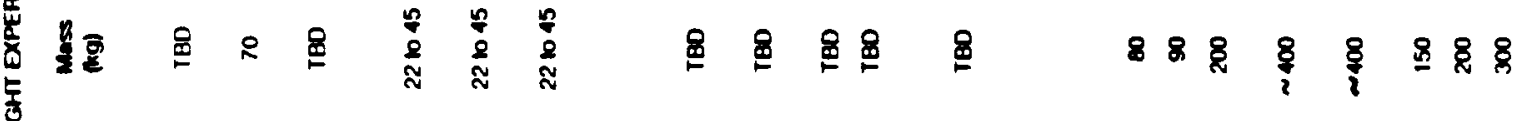

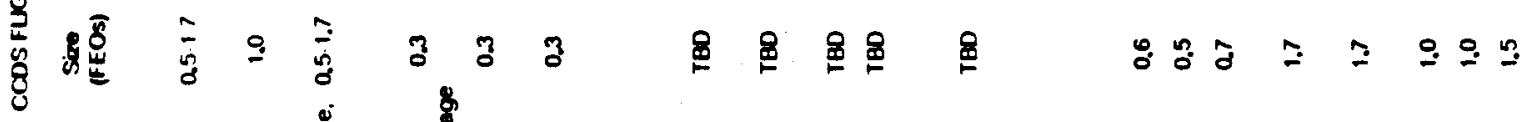

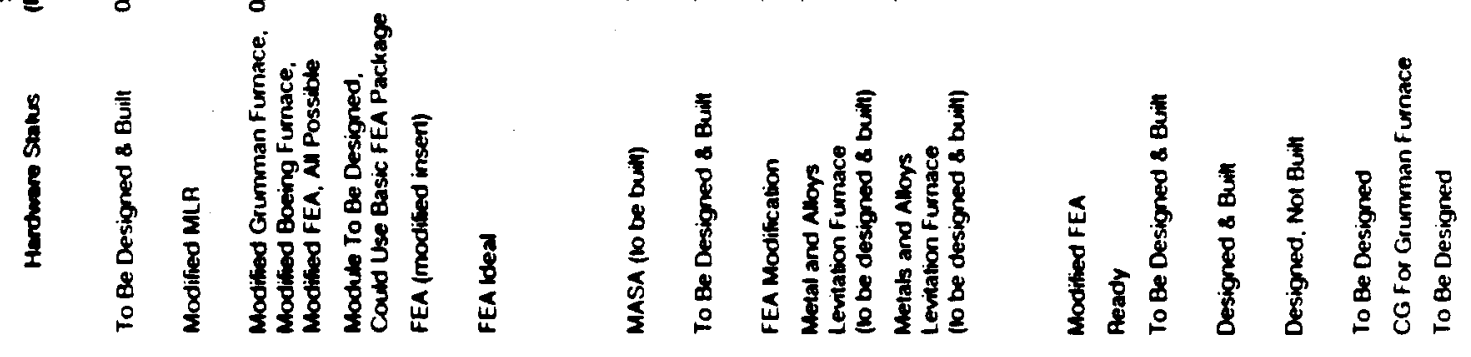

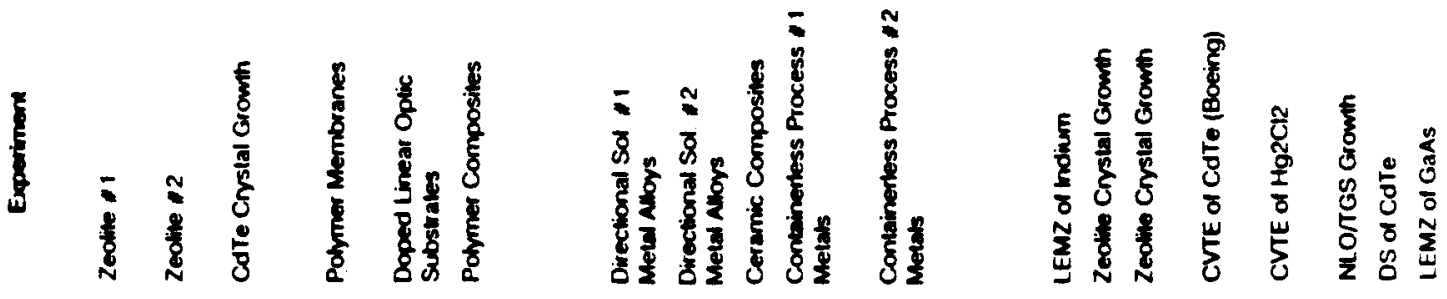


ORIGINĀL PAGE IS

OF POOR QUALITY
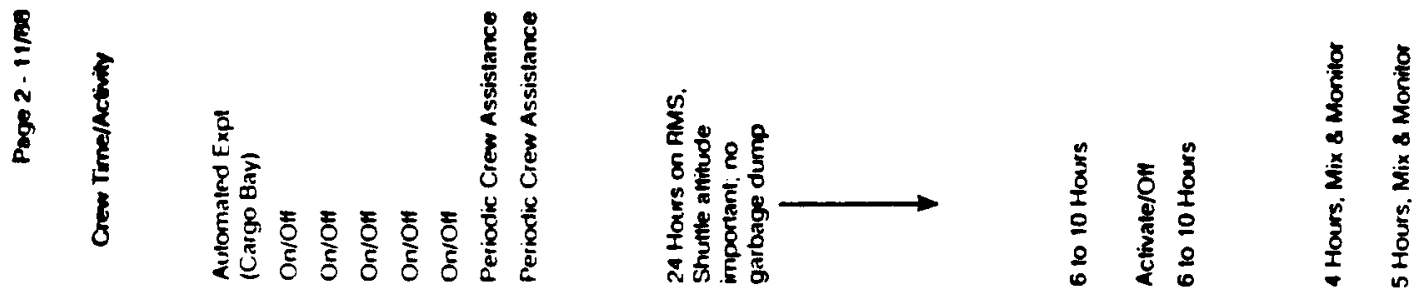

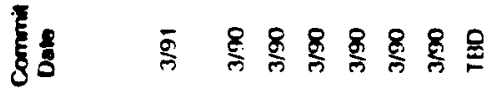

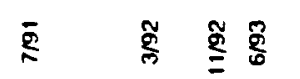

家

s

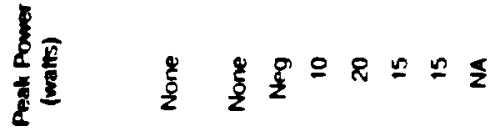

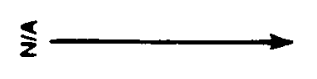

88

8 \&

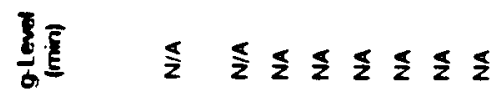

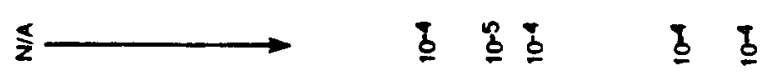

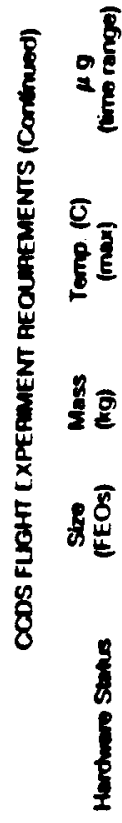

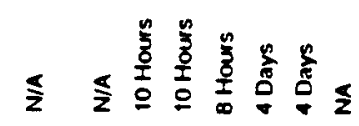

$\leqslant$

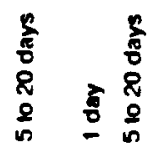

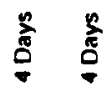

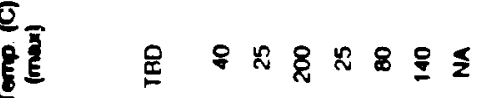

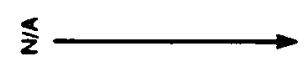

ร. 88

요

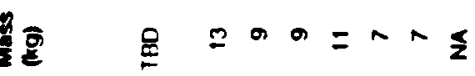

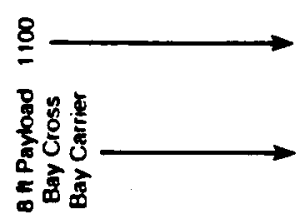

888

88

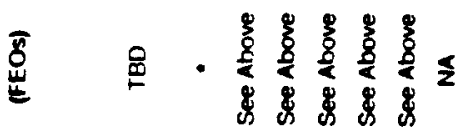

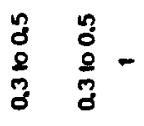

$8:$

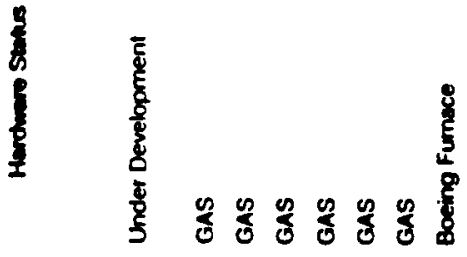

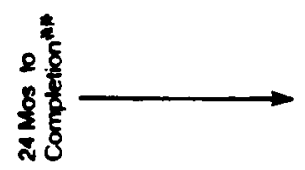

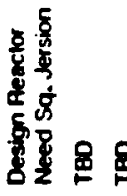

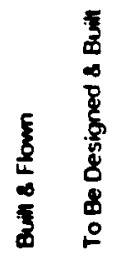

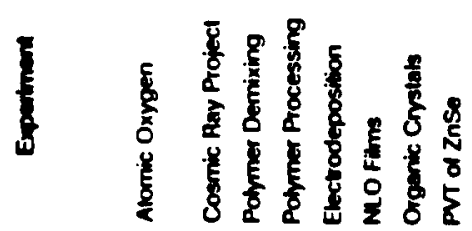

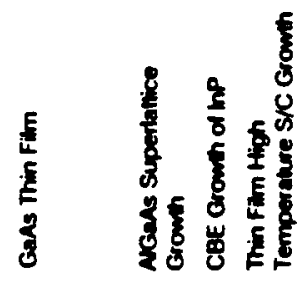

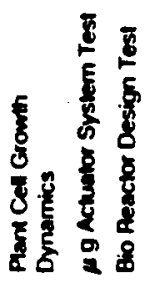

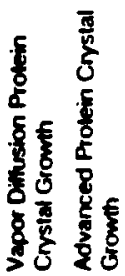




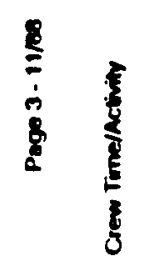

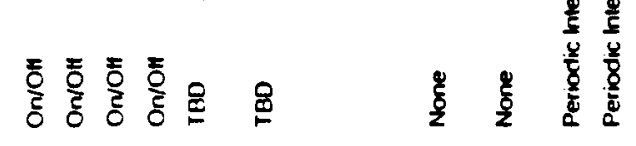

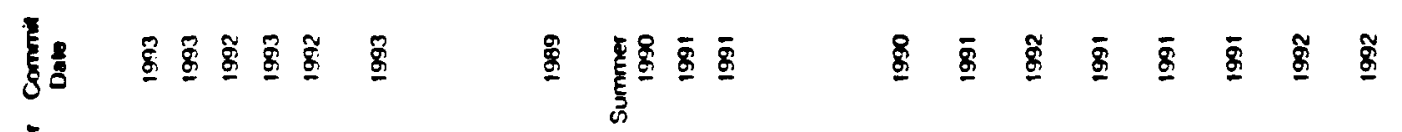

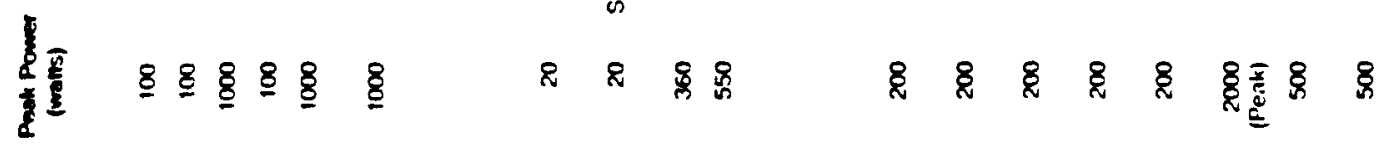

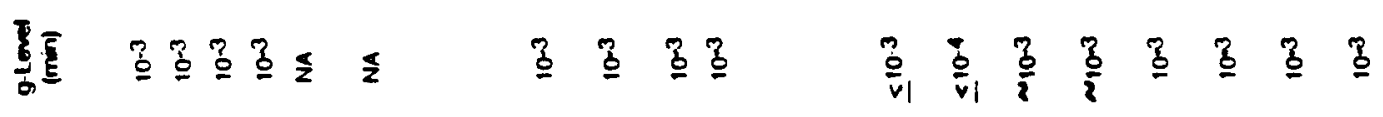

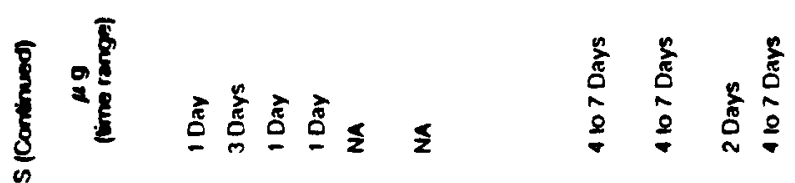

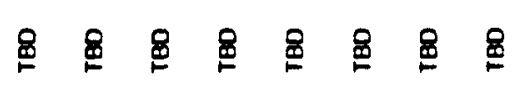

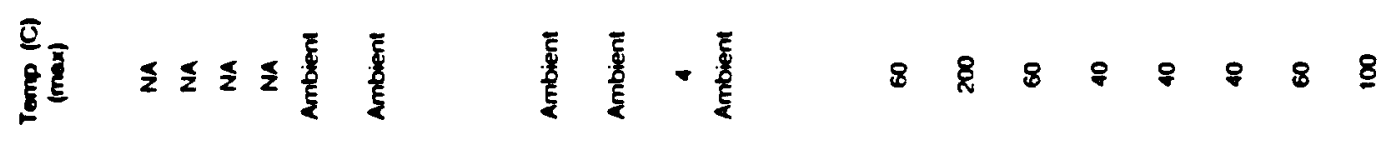

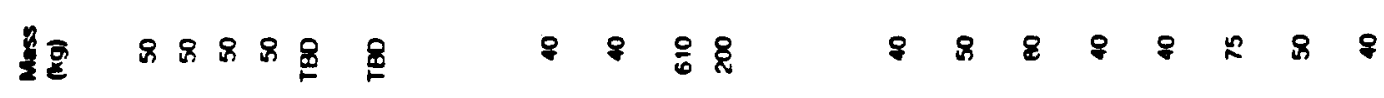

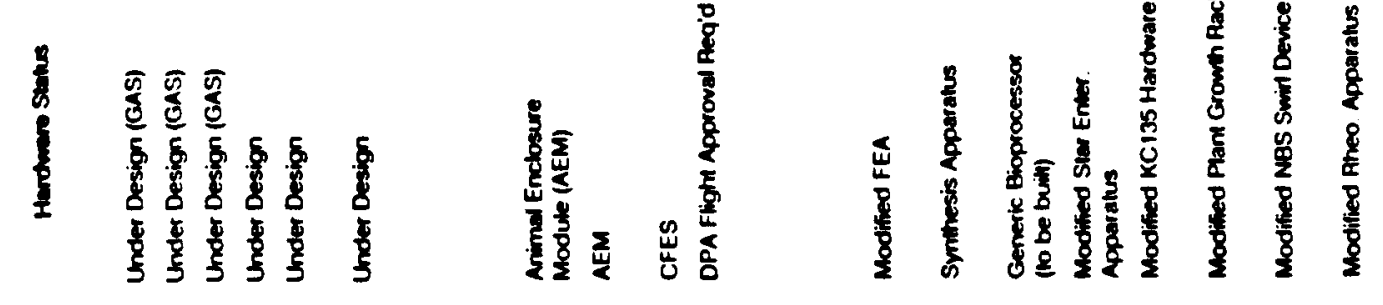

I IIIIn 


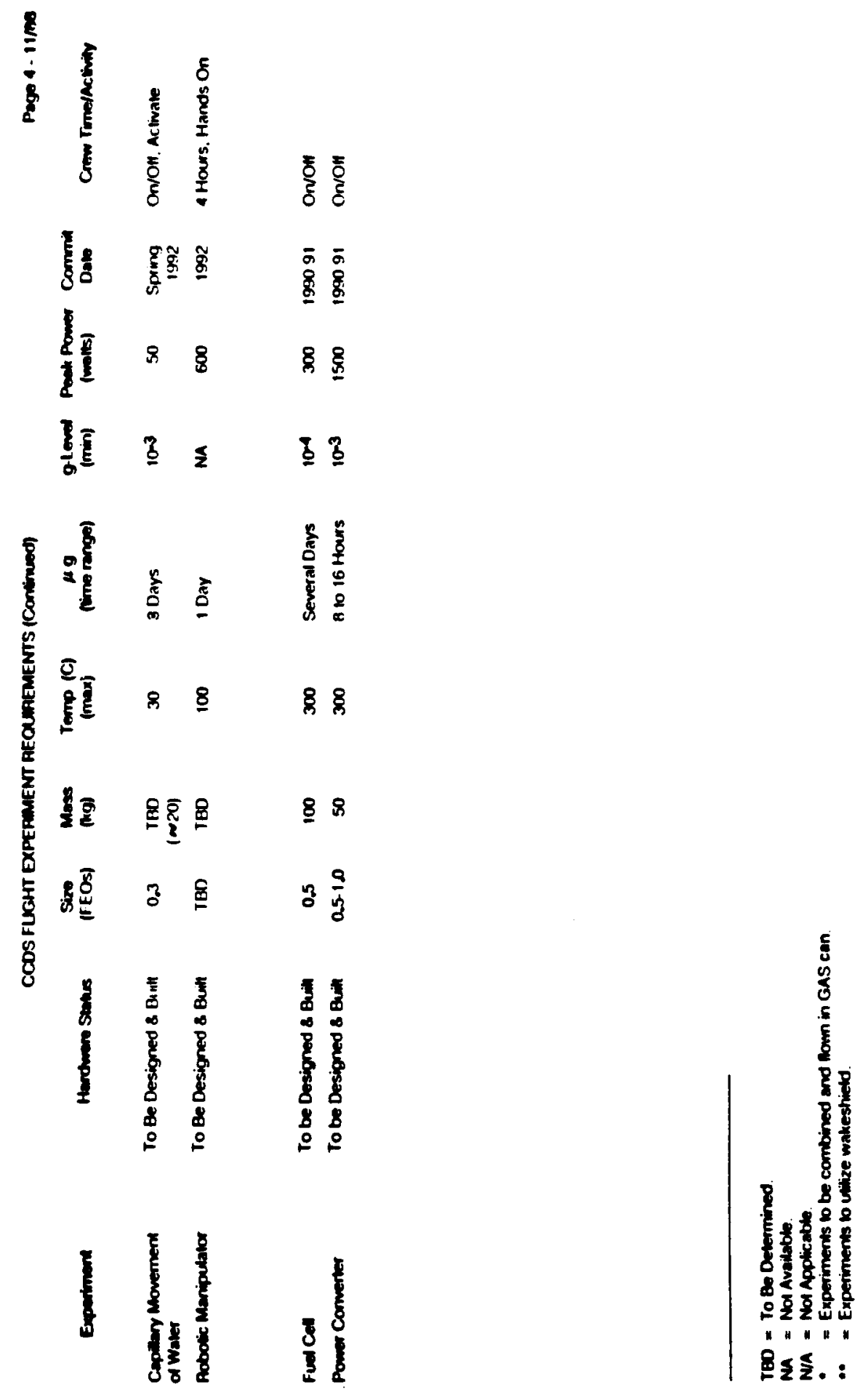




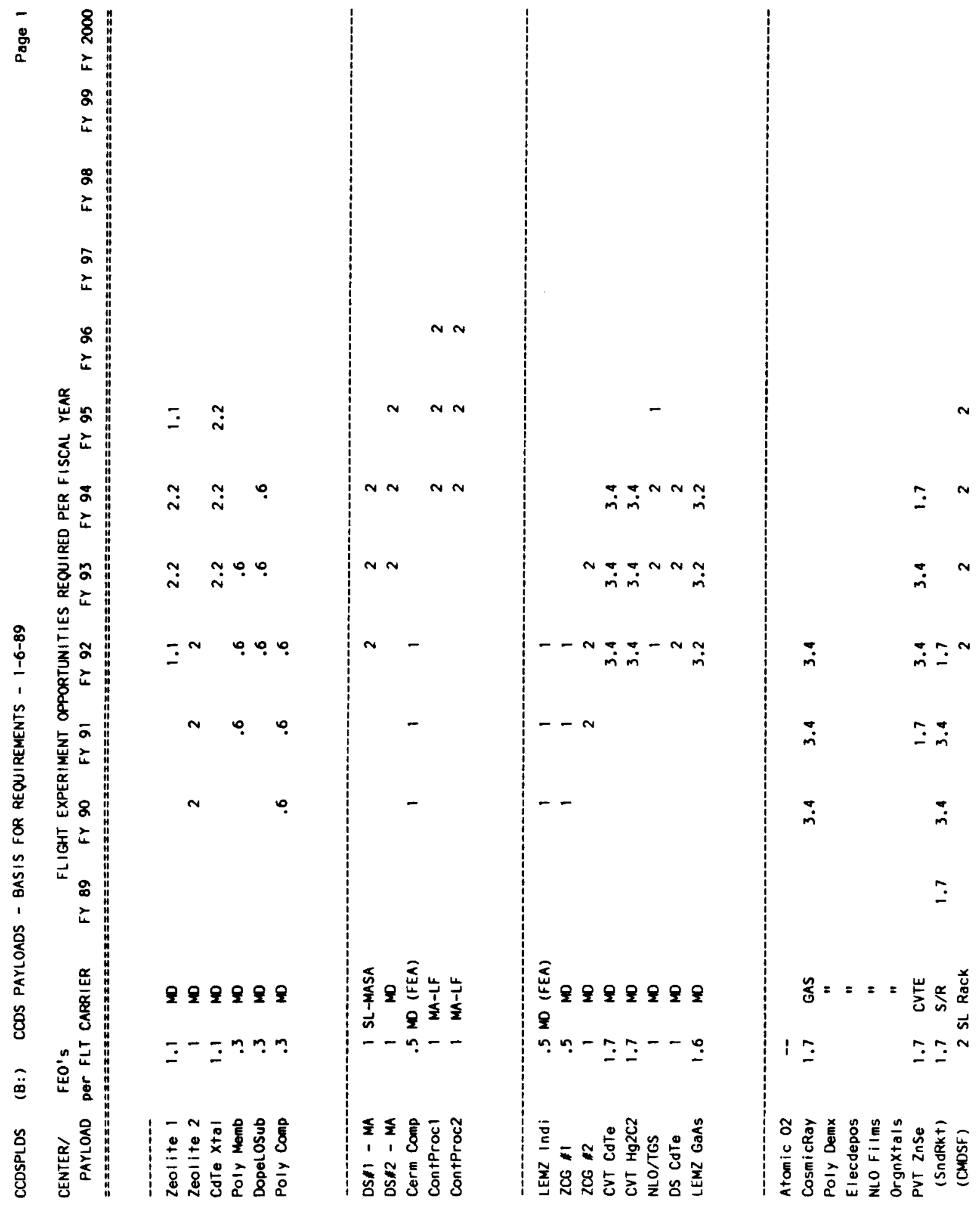




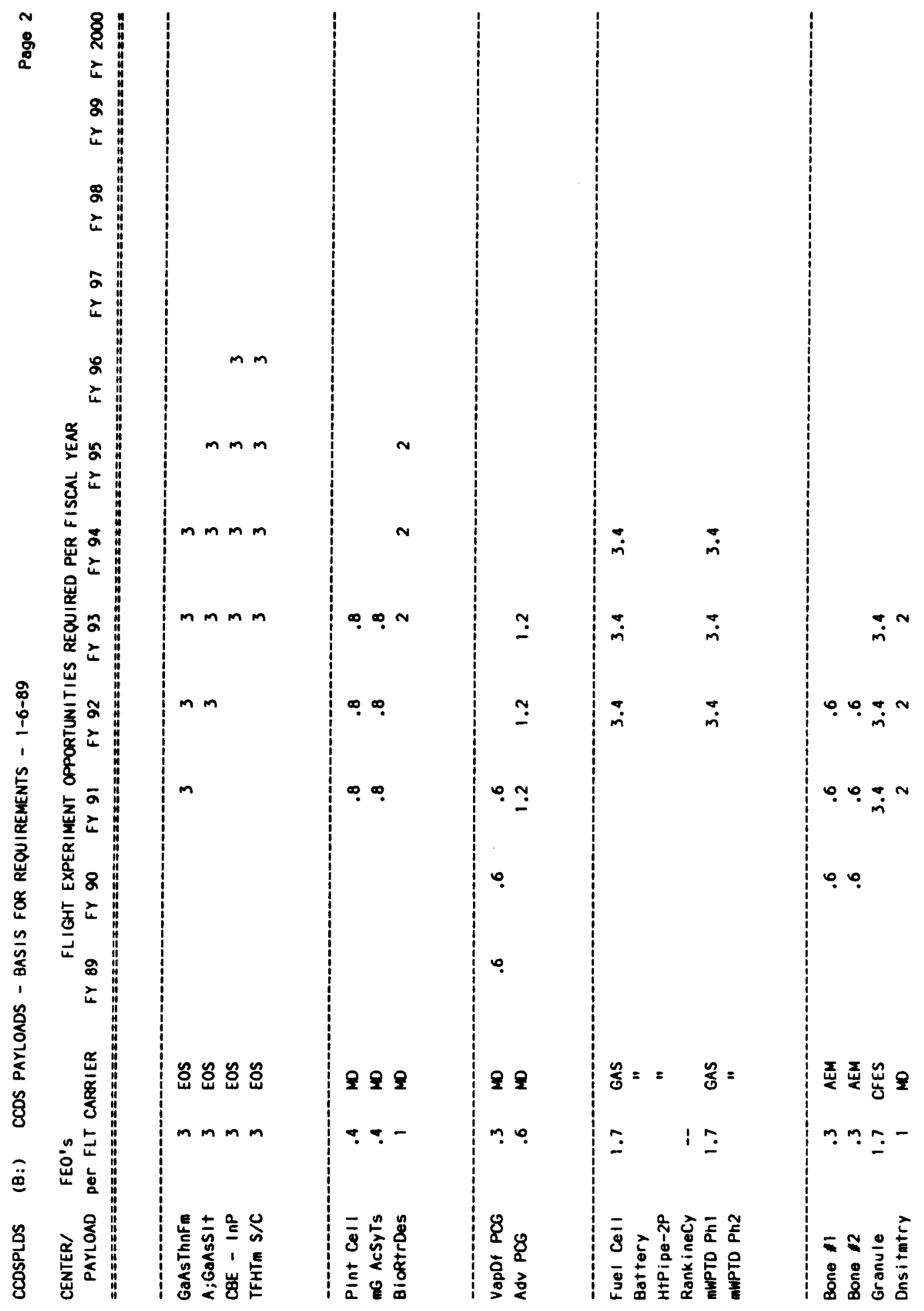




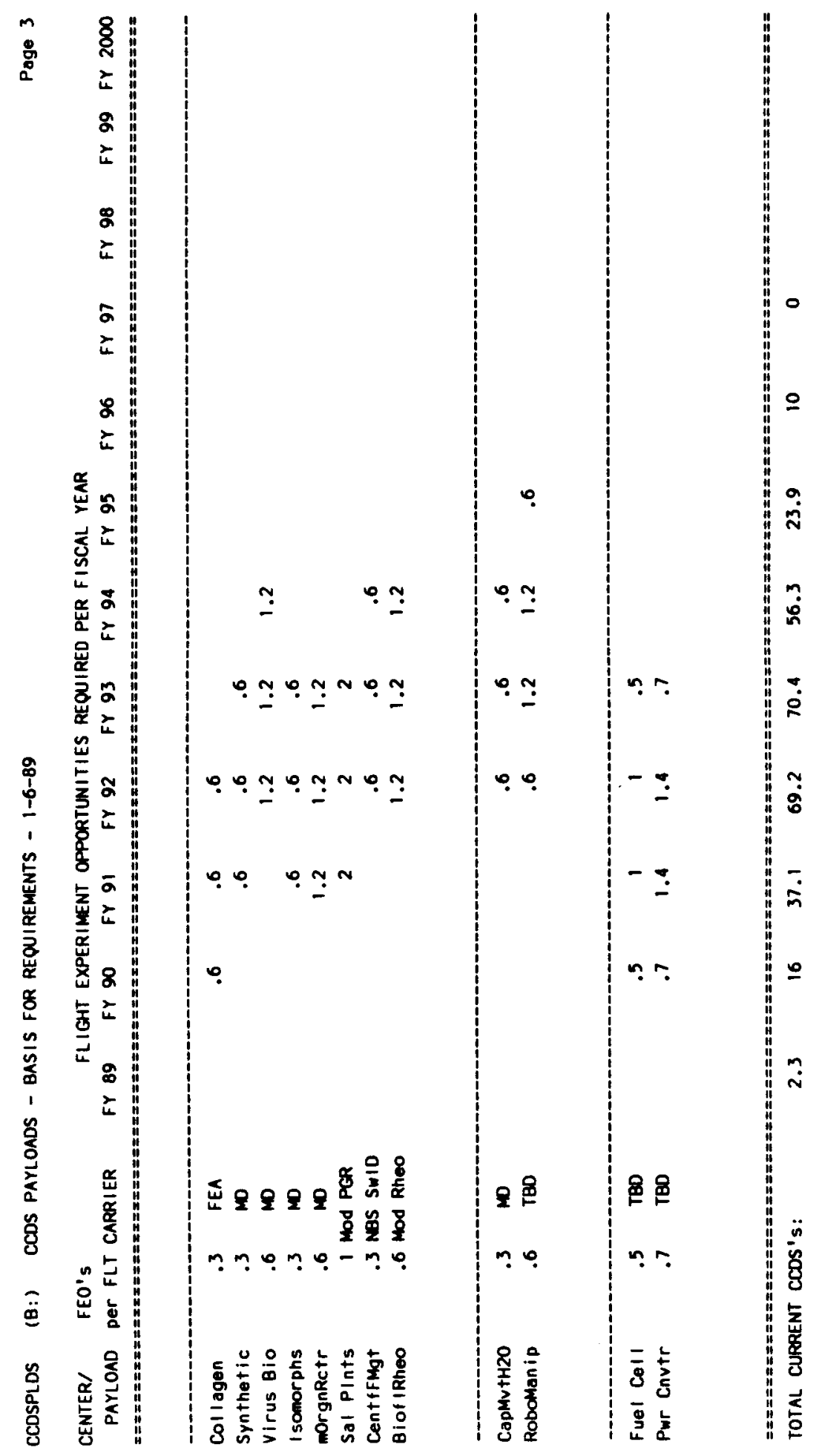




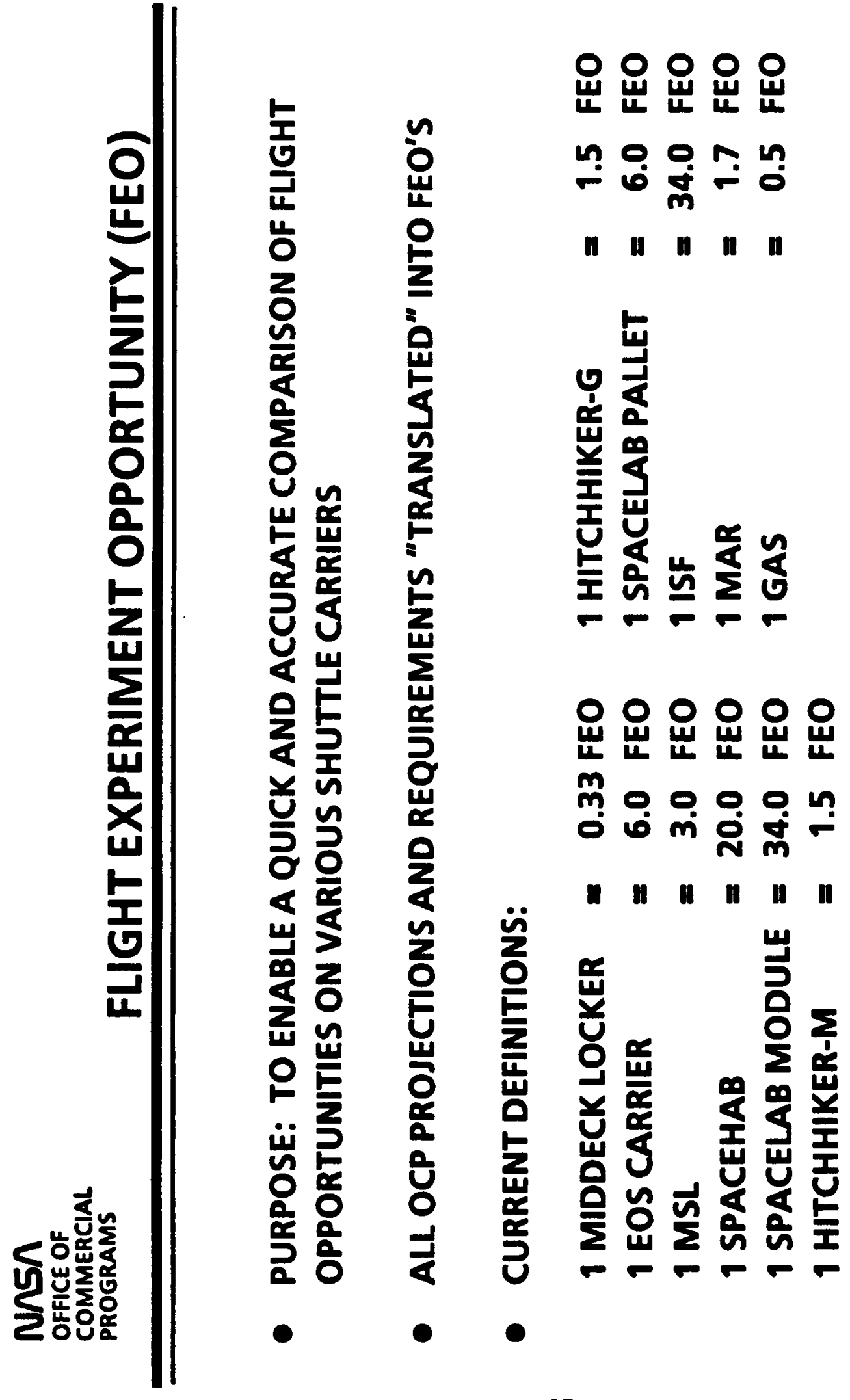

$\frac{5}{5}$
$\frac{5}{8}$
$\frac{8}{8}$
$\frac{8}{8}$
$\frac{\pi}{7}$
$\dot{y}$ 


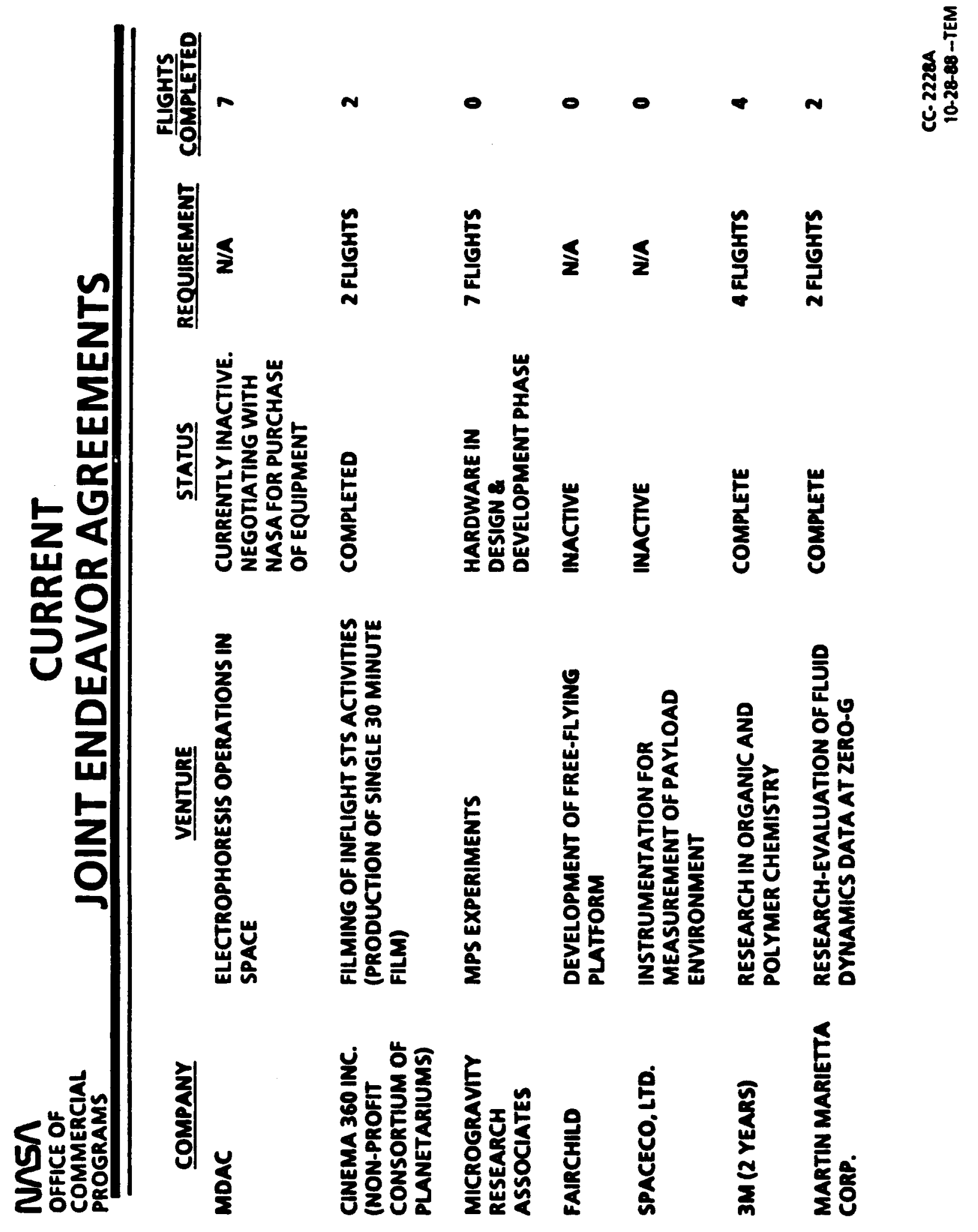




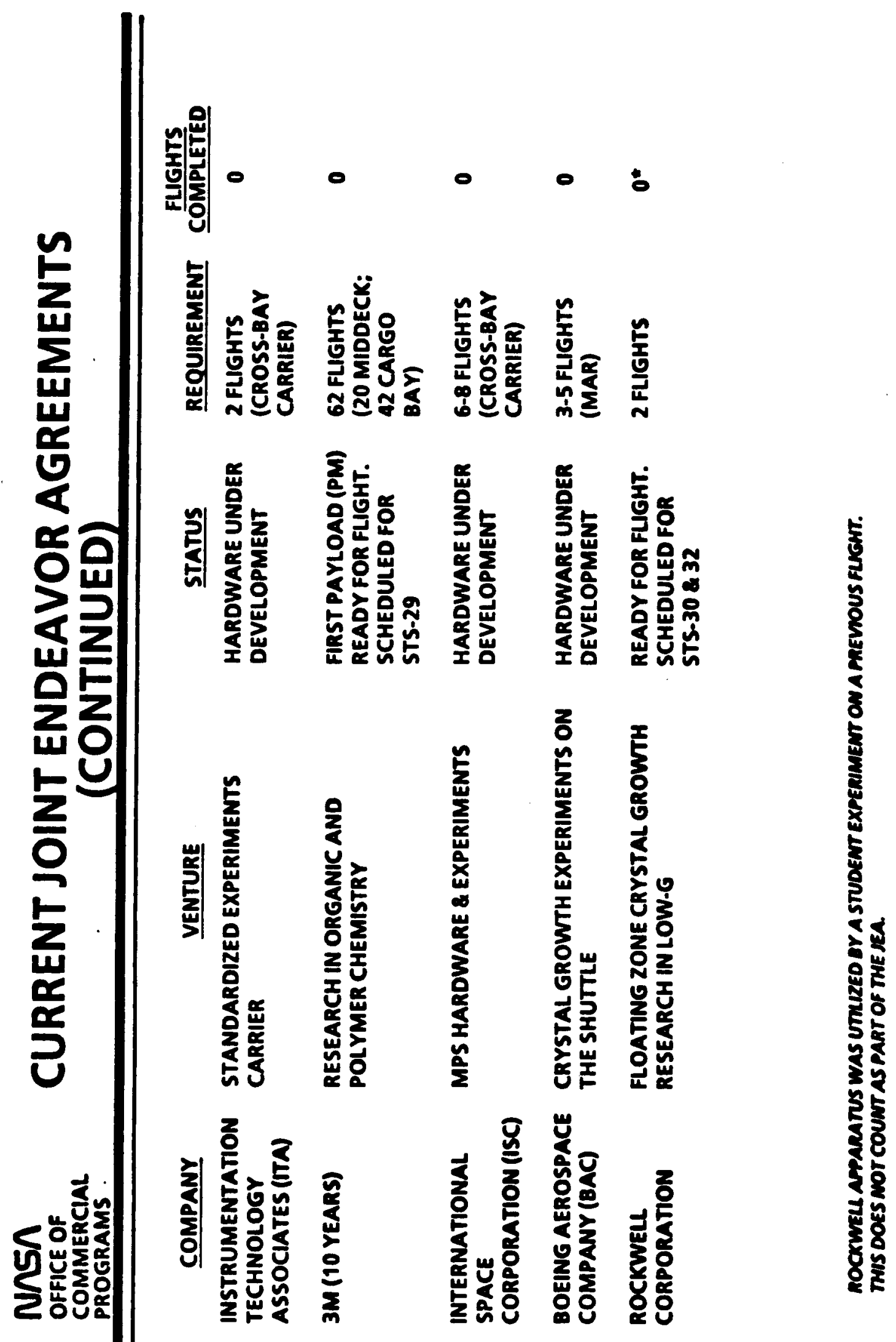




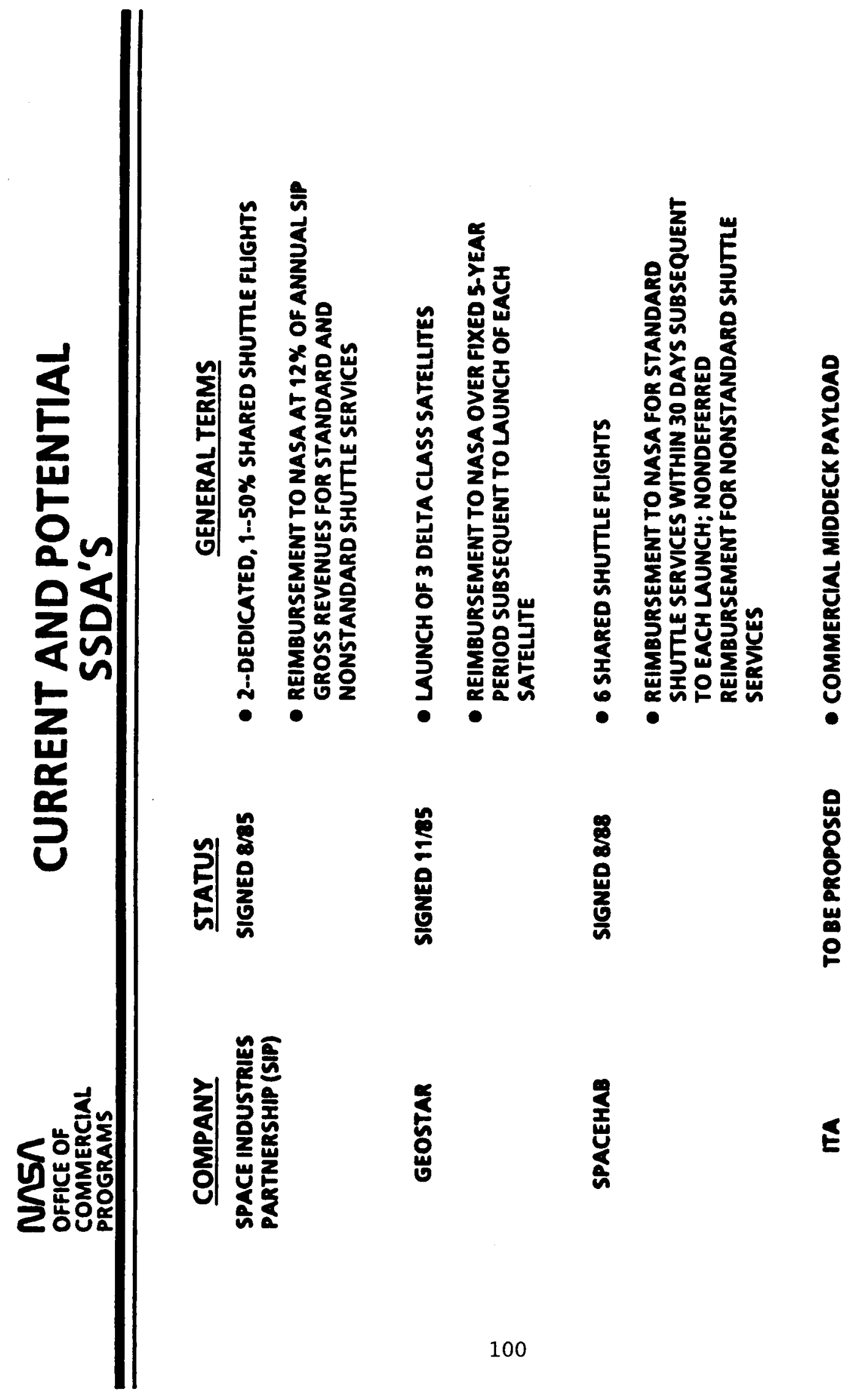

蛋 


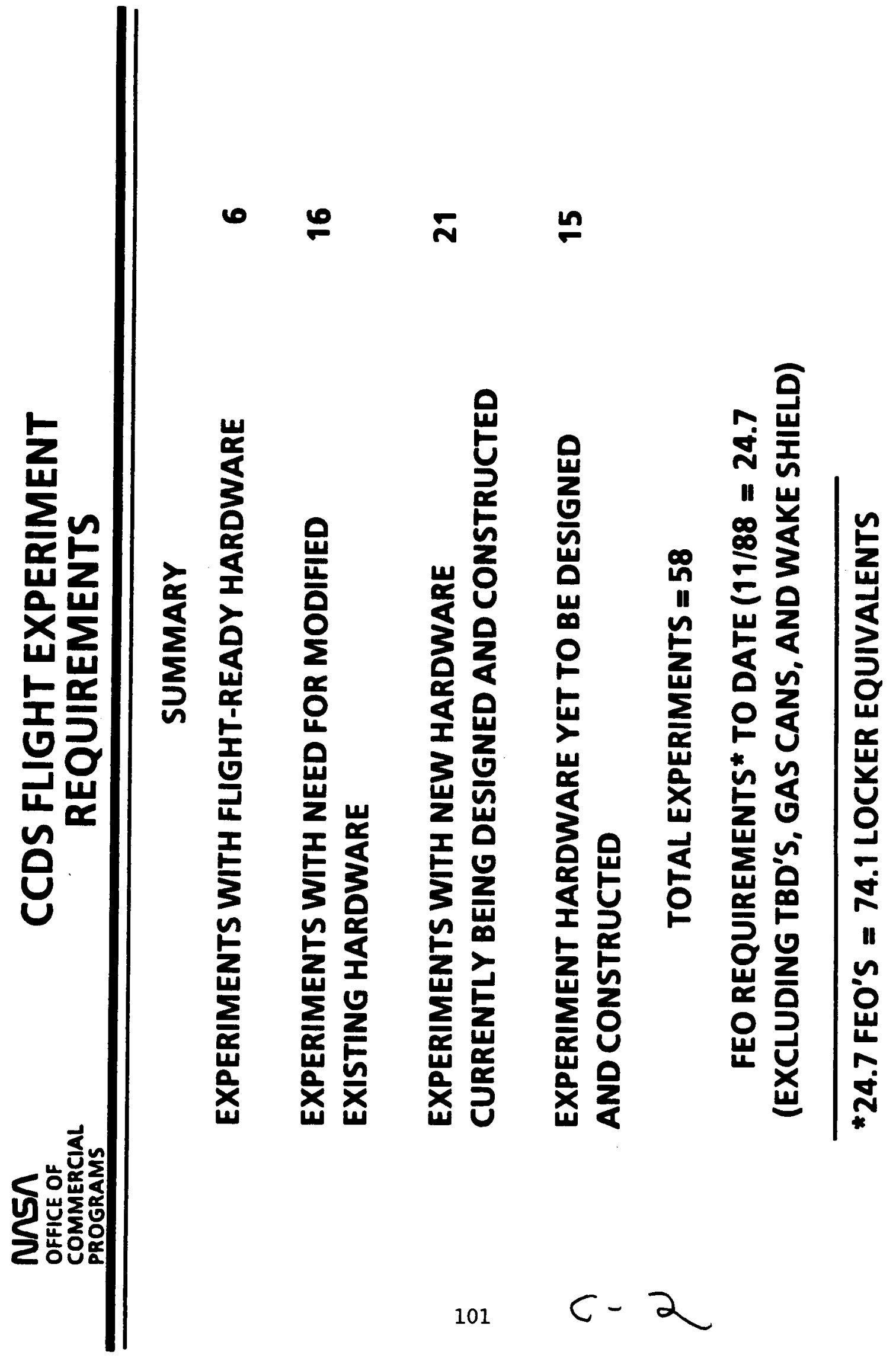


Alexander, Joseph K. January 26, 1989. National Aeronautics and Space Administration (NASA), Office of Space Science and Applications (OSSA), "Requirements for an Extended Duration Orbiter." Viewgraphs for presentation to the National Research Council (NRC) Committee on a Commercially Developed Space Facility (CDSF).

Ambrus, Judith H. November 22, 1988. (NASA, Office of Aeronautics and Space Technology). "In-Space Technology Experiments Program."

Viewgraphs for presentation to NRC Committee on a CDSF.

American Institute of Aeronautics and Astronautics. January 1988. "Space Processing: A National Crisis." An AIAA Position Paper.

Andresen, R-D. December 15, 1988. (ESTEC, European Space Agency) "EURECA and Its First Microgravity Mission." Viewgraphs for presentation to the NRC Committee on a CDSF.

Bartoe, John-David F. January 25, 1989. (NASA, Office of Space Station.) "Space Station Freedom: Capabilities of Freedom to Support Microgravity Science and Applications." Viewgraphs for presentation to the NRC Committee on a CDSF.

Bennett, E., H.P. Schmidt and B. Feuerbacher. 1988. "Materials Science Research in Space by Telescience." International Astronautical Federation (IAF), 39th Congress, preprint IAF-88-016.

Case Western Reserve University. January 12, 1989. "Space-America's Technological Frontier for Industry." Viewgraphs provided to NRC Committee on a CDSF by John Stevens, Dow Chemical Company.

Congressional Research Service. May 1988. Soviet Space Programs: 1981-87. Part 1.

Defense Advanced Research Projects Agency. January 12, 1989. Correspondence to NRC Committee on a CDSF from Raymond Colladay, Director.

Dornier. January 1988. "Microgravity Facilities: Material Sciences and Life Sciences."

Dunbar, Bonnie J. January 25, 1989. (NASA, Lyndon B. Johnson Space Center.) "Microgravity Materials Science Assessment Task Force Status Report to National Research Council." Viewgraphs of presentation to NRC Committee on a CDSF. 
Eilers, D. September 1988. "The Microgravity Environment of the Free-Flying Microgravity Carrier AMICA." AMICA Project Office, MBB/ERNO and GE Astro Space Division.

ERNO. November 29, 1983. "Spacelab System Specification." SY-ER-0001. Fitts, Jerry J. January 26, 1989. (NASA, Office of Space Flight, Transportation Services.) "NASA Manifesting of Microgravity Payloads." Viewgraphs for presentation to NRC Committee on a CDSF.

GE Astro Space Division and MBB/ERNO. December 16, 1988. "Industrial Platform Operations of EURECA and AMICA." Viewgraphs for presentation to NRC Committee on a CDSF.

GE/MBB/ERNO. "The EURECA Mission 1 Payload." Undated manuscript presented at briefing of NRC Committee on a CDSF, December 16, 1988.

GE/MBB/ERNO. "Suitability of MSL Experiment Apparatus for AMICA." Undated manuscript presented at briefing of NRC Committee on a CDSF, December 16, 1988.

Gilbert, C., P. Vits and S. Walther. 1988. "Facilities for Microgravity Research." IAF, 39th Congress, preprint IAF-88-369.

Gilbreath, W. January 27, 1989. (NASA, OSSA, Life Sciences Division.) "Potential Life Sciences Utilization of the Commercially Developed Space Facility." Viewgraphs for presentation to NRC Committee on a CDSF.

Global Outpost, Inc. December 5, 1988. "Outpost Platform Concept Definition." Information provided by letter to NRC Committee on a CDSF.

Herbolsheimer, L.F. November 21, 1988. (NASA Office of Commercial Programs.) "The NASA Commercial Development of Space Program." Viewgraphs for presentation to NRC Committee on a CDSF.

Herfs, W., R.D. Andresen and E. Eilers. 1988. "The Measured and Predicted Micro-G EURECA Environment." IAF, 39th Congress, preprint IAF-88-341.

Hook, W.R. December 16, 1988. (NASA, Langley Research Center.) "Study Status Report for the Commercially Developed Space Facility." Viewgraphs for presentation to NRC Committee on a CDSF.

Hudkins, K. December 15, 1988. (NASA, Office of Space Flight, Systems Engineering and Analysis, Orbiter Division.) Viewgraphs for presentation to NRC Committee on a CDSF.

Ignatiev, A. November 21, 1988. (University of Houston, Space Vacuum Epitaxy Center.) Viewgraphs for presentation to NRC Committee on a CDSF.

Johnson, B. December 1988. (NASA Marshall Space Flight Center.) "Spacelab Carrier Configurations, Definitions and Experiences." Viewgraphs for presentation to NRC Committee on a CDSF.

Johnson, N.L. November 22, 1988. (Teledyne Brown Engineering, Colorado Springs, CO) "Soviet Microgravity Materials Science Programs in Space." Viewgraphs for presentation to NRC Committee on a CDSF.

Kaplan, D., B. de Saint Louvent, G. Muller and C. Chipaux. 1988. "First Foreign Piggy-Back Autonomous Payload Ever Flown on a Retrievable Chinese Capsule Launched by a Long March 2 in August 1987." IAF, 39th Congress, preprint IAF-88-047. 
Keidanren. 1988. "Space in Japan: 1988-89."

Knox, J.R. January 12, 1989. (AMOCO Chemical Company, Naperville, IL.) "AMOCO and Microgravity." Viewgraphs for presentation to NRC Committee on a CDSF, Requirements Subcommittee.

Lemkey, F.D. January 9, 1989. (NASA, OSSA, Microgravity Science and Applications Division.) Letter to Robert H. Korkegi, Director, Aeronautics and Space Engineering Board (ASEB), NRC, regarding requirements estimates for Microgravity Science and Applications Division payloads for the period 1993-97.

Lemkey. January 9, 1989, and enclosure of January 12, 1989. Memorandum to Director, ASEB, NRC, regarding experiment run times and frequency.

Lemkey, and Robert C. Rhome. (NASA, OSSA.) November 21, 1988. "Microgravity Program Briefing." Viewgraphs for briefing to NRC Committee on a CDSF.

Lioy, S., et al. 1988. "Engineering Ground Rules for Development of a Microgravity Facility." IAF, 39th Congress, preprint IAF-88-370.

Ludwig, K. 1988. "Automation and Robotics Onboard European Space Laboratory Modules." IAF, 39th Congress, preprint IAF/IAA-88-488.

Lundquist, Charles. November 21, 1989. "Consortium for Materials Development in Space." Viewgraphs for presentation to NRC Committee on a CDSF.

May, G. Lynwood. December 1987. "New Directions for the People's Republic of China Space Program." Sienal.

MBB-ERNO. September 1988. "The European Retrievable Carrier EURECA 'A Right Platform at the Right Time'." Space Special EURECA, Vol. 13, No.6.

Monti, R. 1988. "Telescience and Microgravity: Impact on Future Facilities, Ground Segments and Operations." IAF, 39th Congress, preprint IAF-88-015.

Napolitano, L., et al. 1988. "Knowledge Engineering and Expert Systems for Microgravity." IAF, 39th Congress, preprint IAF-88-376.

National Aeronautics and Space Administration (NASA). April 1987. "Microgravity Materials Science Assessment. An Examination of the NASA Programs in Microgravity Materials Research." Final Report of the NASA Microgravity Materials Science Assessment Task Force (B.J. Dunbar, Chairperson) to $\mathrm{Dr}$. Sally K. Ride, Office of the NASA Administrator.

NASA. December 7, 1987. "Report on the Potential NASA Utilization of the Space Industries Partnership Industrial Space Facility (ISF). Executive Summary." Manuscript.

NASA. August 1988. "Microgravity Strategic Plan - 1988." Internal NASA document, unnumbered.

NASA. September 1988. "Advancing Automation and Robotics Technology for the Space Station Freedom and for the U.S. Economy." Progress Report 7. Technical Memorandum 101691.

NASA, Ames Research Center. December 14-15, 1987. "ISF Workshop. Assessment Report. Space Life Sciences Payloads Office." Manuscript. 
NASA, Langley Research Center. December 16, 1988. "Study Status Report for the CDSF." Viewgraph briefing prepared for the NRC Committee on CDSF.

NASA, LRC. January 23, 1989. "Concept Development Final Report for the Commercially Developed Space Facility." Viewgraphs for a briefing for Dale D. Myers, NASA Deputy Administrator.

NASA, Marshall Space Flight Center. August 11, 1988. "Spacelab Payload Accommodation Handbook." SLP/2104. Issue 2, Revision 14.

NASA, MSFC. January 13, 1989. "Potential Advantages of a CDSF." Viewgraphs for briefing to the NRC Committee on CDSF Requirements Subcommittee. (Provided by Robert J. Naumann.)

NASA, Office of Aeronautics and Space Technology. May 1988. "Review of OAST Outreach Experiments." Viewgraphs.

NASA, Office of Commercial Programs. September 1988. Accessing Space: A Catalogue of Process. Equipment and Resources for Commercial Users. NASA NP-118.

NASA, OCP. November 1988. "CCDS Flight Experiment Requirements." Viewgraphs for briefing to the NRC Committee on a CDSF.

NASA, OCP. November 1988. "Centers for the Commercial Development of Space--Abstracts." Manuscript.

NASA, OCP. Progress Reports from the Centers for the Commercial Development of Space:

Advanced Materials Center for the Commercial Development of Space. Battelle Columbus Laboratories. 1987. Annual Report FY 1987.

Center for Ce11 Research. The Pennsylvania State University. 1988. Progress Report.

Center for the Development of Commercial Crystal Growth in Space. Clarkson University. September 1, 1986 - August 31, 1987. Annual Report.

Center for Macromolecular Crystallography. University of Alabama at Birmingham. November 1, 1987 - October 31, 1988. Annua1 Report and Grant Renewal Proposal.

Center for Mapping. The Ohio State University. September 1987. Quarterly Report.

Center for Space Automation and Robotics. University of Wisconsin Madison. FY 1987 Annual Report.

Center for the Space Processing of Engineering Materials. Vanderbilt University. October 1, 1986 - October 31, 1987. Annual Report.

Consortium for Materials Development in Space. University of Alabama in Huntsville. September 15, 1986 - September 14, 1987. Annual Report. 
Space Remote Sensing Center. Institute for Technology Development. John Stennis Space Center. Fiscal Year 1987 Annual Report.

Space Vacuum Epitaxy Center. University of Houston. 1986-87. Annual Report.

NASA, OCP. January 13, 1989. "CCDS Payload Selection Process." Viewgraphs for presentation to NRC committee on a CDSF, Requirements Subcommittee.

NASA, Office of Space Flight. January 1989. "Payload Flight Assignments, NASA Mixed Fleet."

NASA, OSF. February 1989. "Secondary Payload Flight Projection."

NASA, Office of Space Science and Applications. January 1988. "Microgravity Science and Applications: Apparatus and Facilities."

NASA, OSSA. May 2-4, 1988. "Microgravity Science and Applications Division Clearwater Planning Meeting. Summary." Prepared by the Universities Space Research Association under NASA Contract NASW-4174.

NASA, OSSA, Flight Systems Division. 1988. "Spacelab and Attached Missions." Summary sheets; no report number.

NASA, OSSA, Life Sciences Division. June 1988. Exploring the Living Universe - A Strategy for Space Life Sciences.

NASA, OSSA, Microgravity Science and Applications Division. 1988. "Ground-Based Research Facilities." Manuscript prepared for the NRC Committee on a CDSF.

NASA, OSSA. 1988. "Microgravity Science and Applications Division. A Program Overview: 1986-87."

NASA, Office of Space Station. January 24, 1989. Correspondence to NRC Committee on a CDSF from James B. Odom, Associate Administrator.

NASA, Space and Earth Sciences Advisory Committee/Task Force on Scientific Uses of the Space Station (SESAC/TFSUSS). Revised April 23, 1987. "Conclusions from the SESAC/TFSUSS Fact-Finding Meeting on March $19-20,1987 . "$

NASA, Space Station Freedom Program Office. April 29, 1988. "Space Station Microgravity Accelerations: Modeling, Analysis, and Results." SSE-E-88-R10.

NASA, SSFPO. June 1, 1988. "Modal Analysis of Selected Space Station Configurations." SSE-E-88-R8.

NASA, SSFPO. September 23, 1988. "Space Vehicle Microgravity Environments and Payload Microgravity Requirements." SSE-E-88-R21.

NASA, SSFPO. October 3, 1988. "Microgravity Environment for Baseline and Selected Alternate Configurations." PSH-520-R88-005.

NASA, SSFPO. December 28, 1988. "Space Station Freedom Rack Microgravity Environment Data." Preliminary Draft.

National Research Council (NRC), Committee on NASA Scientific and Technological Program Reviews. 1986. Post-Challenger Assessment of Space Shuttle Flight Rates and Utilization. 
NRC, Solid State Sciences Committee of the Board on Physics and Astronomy and National Materials Advisory Board Panel on Microgravity Science and Applications. Co-chairmen: Brian R.T. Frost and Albert I. Schindler. 1986. Microgravity Science and Applications - Report of a Workshop.

NRC, Space Applications Board. Chairman: William P. Slichter. 1978. Materials Processing in Space.

NRC, SAB. May 18-19, 1987. "Summary Minutes of the Meeting of the Committee on Industrial Applications of the Microgravity Environment."

NRC, SAB. Chairman: Paul Todd. 1988. Industrial Applications of the Microgravity Environment.

NRC, Space Science Board. 1988. Space Science in the Twenty-First Century: Imperatives for the Decades 1995 to 2015. Seven volumes.

Naumann, Robert J. NASA, Marshall Space Flight Center. June 8, 1988. "Acceleration Requirements for Microgravity Science and Applications Experiments in the Space Station Era." Manuscript.

Naumann. June 8, 1988. "Complementary Use of the Space Station and CDSF for Microgravity Experiments." Manuscript.

Orbital Sciences Corporation. January 12, 1989. Correspondence to NRC Committee on a CDSF from David A. Rossi, Director of Business Development.

Ott, Richard H. NASA, OCP. November 21, 1988. "Flight Program Definition." Viewgraphs for presentation to the NRC Committee on a CDSF.

Podsiadly, Christopher J. 1988. (Science Research Laboratory, 3M Company, St. Paul, MN 55144.) "3M/NASA Microgravity Research Program." Manuscript.

Rhome, Robert C. August 4, 1988. (NASA, OSSA). "Microgravity Flight Programs: Fiscal Years 1988-1993. Comparative Assessment." Viewgraphs.

Rose, James T. (NASA, OCP.) June 7, 1988. "Prepared Remarks for Outlook for Space Conference." Manuscript.

Rose. January 13, 1989. "Office of Commercial Programs Space Flight Requirements." Viewgraphs for briefing to NRC Committee on a CDSF Requirements Subcommittee.

Sacksteder, K.R. 1988. "Facilities for Microgravity Combustion Research." IAF, 39th Congress, preprint IAF-88-355.

Salm, Robert J. (Babcock and Wilcox, Lynchburg, VA.) January 12, 1989. "Particle Coating Microgravity Research Program." Viewgraphs and supporting material for presentation to the NRC Committee on a CDSF, Requirements Subcommittee.

Schrieffer. See Universities Space Research Association.

Slichter. See NRC, Space Applications Board. 1978.

Sowe11, K.D. (NASA Marshall Space Flight Center.) March 24, 1988. Draft Request for Proposal No. 8-1-8-JA-90000 Covering the Lease of a Commercially Developed Space Facility (CDSF).

SPACEHAB, Inc. December 15, 1988. "SPACEHAB Mid-deck Augmentation Module." Viewgraphs and supporting material for presentation to NRC Committee on a CDSF. 
SPACEHAB. 1988. "SPACEHAB: A New Space Shuttle Capability - Manned Experiment Module."

SPACEHAB. 1988. "Space Systems Development Agreement Between the United States of America Represented by the National Aeronautics and Space Administration and Spacehab, Inc. for Launch and Associated Services for the First Six Orbital Flights of the SPACEHAB Middeck Augmentation Module." Launch Agreement No. 1557-001, effective date August 11, 1988.

Space Industries, Inc. March 1989. "Industrial Space Facility Microgravity - Free-Flyer and STS-Attached." Viewgraphs provided to the NRC Committee on a CDSF.

Space Industries Partnership. December 15, 1988. "Presentation to the National Research Council Committee on the Commercially Developed Space Facility (CDSF)." Viewgraphs and Appendixes.

Srinivas, R., N. Moore, and S. Walker. 1988. "Considerations for Accommodating High Temperature Furnaces for Operations in a Manned Environment." IAF, 39th Congress, preprint IAF-88-348.

Stevens, John W., Jr. (Dow Chemical Company, Granville, OH.) January 12, 1989. "Applied Materials - Materfals for Space Structures." Viewgraphs for presentation to the NRC Committee on a CDSF, Requirements Subcomittee.

Stevens. January 12, 1989. "Presentation to NRC Subcommittee on Requirements." Viewgraphs.

Teledyne Brown Engineering. February 2, 1987. "Microgravity and Materials Processing Facility Study Release." Volumes I-IV. NASA Contract No. NAS8-36122.

Teledyne Brown. March 28, 1988. Microgravity and Materials Processing Facility Study (MMPF) - Requirements and Analyses of Commercial Operations (RACO), Preliminary Data Release." NASA Contract No. NAS 8 - 36122 .

Teledyne Brown. December 15, 1988. "Handbook of Characteristics and Capabilities of STS Compatible Carriers." Prepared by MMPF Study Team under NASA Contract No. NAS8-36122.

Titland, Martin N. (Fairchild Space Company.) December 15, 1988. "Commercial Space Platform Services." Viewgraphs for presentation to NRC Committee on a CDSF.

Todd. See NRC, SAB. 1988.

U.S. Air Force Space Command. January 12, 1989. Correspondence to NRC Committee on a CDSF from Lt. Col. F. Uhlik III.

U.S. Congress. June 2, 1988. H.R. 4561.

U.S. Congress. House Subcommittee on Space Science and Applications. 1988. "1989 NASA Authorization Hearings."

Universities Space Research Association. Chairman: J. Robert Schrieffer. October 1987. "Review of Microgravity Science and Applications Flight Programs: January - March 1987." Prepared for NASA, OSSA. Contract No. NASW-4174.

Walter, H.U. (ed.). 1987. Fluid Sciences and Materials Science in Space: A European Perspective. Springer-Verlag. 
Ware, Randolph H. University Corporation for Atmospheric Research (UCAR). December 15, 1988. "Space Phoenix: A National Program for the Scientific and Commercial Use of Shuttle External Fuel Tanks in Space." Manuscript provided to the NRC Committee on a CDSF.

White House. February 11, 1988. "Presidential Directive on National Space Policy, Fact Sheet" and "The President's Space Policy and Commercial Space Initiative to Begin the Next Century."

Wilson, Andrew R. (Maxwe11 Laboratories.) January 12, 1989. "Commercial Power in Space." Viewgraphs for presentation to NRC Committee on a CDSF, Requirements Subcommittee. 